Portland State University

PDXScholar

Dissertations and Theses

Dissertations and Theses

Spring 5-28-2013

\title{
Ecology of White-Cheeked Crested Gibbons in Laos
}

Julia Cleverly Ruppell

Portland State University

Follow this and additional works at: https://pdxscholar.library.pdx.edu/open_access_etds

Part of the Animal Studies Commons

Let us know how access to this document benefits you.

Recommended Citation

Ruppell, Julia Cleverly, "Ecology of White-Cheeked Crested Gibbons in Laos" (2013). Dissertations and Theses. Paper 1007.

https://doi.org/10.15760/etd.1007

This Dissertation is brought to you for free and open access. It has been accepted for inclusion in Dissertations and Theses by an authorized administrator of PDXScholar. Please contact us if we can make this document more accessible: pdxscholar@pdx.edu. 
Ecology of White-Cheeked Crested Gibbons in Laos

\author{
by \\ Julia Cleverly Ruppell
}

A dissertation submitted in partial fulfillment of the requirements for the degree of

\author{
Doctor of Philosophy \\ in \\ Biology
}

Dissertation Committee:

Michael T. Murphy, Chair

Natalie Vasey

Randy Zelick

Susan Masta

Catherine deRivera

Portland State University

2013 
(C) 2013 Julia Cleverly Ruppell 


\begin{abstract}
The endangered white-cheeked crested gibbon (Nomascus leucogenys), native to
\end{abstract} Laos, Vietnam, and perhaps China, remains little known and highly threatened. I studied seasonal variation in the diet, activity budget, and ranging behavior of three groups of white-cheeked crested gibbons in Nam Kading National Protected Area, Bolikhamxay Province, Laos, over 12 months in wet seasonal evergreen forest. Crested gibbons (Nomascus spp.) are speculated to be more folivorous than other gibbons, but this has never been confirmed because of the paucity of fieldwork on the genus. I studied diet in relation to forest seasonality to determine the contribution of leaves to the diet over an annual cycle. Although leaves were the main dietary item throughout the year $(53-85 \%$ of monthly diet), gibbons substantially increased their consumption of fruit during periods when it was most abundant in the forest. Because fruit is a calorically rich source of food, gibbons seek fruit when it is abundant and obtained easily. Young leaf consumption increased when they did not have access to fruit, indicating that their diet is flexible but strongly dependent on seasonal availability of resources. In addition, rainfall had a negative association with fruit abundance and fruit in diet.

Activity budgets are an important aspect of a species' ecology because they are directly related to home range use, energy allocation, and diet, but they have never before been studied in gibbons (Nomascus spp.) of the rainy, mountainous, forests of Laos. Annually, the three groups that I studied spent nearly equal amounts of time resting (30\%), feeding (33\%), and traveling (35\%), but only a small amount of time singing (2\%). However, the proportion of time allocated to different activities showed significant 
seasonal variation associated with rainfall and diet, and correlated with home range use. Gibbons increased traveling time and decreased feeding time when they ate more fruit, and they decreased traveling time and increased feeding time when they ate more leaves. When the gibbons spent more of their time traveling, they also had longer day range lengths, and used a higher percentage of their total home range. Moreover, when rainfall was high, the gibbons decreased traveling time and increased time resting and feeding. Average home range size was 37.9 hectares and daily average distance over which the gibbons ranged over the 12 month study was $1.48 \mathrm{~km}$ per day. Differences existed among the three groups. Overall, white-cheeked crested gibbons have a home range similar in size or larger than frugivorous gibbons, and larger than the folivorous siamang. Ranging was highly seasonal with shorter day ranges during times of low fruit availability and consumption. During times of high fruit availability and low rainfall, the gibbons took on an energy maximizing strategy where they maintained large home ranges, traveled longer distances and consumed larger quantities of fruit.

Gibbons and their habitat in Laos have faced continuous threats over the past 10 years because of large scale development projects and subsistence hunting. Given the highly threatened status of the species in Vietnam and China, the Lao population is certainly the world's largest and the best hope for conservation of behavioral, ecological, and genetic diversity. Resources for conserving species in the country are very limited, and wildlife populations are already greatly fragmented. I describe the current conservation issues and based on the dietary and ranging information that I collected, 
recommend important conservation measures to safeguard the remaining populations of endangered gibbons from extinction. 


\section{Acknowledgments}

I am grateful and indebted to so many people without which this study would not have been possible. My greatest thanks go to Dr. Michael Murphy and Dr. Natalie Vasey for their kindness, support, and supervision of this study. I am also grateful for their careful review of my manuscripts and instruction in all aspects of this project. I thank Dr. Michael Murphy for overseeing my work and providing essential advice and thoughtful guidance from beginning to end.

Committee members Dr. Susan Masta and Dr. Randy Zelick provided helpful advice prior to my fieldwork and during stages of the writing process, and helped with constructive comments on various issues. I thank Dr. Catherine deRivera for serving as the graduate office representative on my thesis committee and for providing ideas, support and advice throughout this project. Collective thanks go to my colleagues at Portland State University who have supported me in various ways.

During my stay in Laos I received valuable support from many sources, most importantly the Wildlife Conservation Society (WCS), the National University of Laos, and the United States Embassy Vientiane. I am thankful to WCS for arranging my working visa and permits in Laos and offering much help along the way. Alex McWilliam and Bounthavy Phommachanh thoughtfully assisted me in the planning aspects of this project and guided me through the complex process of getting the official permissions required for working in Laos. Chris Hallam (WCS) kindly provided valuable information on potential gibbon sites. 
I thank the official authorities on the national, provincial and district level for their permission to conduct fieldwork in Nam Kading National Protected Area (NPA) Viengthong District, Bolikhamxay Province. I give many thanks to the Integrated Ecosystems and Wildlife Management Project (IEWMP) staff, park rangers, and villagers who accompanied me into Nam Kading NPA. I am indebted to Souliya Pouthabounma who joined me as a student in Nam Kading NPA.

Funding was provided by the Oregon Zoo, the International Primatological Society, the Northwest Primatological Society, Primate Action Fund, the Margot Marsh Biodiversity Foundation, and a Fulbright scholarship. I also received support during my final year from the Sasakawa Young Leaders Fellowship Fund (SYLFF).

Throughout my stay in Laos I was deeply impressed by the friendliness, kindness, hospitality and helpfulness of the Lao people. I am thankful for this unforgettable experience.

Very special thanks go to my family David, Joyce, Jocelyn, and Evan Ruppell and my fiancé Jack Gordon. 


\section{Table of Contents}

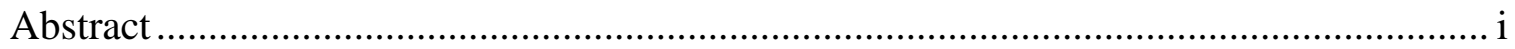

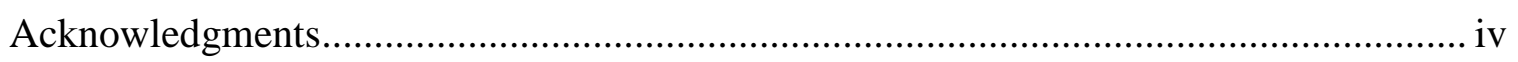

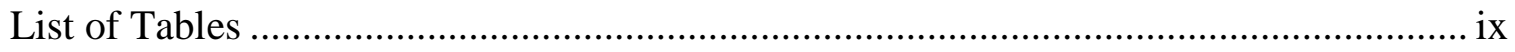

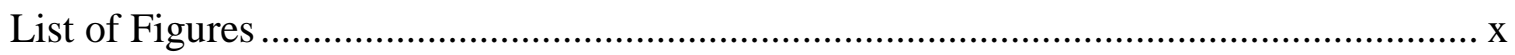

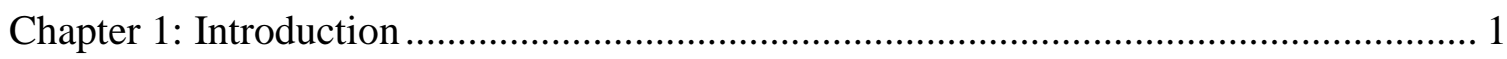

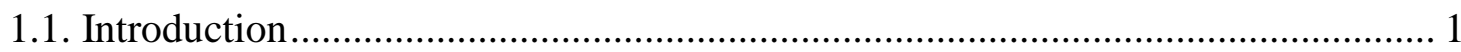

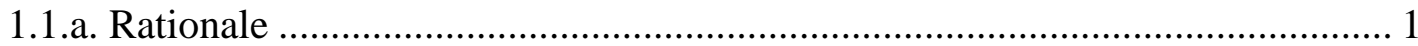

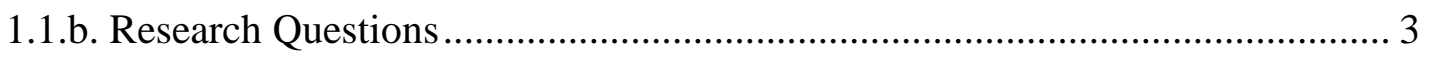

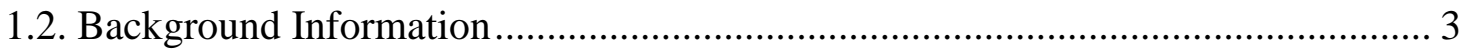

1.2.a. Taxonomy, Geography, Anatomy, Vocalization ........................................ 3

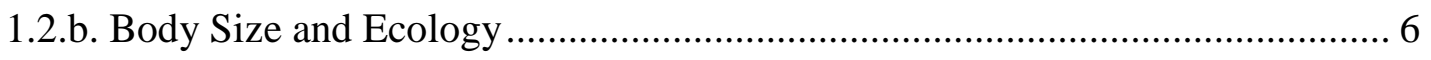

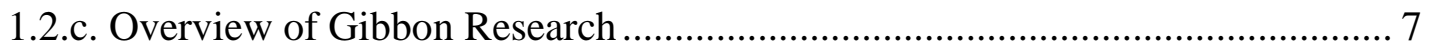

1.2.d. Crested gibbon (Nomascus) Specializations .............................................. 10

1.2.e. Conservation in Laos............................................................................. 12

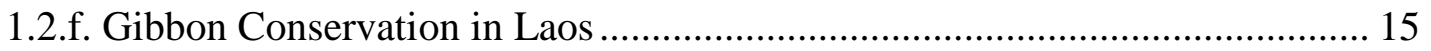

Chapter 2: Influence of Forest Seasonality on Diet of Nomascus leucogenys ................ 17

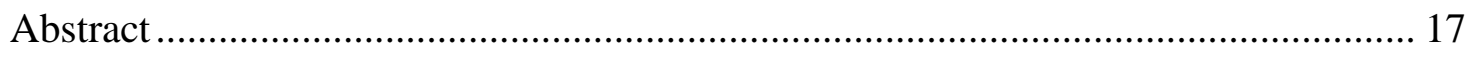

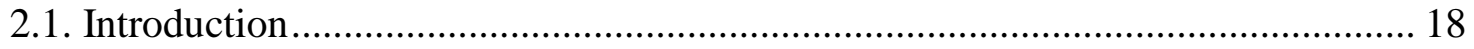

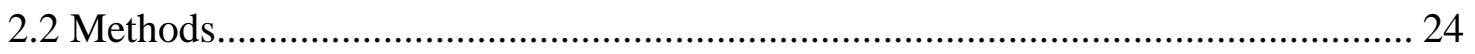

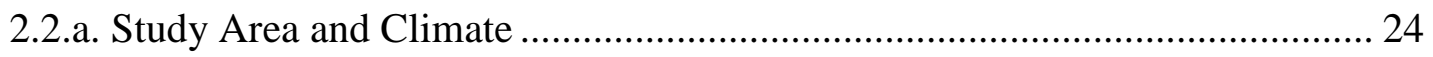

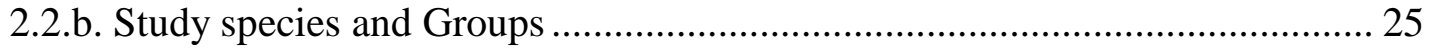

2.2.c. Data Collection: Climate and Phenology .................................................. 26

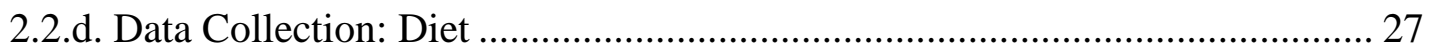

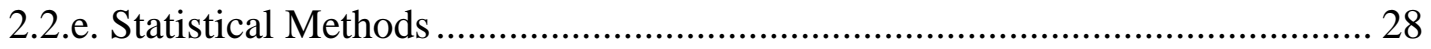

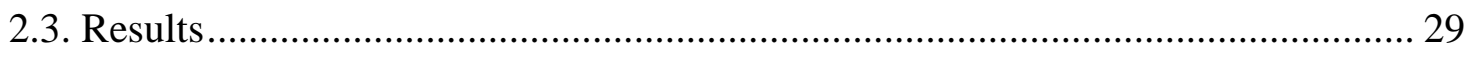

2.3.a. Seasonality: Climate and Phenology........................................................... 29

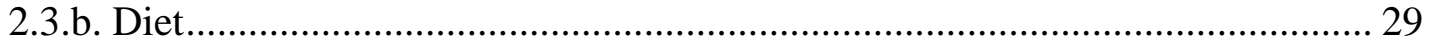

2.3.c. The Effect of Resource Availability and Rainfall on Diet ........................... 31 


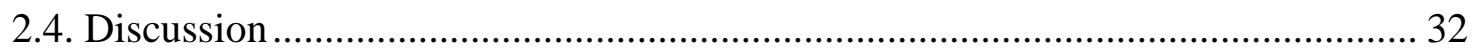

Chapter 3: Seasonal Variation in Activity Budget of Nomascus leucogenys: .................. 40

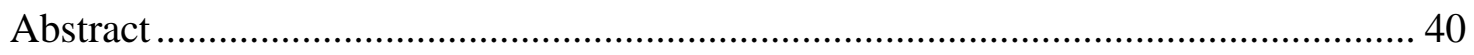

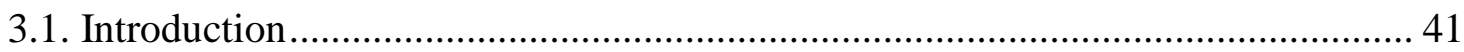

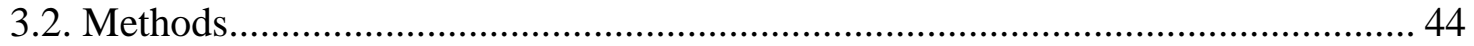

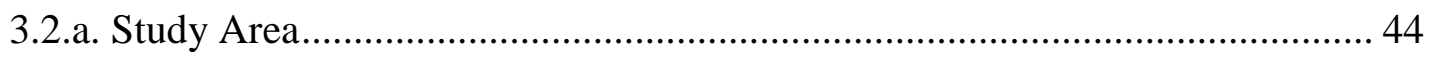

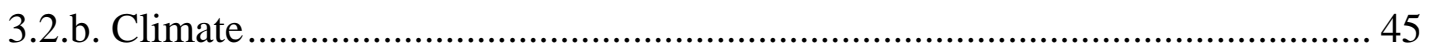

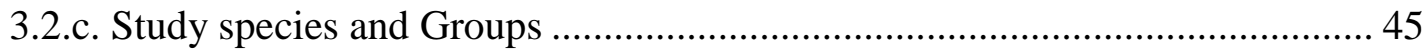

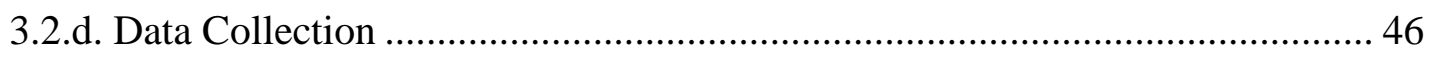

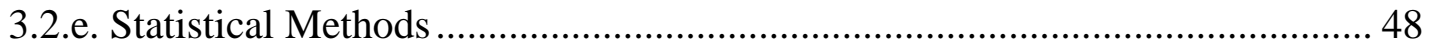

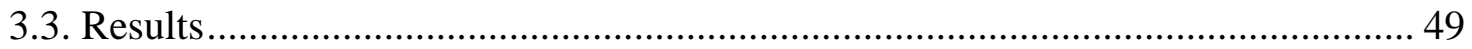

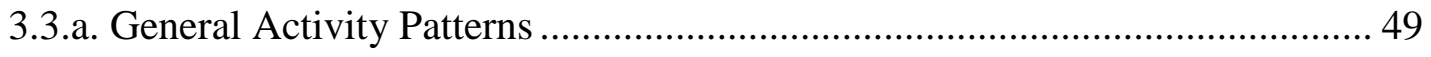

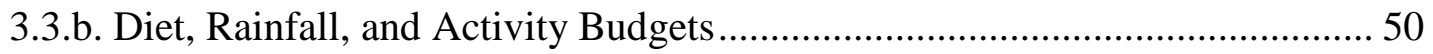

3.3.c. Ranging and Activity Budgets .......................................................... 51

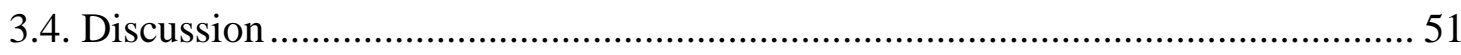

3.4.a. Activity Rhythm and Activity Budget .................................................... 51

3.4.b. Effects of Diet on Monthly Variation in Activity Budget ............................ 53

3.4.c. Effects of Rainfall on Monthly Variation ................................................ 55

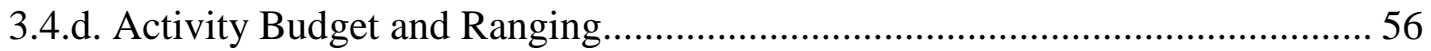

Chapter 4: Ranging behavior of Nomascus leucogenys.............................................. 58

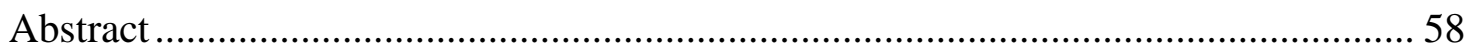

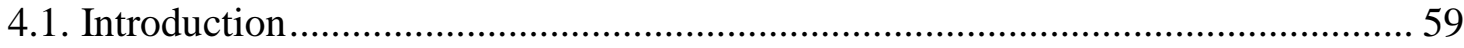

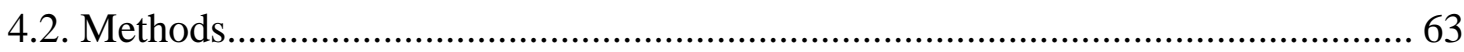

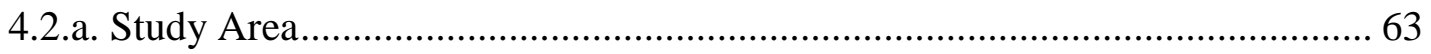

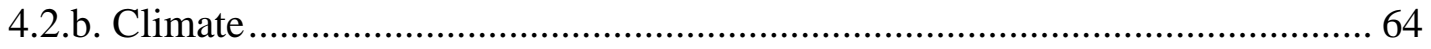

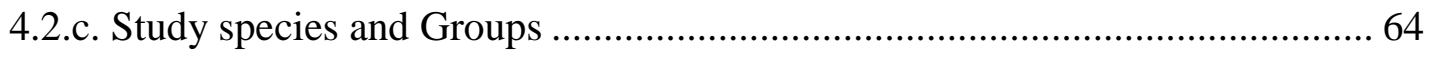

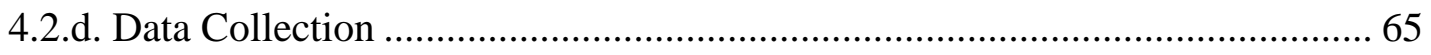

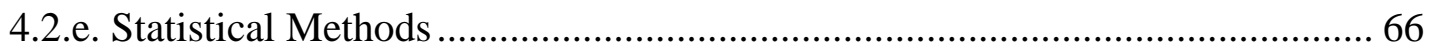

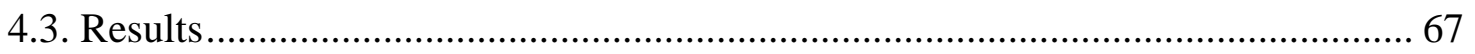

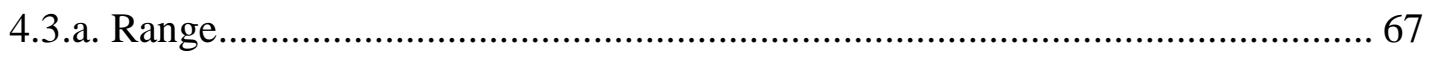


4.3.b. Relationships of Ranging with Diet, Fruit Availability, and Rainfall ........... 68

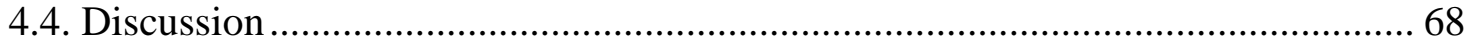

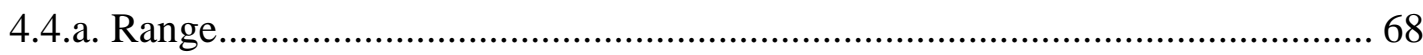

4.4.b. Ranging, Diet, Fruit availability, and Rainfall....................................... 75

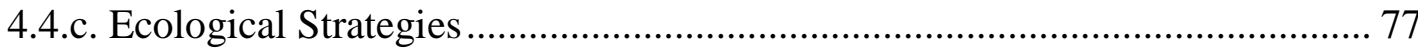

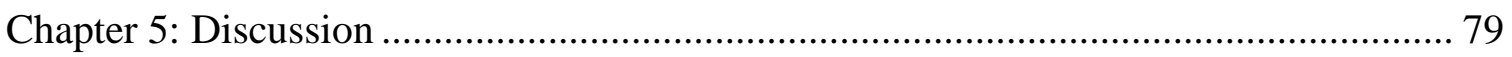

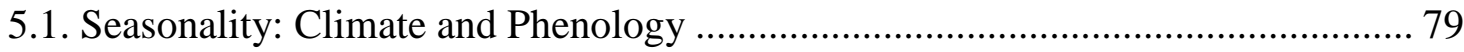

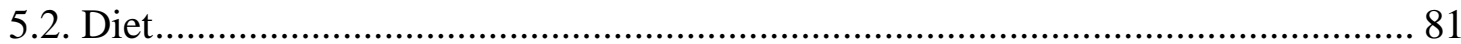

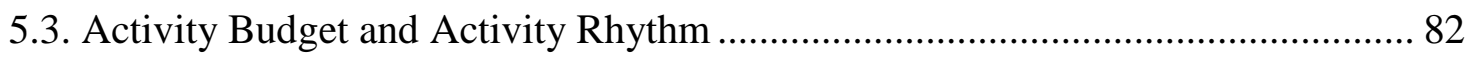

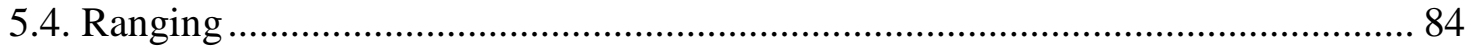

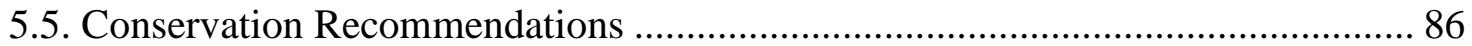

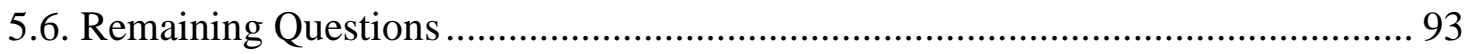

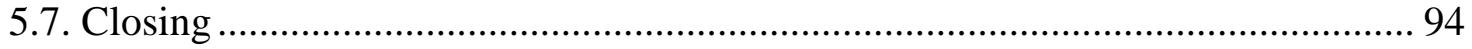

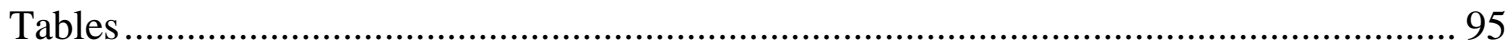

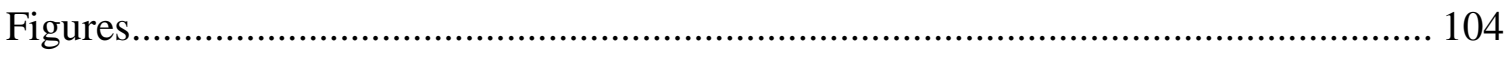

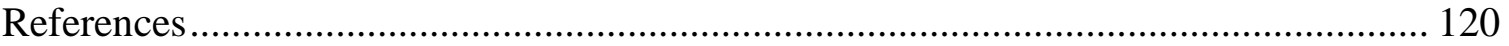




\section{List of Tables}

Table 1. Gibbon body weights (after Smith and Jungers, 1997).

Table 2. Classification of the Hylobatidae, showing scientific, English, and common

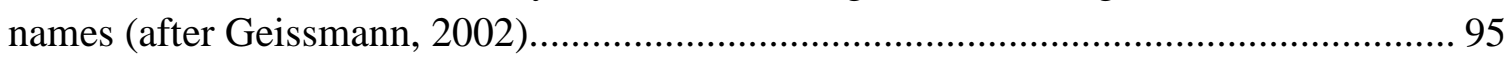

Table 3. Divisions of Hylobatidae based on chromosome number .............................. 96

Table 4. Diet, \% folivory and body mass of selected folivorous primates ...................... 96

Table 5. Results of General Linear Models for diet for gibbons in Nam Kading NPA, Laos, June 2011- May 2012 evaluating all of the possible influences concurrently....... 97

Table 6. Results of partial correlations on the diet of gibbon groups in Nam Kading NPA,

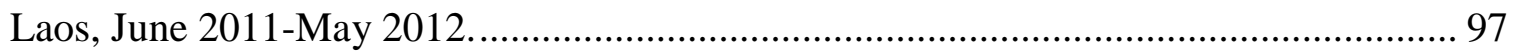

Table 7. Diet of different gibbon species (adapted from Bartlett, 2009)....................... 98

Table 8. Results of General Linear Models for Activity Budget for gibbons in Nam Kading NPA, Laos, June 2011- May 2012 evaluating all of the possible influences concurrently.

Table 9. Results of correlations between monthly activity budget and dietary proportions

Table 10. Results of correlations between monthly variations in activity budget and ranging 100

Table 11. Activity budgets of gibbon species in different study areas (adapted from Fan et al., 2008). 101

Table 12. Results of General Linear Models for range area and day range length for gibbons in Nam Kading NPA, Laos, June 2011- May 2012 evaluating all of the possible influences concurrently. 102

Table 13. Results of correlations between ranging and fruit in diet, fruit availability, and rainfall for gibbons in Nam Kading NPA, Laos, June 2011-May 2012 . ....................... 102

Table 14. Home range size of selected gibbon species............................................ 103 


\section{List of Figures}

Figure 1. Map of Southeast Asia with location of field site: Nam Kading NPA........... 104

Figure 2. Systematic position of the gibbons within the primate order........................ 105

Figure 3.The species distribution for the genus Nomascus. Striped areas indicate assumed original distribution areas of the respective species. 105

Figure 4. Crested gibbon occurrence in Laos. Lines represent approximate locations of taxonomic boundaries for Nomascus leucogenys, and northern and southern Nomascus siki. Map from Duckworth et al. (1999), modified. The distribution of Nomascus leucogenys likely extends south into Nam Kading NPA. The likely boundary between Nomascus leucogenys and Nomascus siki in Nam Kading NPA is indicated by a line.. 106

Figure 5. Female Nomascus leucogenys and male Nomascus leucogenys showing white cheek pattern characteristic of adult males. Photos: Fan Peng Fei 107

Figure 6. Total rainfall (mm) and Average daily temperature (C) in Nam Kading NPA,

Laos, June 2011- May 2012. 107

Figure 7. Percentage of phenology trees with fruit each month and rainfall in Nam Kading NPA, Laos, June 2011- May 2012. 108

Figure 8. Diets of Groups A, B, and C in Nam Kading NPA, Laos, June 2011- May 2012.

Figure 9. Monthly fruit consumption of Groups A, B, and C in Nam Kading NPA, Laos, June 2011- May 2012 109

Figure 10. Seasonal variation in gibbon diet in Nam Kading NPA, Laos, June 2011- May 2012

Figure 11 . The monthly percentage of fruit consumed compared to the percentage of trees with fruit and rainfall in Nam Kading NPA, Laos, June 2011- May 2012. 110

Figure 12. The monthly percentage of young leaves consumed compared to the percentage of trees with young leaves and rainfall in Nam Kading NPA, Laos, June 2011May 2012.

Figure 13. Time spent in different activities by gibbon groups A, B, and C in Nam

Kading NPA, Laos, June 2011- May 2012.

Figure 14. Daily activity rhythm of gibbons in Nam Kading NPA, Laos, June 2011- May 2012

Figure 15. Time gibbons spent in different activities in Nam Kading NPA, Laos, June 2011- May 2012 
Figure 16. The percentage of fruit and leaves consumed over the course of the day by gibbons in Nam Kading NPA, Laos, June 2011- May 2012.

Figure 17. The percentage of fruit consumed by gibbons compared to the percent of time spent feeding, resting, and travelling in Nam Kading NPA, Laos, June 2011- May 2012.

Figure 18. The percentage of leaves consumed by gibbons compared to the percentage of time spent resting and traveling in Nam Kading NPA, Laos, June 2011- May 2012 .... 113

Figure 19. The percentage of other items consumed by gibbons compared to the percentage of time spent feeding and traveling in Nam Kading NPA, Laos, June 2011May 2012.

Figure 20. Rainfall compared to the percentage of time spent resting and traveling by gibbons in Nam Kading NPA, Laos, June 2011- May 2012. 114

Figure 21. Average day range length and percentage of home range used by gibbons compared to the percentage of time spent traveling in Nam Kading NPA, Laos, June 2011- May 2012......

Figure 22. Average day range length and percentage of home range used by gibbons compared to the percentage of time spent resting and feeding in Nam Kading NPA, Laos,

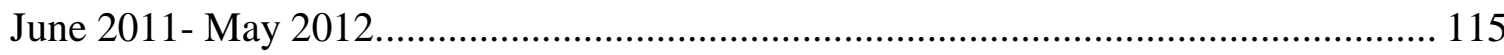

Figure 23. Average day range lengths $(\mathrm{km})$ across months for gibbon groups $\mathrm{A}, \mathrm{B}$, and $\mathrm{C}$ in Nam Kading NPA, Laos, June 2011- May 2012.

Figure 24. Home ranges for gibbon groups A, B, and C with an inset (light gray) of the total range area in the rainy season in Nam Kading NPA, Laos, June 2011- May 2012.116 Figure 25. Proportion of total range used across months for gibbon groups $\mathrm{A}, \mathrm{B}$, and $\mathrm{C}$ in Nam Kading NPA, Laos, June 2011- May 2012.

Figure 26. Gibbon day range lengths $(\mathrm{km})$ across months compared to fruit in diet and fruit abundance in Nam Kading NPA, Laos, June 2011- May 2012.

Figure 27. Gibbon day range lengths $(\mathrm{km})$ and home range use across months compared to rainfall in Nam Kading NPA, Laos, June 2011- May 2012. 118

Figure 28. Gibbon home range use across months compared to fruit in diet and fruit abundance in Nam Kading NPA, Laos, June 2011- May 2012.

Figure 29. A bivariate plot of gibbon home range and body size. Folivores are represented in black and frugivores in gray. 


\section{Chapter 1: Introduction}

\subsection{Introduction}

\section{1.a. Rationale}

Primate research has made vast contributions towards an understanding of ecological and behavioral diversity and life history strategies in animals. Distinct patterns have emerged that help us better comprehend how and why life histories evolve and studies of the great apes have figured prominently in this work. However, crested gibbons (Nomascus), members of the closely related "lesser apes", are the only apes whose behavior and ecology is not well known. They are therefore an important group of primates in need of study in order to better understand the adaptations and evolutionary history of living apes. To that end, I initiated research on white-cheeked crested gibbons groups (N. leucogenys) with a primary focus of documenting their ranging behavior, diet, and activity patterns. I conducted my research in the Nam Kading National Protected Area (NPA) in Bolikhamxay Province of Laos (Fig. 1) using methods developed through past studies of the behavioral ecology of other gibbon genera (e.g., Gittins, 1979; Raemaekers, 1979, 1980; Tilson, 1979; Palombit, 1997; Whitten, 1982a; b). Ultimately, evolutionary studies of behavior must be comparative, and the use of similar methods maximized my ability to compare among gibbon species so that I could increase our understanding of the behavior, ecology, and evolution of very poorly known apes, the crested gibbons.

Body size greatly influences animal physiology, morphology, ecology, evolution, extinction risk, and a host of behaviors, including ranging behavior and territory/home 
range use (Harvey and Clutton-Brock, 1981; Peters, 1983; Garber, 1987; Davies and Oates, 1994). The sizes of organisms are determined by their interactions with their environment and related ecological and evolutionary processes, and specifically, phylogeny. Gibbons are composed of four genera, Nomascus gibbons, with a body mass range of between 7 and $8 \mathrm{~kg}$, are larger than Hylobates and Hoolock (Smith and Jungers, 1997). However, all three are smaller than Symphalangus (Table 1). This morphological disparity should lead to significant differences in the bioenergetics of food acquisition and hence diets. Past research of primates synthesizing the allometric relationship between body size and ecology indicates that a larger body size is associated with more folivorous diets, and consequently, a smaller home range area and decreased ranging patterns, including shorter day ranges (Harvey and Clutton-Brock, 1981; Peters, 1983; Garber, 1987; Fleagle, 1999). Preliminary observations (Ruppell in Nam Kading NPA, 2009) and preliminary studies in China (Bleisch and Chen, 1991; Chen, 1995) suggested extensive folivory and low frugivory in Nomascus compared to other gibbons. However, based on my own preliminary studies (Ruppell, 2007a; b; 2008) and other's work (Bleisch and Chen, 1991; Chen, 1995), the home range size of crested gibbons appeared to be larger than other gibbons. Large home ranges are not expected for a primate folivore (Harvey and Clutton-Brock, 1981; Peters, 1983; Davies and Oates, 1994). The reasons for this are unclear, but it may be because crested gibbons live in an extreme habitat or face different physical stresses associated with their occupation of generally higher elevation sites than other gibbons. 


\section{1.b. Research Questions}

My goal in conducting this work was to fill an existing void in gibbon studies by describing the ecology and behavior of Nomascus leucogenys, to compare the results with those of previous studies of other gibbon genera and other primates in order to test current views regarding the evolution of ecological strategies of primates that are linked to diet, and finally to advise on conservation plans for the species. Specifically, I proposed to address the following questions:

(1) What is the ranging behavior of crested gibbons? In other words, what are the minimal space needs for a group of crested gibbons?

(2) What are the primary food components in crested gibbon diet? Are they frugivores or folivores?

(3) Is there seasonal variation in food availability? Rainfall is highly seasonal in Laos, and does this drive changes in forest resources such that gibbon diets must be flexible and follow seasonal changes in resources?

(4) What are the primary behaviors of crested gibbons, and how do crested gibbons budget their time to different activities?

(5) And based on answers to the above questions, how do crested gibbons differ from other gibbon genera and other primates in their ecology and behavior?

\subsection{Background Information}

\section{2.a. Taxonomy, Geography, Anatomy, Vocalization}

Gibbons are pair bonded arboreal apes that live in East Asian rainforests.

Gibbons, the great apes, and humans form the monophyletic group Hominoidea (Groves, 1989). They are widely accepted as the sister group to the great apes and humans (Fig. 
2), and show the most primitive characteristics within the Hominoidea (apes) (Fleagle, 1984; 1999). This view is supported by results from comparative studies of a wide array of morphological (Biegert, 1973; Schultz, 1933; 1973), physiological (Hellekant et al., 1990), cytogenetic (Wienberg and Stanyon, 1987) and molecular data (Darga et al., 1973, 1984; Doolittle et al., 1971; Felsenstein, 1987; Goldman et al., 1987; Sarich and Cronin, 1976; Sibley and Ahlquist, 1984; 1987).

Gibbons can be split into four taxonomic groups that appear to be of roughly similar phylogenetic age: Nomascus, Hoolock, Symphalangus, and Hylobates. The molecular distances among the four gibbon groups are in the same range as those between humans (Homo) and chimpanzees (Pan), or even greater, and all four gibbon groups are considered separate genera (Roos and Geissmann, 2001) (Table 2). The diploid chromosome number (karyotype) differs among all four genera (Table 3). In addition, the classification of gibbons into four separate genera received strong support from a comparative analysis of DNA sequences (Roos and Geissmann, 2001).

Crested gibbons are found in Vietnam, Laos, Cambodia, and southern China including Hainan Island (Fig. 3). Currently up to six species of crested gibbons are recognized. However, crested gibbon taxonomy is disputed and requires further study (Konrad and Geissmann, 2006; Ruppell, 2009). Based on recent taxonomic research, I refer to white-cheeked crested gibbons as two species (the northern, Nomascus leucogenys and the southern, Nomascus siki) (Fig. 4). These species have not been studied in the wild aside from a few reports on vocalizations, taxonomy, and population density (Ruppell, 2007a; b; 2008; 2009). 
Gibbons are highly specialized, and very uniform in anatomy. Compared to all other primates, gibbons have highly specialized extremities as adaptations for brachiation, a specialized arm-swinging form of locomotion. Relative to their body size, gibbons have the longest arms, but also very long legs (Jungers, 1984). Gibbons are the only apes that consistently exhibit ischial callosities, a thickened piece of skin found on the buttocks of animals (Schultz, 1933). In addition, the females have noticeable sexual swellings, during which the labiae majorae undergo cyclic changes in their color and form (Schultz, 1933).

All extant gibbon species appear to be characterized by small territorial groups, long term monogamous pairing, and loud songs which in most species are structured duets between the breeding pair. Strong defense of territories by small cohesive groups is likely an adaptation to defend preferred food trees that fruit asynchronously over a wide area (Chivers, 2001). Territoriality in gibbons is routinely maintained through loud morning song bouts (Leighton, 1987). Mates typically combine their species-specific and often sex-specific vocalizations to produce well-patterned duets. Duetting may serve several functions in gibbons and the importance of each function may differ between gibbon species. Some of the suggested adaptive functions of gibbon song are mateguarding, pair-advertising, strengthening of the pair bond, and advertising pair bond strength (Geissmann and Orgeldinger, 2000). The song repertoire is notably constant in structure and organization for each species, and believed to be largely genetically determined (Geissman, 1984). 


\section{2.b. Body Size and Ecology}

Body size is related to animal ecology because nutritional requirements of a mammal are directly related to its metabolic rate, and body size largely dictates basal metabolic rates (Peters, 1983). The higher the basal metabolism, the greater the amount of energy the food must be able to deliver per unit volume of body tissue (Peters, 1983). While large mammals (and other taxa) have greater total metabolic requirements than small mammals, they require less energy intake per unit body weight. This negative allometric relationship between body weight and mass-specific energetic and nutritional requirements has important implications for the co-evolution of diet and body size (Schmidt-Nielsen, 1984). Large mammals, because of their high daily total food requirements, are usually unable to base their diets primarily on widely distributed, highenergy foods, those high in calories but hard to find or catch, such as insects (Peters, 1983; Sailer et al., 1985). On the other hand, large mammals, because of their lower perunit weight food requirements do not need to provide a high rate of nutrient flow to their tissues and are thus able to subsist on lower quality foods in bulk (Peters, 1983; Sailer et al., 1985). For example, the largest primates, gorillas $(68-180 \mathrm{~kg})$, consume mostly nutrient-poor leaves and bamboo in very large quantities (McNeilage, 2001). Small mammals have the reverse problem: they do not have large total food requirements, and thus larger fractions of their diet can consist of less readily available, but higher energydensity foods. However, small mammals must nourish their tissues at high rates and therefore must concentrate on high-quality foods (Gaulin, 1979; Sailer et al., 1985). For example, some of the smallest bodied primates, tarsiers (100-153 g), consume mostly insects that are high in nutrients but not abundant (Gursky, 2007). In tropical forests, 
leaves are generally abundant but are usually a much poorer source of energy than fruit (Brockelman, 2011). Fruits are a higher energy food item, but tend to be more patchily distributed and availability can vary dramatically among seasons. Therefore, current thinking is that primarily fruit-eating species require larger ranges and consequently have increased metabolic requirements. Larger animals, due to their ability to subsist on large quantities of leaves because of their low metabolism need to travel less to obtain enough food. Smaller animals, because they require higher energy foods, such as fruit or insects, which are more widely dispersed, must travel more to feed. Thus body size greatly effects diet and ranging behavior.

\section{2.c. Overview of Gibbon Research}

Clarence Ray Carpenter, one of the founders of field primatology was the first to conduct fieldwork on behavior and social relations among gibbons (1940) and much of what we know of gibbon behavior and ecology was first presented by him. David Chivers (1974) was the first to compare gibbon species and genera. He was particularly interested in whether or not generic level distinctions were justifiable on behavioral as well as morphological grounds. His conclusions about the ecological differences between two gibbon genera (Hylobates and Symphalangus) suggest that there are differences between other genera as well. Chivers' predictions about different adaptations between genera revealed the need for cross-genera comparisons of behavior and ecology.

Chivers described siamang (Symphalangus) diet and activity patterns, but he was also concerned with the future prospect for gibbons and siamangs in the face of deforestation. His survey data suggested that siamangs were not disturbed by selective logging, but clear-cutting resulted in isolated arboreal islands with little opportunity for 
dispersal. Are siamangs typical of all gibbons, or might other gibbon species respond differently to logging and human disturbance? This pressing question is a further incentive to compare and more fully understand potential ecological and behavioral differences among genera as this information is essential for the initiation and organization of conservation work.

Following Chivers, detailed observations of behavior and ecology have been made for nearly all species (except those within the genus Nomascus) including Hoolock hoolock (Tilson, 1979; Ahsan, 2001), Hylobates agilis (Gittins, 1979; 1982) Hylobates moloch (Kappeler, 1984), Hylobates muelleri (Leighton and Leighton, 1983), Hylobates lar; (Raemaekers, 1979, 1980), Hylobates pileatus (Srikosamatara 1984), and Hylobates klossii (Whitten 1982a; b). Long term observations of group formation and dynamics exist for only two species: Symphalangus syndactylus and Hylobates lar (Chivers, 1974; Gittins and Raemaekers, 1980; Palombit, 1997; Bartlett, 1999). The socio-ecology of Hoolock hoolock has also been studied extensively (Tilson, 1979; Ahsan, 2001).

The largest of the gibbons, siamangs (Symphalangus) can be twice the size of other gibbons (Table 1). Their longer digestive tract is able to break down leaves through longer passage times, and as a result, siamangs, on average, live in smaller territories, have shorter day ranges, spend less time searching for food and spend more time eating than other gibbons (Gittins and Raemaekers, 1980; Palombit, 1997). By contrast, other gibbons usually eat more fruit and less leaves than siamangs, but travel farther to find it (Gittins and Raemaekers, 1980). Eating leaves requires less travel, but to obtain the same energy from this diet, siamangs must eat large quantities. Siamangs (Symphalangus syndactylus), on average, live in smaller territories (9-23 ha) than Hylobates lar (23-34 
ha) (Chivers, 1974; Gittins and Raemaekers, 1980; Palombit, 1997; O’Brien et al., 2004; Bartlett, 2009). Siamangs also have shorter day ranges (average $800 \mathrm{~m}$ ) than Hylobates lar gibbons (average 1300 m) (Chivers, 1974; Gittins and Raemaekers, 1980; MacKinnon and MacKinnon, 1980; Bartlett, 1999). Palombit's (1997) study of sympatric siamang and Hylobates lar indicated that siamangs rely heavily on more immature foliage while Hylobates lar gibbons heavily exploit the more pulpy fruit of trees. Gibbon dietary composition may, however, exhibit strong seasonal and local fluctuations (Palombit, 1997). Where siamangs and Hylobates lar occur in sympatry, siamangs can more easily adopt a higher proportion of low-energy leaves in their diet. Thus, larger body size enables siamangs to be more ecologically flexible (Palombit, 1997).

Little is known about wild Nomascus behavior and ecology. In the only published accounts, sample sizes are small, study durations are short and there is little quantitative data where gibbons were actually observed. The first published field study of crested gibbons was a report on the ecology of Nomascus leucogenys in Yunnan Province, southern China, which described habitat (i.e., types of trees and foliage used) indicating possible food sources of the gibbons (Hu et al., 1989, 1990). Reports on the social structure and group dynamics of the Cao Vit Gibbon (Nomascus nasutus) in Bangliang, Jingxi, China suggested that polygyny may occur in this species (Fan et al., 2010). The black crested gibbons (Nomascus concolor) are presently the most studied of all crested gibbons. Chen's (1995; see also Bleisch and Chen, 1991) studies from China suggested the possibility that they were polygynous. Recently, reports have been published on ranging patterns and seasonality of activity budgets in habituated western black crested gibbons in central Yunnan China (Fan and Jiang, 2008; Fan et al., 2008). 
Fan et al have also studied the forest use of the same group of black crested gibbons (Fan et al., 2009). Fan recently conducted a survey of the remaining habitat of white-cheeked crested gibbons in China and reported the species extinct in the country (pers. comm).

\section{2.d. Crested gibbon (Nomascus) Specializations}

Nomascus males and females weigh on average $7.5 \mathrm{~kg}$, distinctly smaller than Symphalangus (11 kg), but larger than Hylobates and Hoolock (5.8 kg). Their forelimbs are "elongate even for a lesser ape" (Jungers, 1984:167). Nomascus species have longer skeletal trunk length and forelimb length and shorter hindlimb length than the average among the hylobatids (Napier, 1963; Jungers, 1984). On average, the brachial index (radius x 100/humerus) is 115.5 , crural index (tibia x 100/femur) 87.5 , and humerofemoral index (humerus x 100/femur) 122.2 (Jungers, 1984). In N. leucogenys, the intermembral index (arm length x 100/leg length) ranged from 121 to 140 in a sample of 14 individuals (Groves and Wang, 1990). The slender elongated forelimbs of gibbons are adaptations for brachiation, and the longer forelimbs of Nomascus may point to the potential for faster travel.

As with other hylobatids north of the Isthmus of Kra (Chivers, 2001) crested gibbons are sexually dichromatic. Crested gibbons undergo several conspicuous changes in their fur coloration during development that does not occur in other gibbons. Most crested gibbons are born with a yellow natal coat that resembles the coloration of adult females. Near the end of their first year of life, all immature crested gibbons change to a black coat that is virtually identical to that of adult males. Only upon reaching sexual maturity do young females change fur color for a second time to assume the yellowish coat typical of adult females (Fig. 5). The exception among crested gibbons is Nomascus 
nasutus in which the young are born black. Based on genetic studies, N. nasutus is the most basal of the crested gibbons, which suggests that the color change observed in the other species are derived (Thinh et al., 2010; 2011). Immature crested gibbons participate in the songs of their parents even during their first year of life. Interestingly, they exclusively produce short phrases like the great call (i.e., they sing the female song) until they are sexually mature. Once sexually mature, males change their repertoire and begin to sing male phrases. Thus, during the first several years of their life, all young crested gibbons have fur coloration like adult males but sing like adult females. These immature gibbons continuously provide contradictory information about their sex. This feature appears to be unique among mammals, including other gibbons, and its ultimate basis is unknown. A possible suggestion is that it reduces the sexual attractiveness of young gibbons by emitting contradictory signals (Geissmann, 2002). This may reduce the risk of incest as long as the offspring stay in their natal group. Unfortunately, very little is known about these ontogenetic phenomena and the hormones involved, although I would speculate that melanocyte stimulating hormone is the antecedent to coat color change. Both sexes reach sexual maturity at 7 or 8 years of age (Keeling and McClure, 1972).

Nomascus leucogenys and gabriellae recognize their reflections in mirrors (Ujhelyi et al. 2000). This behavior, most commonly documented in great apes, and not documented in any of the other gibbon genera, indicates high cognitive functioning.

In terms of singing behavior, crested gibbons also exhibit a number of unique characteristics that are unlike other gibbons. Song bouts of mated pairs of the genus Nomascus are highly stereotyped and male-dominated, whereas solo songs appear to be produced by non-mated individuals only (Ruppell, 2009). In addition, crested gibbons 
exhibit the highest degree of sex-specificity in their songs, as there is typically no overlap between the sexes in either note repertoire or phrase repertoire (Konrad and Geissmann, 2006). The song of crested gibbons reaches the highest frequencies of all gibbons at up to 4 kHz (Ruppell, 2009).

The habitat of crested gibbons also differs from other gibbons. Crested gibbons primarily live in mountainous forests with a karst limestone landscape. The countries that crested gibbons inhabit (China, Laos, Vietnam and Cambodia) contain the most mountainous terrain in Southeast Asia (Singh, 2008). Crested gibbons are almost solely found at higher elevations (from 400 to 1,900 meters) than other gibbons (typically from sea level to 500 meters) where rainfall and temperature may vary more widely temporally and seasonally than at lower elevations (Francis, 2008). Divergent ecological strategies may be a consequence of living at higher elevations. Having worked in the different geographic areas where gibbons are found and observed the differences in topography, it seems possible that the ecological and behavioral differences (such as differences in song and morphology) between Nomascus and other genera may represent localized adaptations to the properties of altered terrain.

\section{2.e. Conservation in Laos}

The current major challenges facing Laos' environment are the internal pressures of economic growth and the external pressures from the country's neighbors (in particular China, Vietnam, and Thailand) who seek to exploit, to the full extent possible, the abundant resources remaining in Laos (Singh, 2008). With 6.5 million people, Laos has one of the lowest population densities in Asia, but the total population has more than doubled in the last thirty years, and continues to grow (Singh, 2008). Laos is notable for 
its remarkably intact biodiversity (Timmins and Duckworth, 1999). Because of its isolation, political turmoil, war, and culture (a common tradition is "Bounbanhao Khoylin Khoykin" which means "no need to hurry") the country has remained relatively undeveloped compared to its neighbors. The environment has long benefited from the country's small population. However, with a growing population of poor, for whom wildlife equates to protein, all species are being threatened at a progressively alarming rate (Bleisch et al., 2008) There are also ongoing problems of illegal logging and a renewed governmental pursuit of arranging to sell rivers to foreign hydropower developers (Ruppell, pers. obs).

Laos shares borders with China, Myanmar, Thailand, Cambodia and Vietnam. Mountains and plateaus cover over $70 \%$ of the country. Parallel to the Mekong River is the Annamite Chain, a mountain range with peaks averaging between 1500 and $2500 \mathrm{~m}$ in height (Sterling et al., 2006). All the rivers and tributaries west of the Annamite Chain drain into the Mekong, while waterways east of the Annamites flow into the Gulf of Tonkin off the coast of Vietnam (Sterling et al., 2006). As in Cambodia, Vietnam, Myanmar and much of Thailand, most of the fauna in Laos belong to the Indochinese zoogeographic realm (as opposed to the Sundaic found south of the Isthmus of Kra in southern Thailand or the Palearctic to the north in China) (MAF, 2011). Among the most notable of Laos' wildlife are the primates including Phayre's leaf monkey (Trachypithecus phayrei), Francois' langur (Trachypithecus francoisi), Douc langur (Pygathrix nemaeus), pygmy slow loris (Nyticebus coucang), several species of macaque (genus Macaca), and gibbons (Nomascus and Hylobates, the latter being found on the 
western side of the Mekong in northern Laos). All of these primates are endangered and on the IUCN Redlist (2011).

To a certain extent, all wild animals in Laos are endangered because of widespread hunting and persistent habitat loss. Aside from primates, several dozen mammals in Laos are on the IUCN Redlist, including the Asiatic black bear (Ursus thibetanus), Malayan sun bear (Ursus malayanus), cattle such as the guar (Bos gaurus) and banteng (Bos javanicus); and the clouded leopard (Neofelis nebulosa) and tiger (Panthera tigris) (MAF, 2011). Some endangered species are so rare that they were unknown until recently. Among these is the saola (Pseudoryx nghetinhensis), a horned mammal found in the Annamite Chain (IUCN, 2011), and the Laotian rock rat, (Laonastes aenigmamus) a genetically distinct rodent considered a living mammalian fossil (Huchon et al., 2007).

There are 23 National Protected Areas (NPAs) in Laos and several provincial protected areas (National Assembly Laos, 2007). NPAs have local communities living within their boundaries, unlike most American National Parks, where only rangers and those working in the park are allowed to live. Even with the abundance of protected space in Laos, specific laws protecting wildlife do not exist. Most Lao people are unaware of world conservation issues and there is little will and less money to pay for conservation projects. The country's goal of large-scale development demonstrates a huge conflict of interest with wildlife and resource conservation. Lack of communication, corruption, and poor definitions of authority add to the issues. 


\section{2.f. Gibbon Conservation in Laos}

In Laos, the distribution of crested gibbons is not well known but has been estimated based on coat coloration and song characteristics of gibbons in protected areas (Figs. 4 and 5). Nomascus leucogenys is categorized as "Critically Endangered" on the IUCN Red List, with subcategories A1cd $+2 c d$, indicating that the taxon has seen a population reduction of at least $50 \%$ over the last 3 generations, as a result of habitat modification and exploitation. A similar reduction is projected for the next 3 generations (IUCN, 2004; 2011). Nomascus siki is categorized as "Data Deficient" meaning there is not enough information to place them in a category.

Deforestation and habitat fragmentation are major threats to the long-term survival of primate populations. These processes isolate populations, reduce population sizes, and increase the probability of inbreeding, all of which increase the risk of extinction. The degree to which gibbons can disperse across areas of non-forest has not been clearly demonstrated, but it is unlikely that arboreal species can travel significant distances across roads, grassland, scrub or cultivated areas to reach nearby forest patches. While loss of habitat is an acknowledged strain on remaining wildlife populations, unrelenting over-harvesting of species is also devastating wildlife populations in Laos (Bleisch et al., 2008; MAF, 2011).

In Laos, some ethnic groups have taboos against killing gibbons, because some feel they are closely related to humans, or they represent spirits that would seek revenge on hunters, or simply because they sing pleasantly in the morning and do not raid crops. These hunting taboos have led to lower rates of gibbon population decline compared to Vietnam (Wildlife Conservation Society internal reports, 2011; Ruppell, pers.obs.). 
Gibbons are truly representative animals of Southeast Asia, in that they occur throughout the region and extend only marginally outside it. They are also among the most distinctive and detectable, with their prolonged loud songs, diurnal activity and dramatic arm-swinging motion through the vegetation. Looked at internationally, Laos has a number of strong positive attributes for gibbon conservation. First, it possesses among the highest number of gibbon species of any country (at least 6 species), despite its relatively small size (Duckworth, et al., 1999). Second, it retains much larger tracts of forest (i.e., gibbon habitat) than do many other countries with gibbons. While large tracts of forest remain, very few areas are still inhabited by gibbons. The empty forests point to hunting as the factor driving declines in Lao gibbons. These attributes mean that with sufficient interest, gibbons can be conserved in Laos, the more so because they are arboreal and not threatened by the heavy levels of ground-level snaring and trapping in many forest areas (Duckworth et al., 1999; Ruppell, 2008). Animals with high financial value in the illegal international trade, such as tigers and Asian elephant (Elephas maximus), are difficult to conserve because high vested financial interests drive continued poaching (MAF, 2011). Gibbons are at the opposite extreme in that even a modest raising of public awareness of their protected and threatened status combined with basic patrolling could result in rapid declines in hunting levels. 
Chapter 2: Influence of Forest Seasonality on Diet of Nomascus leucogenys

\begin{abstract}
Gibbons are considered to be frugivorous. However, crested gibbons (Nomascus spp.) are thought to be more folivorous than other gibbons, but this has never been confirmed because of the paucity of fieldwork on the genus. I studied the diet of three groups of white-cheeked crested gibbons ( $N$. leucogenys) in relation to forest seasonality to quantify diet, and in particular, determine the contribution of leaves to the diet. I collected data over 12 months in wet seasonal evergreen forest in Nam Kading National Protected Area, Bolikhamxay Province, Laos. Although leaves were the main dietary item throughout the year (53-85\% of diet), gibbon diet was strongly influenced by the availability of fruit because they increased their consumption of fruit during periods when fruit was most abundant in the forest. Thus, gibbons appear to seek nutritionally rich fruit as food when it is abundant and obtained easily. Young leaf consumption increased when they did not have access to fruit, indicating that their diet is flexible but strongly dependent on seasonal availability of resources. In addition, rainfall had a negative association with fruit abundance and fruit in diet. Hence, white-cheeked crested gibbons are indeed more folivorous than other gibbons, potentially because they live in a highly seasonal environment where fruit is often scarce.
\end{abstract}




\subsection{Introduction}

Although tropical forests have traditionally been viewed as some of the most stable environments on earth, much research has now shown that they exhibit seasonal variability (reviewed in Brockelman, 2011). Foraging animals are forced to make decisions on which resources to exploit to ensure they obtain adequate nutrition and maintain a sufficient body condition for reproduction, territory maintenance, and survival. Consequently, many forest primate species display seasonal changes in feeding behavior that are related to the abundance of specific food items or climatic factors (Chivers, 1974; Leighton and Leighton, 1983; Leighton, 1993; Julliot, 1996; Davies et al., 1999; DiFiore and Rodman, 2001; Su and Lee, 2001; McConkey, et al., 2003). However, diet and climate relationships have never been elucidated for any of the primates found in wet, seasonal, mountainous forests of Laos or Vietnam, including, most notably, crested gibbons (Nomascus spp.).

The timing of phenological cycles in a forested environment is an important aspect of primate ecology. Climatic variables play an important role in initiating availability of plant parts such as fruit, flower, or leaves (Frankie et al., 1974; Augspurger, 1982; Wright and van Schaik, 1994) that represent the vital resources available to resident primate populations. Several authors (Chivers, 1974; Ahsan, 1994; 2001; Bricknell, 1999; McConkey et al., 2002; 2003) have found a direct relationship between the availability of particular food items in the forest and their frequency in the diet of other gibbon genera. For example, fruit consumption was positively correlated with fruit availability for gibbons in several studies (Chivers, 1974; Ahsan, 1994; 2001; Bricknell, 1999; McConkey et al., 2002; 2003). Hoolock hoolock altered its diet to 
include more figs when they became available (Ahsan, 2001), whereas Hylobates muelleri $\mathrm{x}$ agilis consumed seedless fruit preferentially when they ripened (McConkey et al., 2002).

At a body mass of $7.5 \mathrm{~kg}$ crested gibbons (Nomascus) are intermediate in size to the larger Symphalangus (11 kg) and smaller species in the genus Hylobates $(5.5 \mathrm{~kg})$. Thus, crested gibbons vary distinctly from other genera (Peters, 1983; Smith and Jungers, 1997), and given that body size and diet often covary, it may be that diet also exhibits considerable variation among genera. The sizes of organisms are determined by an evolutionary history of interactions with their environment and related ecological processes. It is well established that body size greatly influences animal physiology, morphology, ranging patterns, ecology, and extinction risk, and that differences in body size and resulting constraints influence the foraging behavior of each species (Peters, 1983). Allometric scaling demonstrates relationships between body size, metabolism, and ecology, and one finding is that large body size is often associated with consumption of plant material, and in primates in particular, with a more folivorous diet (Peters, 1983; Terborgh, 1983). My preliminary observations lend support in that I detected extensive folivory and low incidence of frugivory in Nomascus compared to other gibbons (Ruppell, 2007; 2008; Ruppell in Nam Kading NPA, 2009). Studies of Symphalangus syndactylus (siamang) and Hylobates lar (white-handed gibbons) have demonstrated dietary differences based on body size and have suggested that observed levels of frugivory represent metabolically based maxima (Chivers, 1974; Chivers and Raemaekers, 1986). Raemaekers' (1979) research provided the most rigorous demonstration of dietary contrasts, with siamangs eating mostly leaves and few fruits 
whereas white-handed gibbons consumed large amounts of fruit and little foliage. However, subsequent study by Palombit (1997) has shown that the amount of fruit in the diet varies between siamang populations and that different species of plants comprise the diet in different geographic populations.

Body size is related to animal ecology because the nutritional requirements of a mammal are directly related to metabolic rate. Higher basal metabolism demands that greater amounts of energy be acquired per unit volume of body tissue (Peters, 1983). While small mammals require more energy intake per unit body mass, the greater size of large mammals requires a greater overall daily intake of food. The negative allometric relationship between body mass and mass-specific nutritional requirements has important implications for the co-evolution of diet and body size (Schmidt-Nielsen, 1984). Large mammals, because of their high daily total food requirements, are usually unable to base their diets primarily on rare, high- energy foods (those high in calories but hard to find or catch, such as fruit and insects) (Gaulin, 1979; Peters, 1983). On the other hand, large mammals, because of their lower mass-specific food requirements, can function with a lower rate of nutrient flow to their tissues and are thus able to subsist on lower quality foods consumed in bulk, such as leaves (Bauchop, 1978; Peters, 1983; Garber, 1987).

Dietary preferences likely reflect a compromise between the presence of plant secondary metabolites and the digestibility of food items (Gaulin and Konner, 1977; Ganzhorn, 1992). Folivory is a common strategy in several radiations of primates including New World monkeys (Alouatta palliata and Brachyteles arachnoides), Old World monkeys (subfamily Colobinae), and lemurs (genus Propithecus and Indri) and these primates utilize different ecological strategies in relation to their diet (Table 4). 
Diets of primate folivores may comprise up to $70 \%$ leaves (e.g. medium-sized colobines: Oates, 1977), which require anatomical specializations that include a multi-chambered, complex stomach to aid the digestion of hard-to-digest leaves (Davies and Oates, 1994; Kay and Davies, 1994; Groves, 2005). Oates et al. (1977) report that leaves from three tree species comprise $69 \%$ of all feeding records for colobine monkeys indicating that this primate is highly selective in its feeding behavior. Thus, anatomically specialized folivores are able to subsist on a relatively monotonous diet of mature leaves, consisting of a small number of tree species.

Food selectivity can be correlated with an avoidance of secondary plant compounds and a preference for leaves of high nutritional value (Freeland and Janzen, 1974; Gaulin and Gaulin, 1982). Behavioral folivores have only minor digestive specializations (Garber, 1987; Hemingway, 1998) and are more sensitive to problems associated with plant toxicity and consequently, they sample and consume small amounts of young leaves from a variety of species, and less mature leaves than anatomically specialized primates (Glander, 1982; Ganzhorn, 1989). For instance, howler monkeys (Alouatta palliata) are highly folivorous New World primates. Although they possess a spacious hindgut, they do not exhibit other morphological specializations associated with leaf eating. They can efficiently extract nutrients from their food by retaining and processing it for longer periods of time (Milton, 1981). By contrast, the woolly spider monkey (Brachyteles arachnoides) has a large gut capacity and short passage rate that facilitates rapid expulsion of relatively indigestible remains (Milton, 1984). Remarkably, howler monkeys have a colon that is twice the size of a woolly spider monkey colon, even though they weigh less than woolly spider monkeys (Milton, 1981). Therefore, the 
digestive strategy of woolly spider monkeys is based on rapid turnover of low quality plant food, whereas the howler monkey diet is predicated on the efficient and slow digestion of high quality plant foods (Milton, 1984).

Comparative data from other primate groups are instructive. Indris (Indri indri) and sifakas (Propithecus diadema) are the two largest living lemur species $(6.5 \mathrm{~kg}$; Glander and Powzyk, 1995). Their geographic ranges are nearly identical, but distinct interspecific differences exist in their ecology and behavior that are related to their gut morphology, feeding behavior, and nutrient content of preferred foods. For example, indris defend their home ranges relatively inexpensively by singing rather than by active patrols. They are also highly discriminating in the plants they select to consume, while the sifaka consumes a high diversity of plant species and is more active in patrolling and foraging (Powzyk and Mowry, 2003). In addition, sifakas and indris have little overlap in their choice of specific food items which may reduce competition (Powzyk and Mowry, 2003). Both species preferentially feed on young leaves, but, the sifaka diet overall is significantly richer in fat and water soluble carbohydrates than indris (Powzyk, 1997). Sifakas have a relatively longer small intestine than indris, which increases sites for simple carbohydrate absorption. Conversely, indris have a relatively longer caecum which increases areas for fermentation. Sifakas consume more food and pass it more quickly as indicated by their faster gut passage rate and more time spent feeding (Powzyk, 1997).

The Gibbons (family Hylobatidae) of Southeast Asia are considered frugivores, with some species supplementing their diet with flowers, leaves, or insects. In tropical forests, leaves are generally abundant but are usually a much poorer source of energy 
than fruit. On the other hand, fruits tend to be very patchily distributed compared to foliage. As a corollary, and also evidence of the importance of fruit to gibbons, gibbons are considered reliable and effective seed dispersers and are viewed by some as one of the most important frugivores in Asian rain forests (McConkey and Chivers, 2007).

In particular, gibbons consume large quantities of figs (Ficus spp.) and several researchers argue that gibbons prefer figs over other fruits (MacKinnon and MacKinnon, 1980; Chivers and Raemaekers, 1986; Palombit, 1997). This suggests that compared to other frugivorous primates, gibbons seek out figs whenever they are available and seek out other fruit secondarily. Many fig trees are considered keystone species in communities of fruit eating animals because of their asynchronous fruiting patterns that provide a more reliable source of nutrition (Terborgh, 1986). From the plant's perspective, fruiting asynchrony is individually favored because it reduces competition for seed dispersers (Terborgh, 1986). If gibbons are truly fig specialists, their diet and feeding behavior should be relatively unaffected by overall fluctuations in fruit abundance because figs are generally present year-round in small but stable amounts (Bartlett, 2009).

Crested gibbons (genus Nomascus) are found in Vietnam, Laos, Cambodia, and southern China including Hainan Island. Currently up to six species of crested gibbons are recognized. However, crested gibbon taxonomy is disputed and requires further study (Konrad and Geissmann, 2006; Ruppell, 2009). The locations of boundaries between species are not well established. Based on recent taxonomic research, the gibbons at my study site in Nam Kading NPA, Laos are recognized as northern white-cheeked crested gibbons (Nomascus leucogenys). Aside from a few reports on vocalizations, distribution, 
and population density (Konrad and Geissmann, 2006; Bleisch et al., 2008; Ruppell, 2007a; 2007b; 2008; 2009) this species has not been studied in the wild, and basic information on foraging behavior and diet do not exist.

I spent a year in the field documenting diets of free ranging gibbons (Nomascus leucogenys) with the goal of (1) characterizing diet (i.e., proportion of fruit vs. leaves, (2) evaluating the relationship between fruit availability and rainfall so that I could test the predictions that (a) diet changes over the annual cycle in association with seasonal variability in rainfall and resource availability, and (b) because of their larger body size and reduced energy needs, crested gibbons subsist on a higher proportion of leaves in their diet than other gibbons.

\subsection{Methods}

\section{2.a. Study Area and Climate}

My study was conducted in the Nam Kading National Protected Area (NPA) in Bolikhamxay Province of Laos (18 40’51 N and $\left.104^{\circ} 08^{\prime} 11 \mathrm{E}\right)$ in wet seasonal evergreen forest distributed over a rugged, mountainous landscape that ranged from 400-1,200 $\mathrm{m}$ in elevation. The climate is hot, humid, and monsoonal. Temperature and especially rainfall indicate a highly seasonal climate (Fig. 6). Although mean monthly rainfall was $272 \mathrm{~mm}$ from June 2011- May 2012, it ranged from 0 to $50 \mathrm{~mm} / \mathrm{month}$ during dry months (October to April) to between 200 to $918 \mathrm{~mm} / \mathrm{month}$ in rainy months (May to September). Rainfall less than $100 \mathrm{~mm}$ in a month is a coarse indication of a "dry" month (Brockleman, 2011), and therefore, I will henceforth refer to the period from October to April as the dry season and May to September as the rainy season. The dry season became cool from October to February, with the lowest temperatures in December. In 
addition, there was almost no rain from November to January. Average daily temperature was $26^{\circ} \mathrm{Celsius,} \mathrm{but} \mathrm{varied} \mathrm{seasonally} \mathrm{from} 20^{\circ}$ to $30^{\circ} \mathrm{C}$ across months. Temperature varied throughout the day with cool mornings (average $22^{\circ} \mathrm{C}$ ) and hot afternoons (average $29^{\circ} \mathrm{C}$ ). The hottest days were from March to May with average daily temperatures as high as $30^{\circ} \mathrm{C}$ which were transitional months between the very dry and very wet periods.

\section{2.b. Study species and Groups}

The northern white-cheeked crested gibbon (Nomascus leucogenys) ranges from northern Vietnam and northern Laos to central Vietnam and central Laos and from the eastern border of Vietnam to the western boarder of Laos (Geissmann et al., 2000). White-cheeked crested gibbons are a territorial species and the density of gibbons in the Nam Kading NPA is much higher than what I previously documented from earlier site visits to Vietnam (Ruppell, 2007a; 2008). On the basis of early observations by Delacour (1933), minimum home range requirements of un-hunted groups in intact forests may be about one hundred acres (40 ha). Males and females weigh about the same (7.3-7.4 kg) (Smith and Jungers, 1997) and adults of both sexes have exceptionally long arms and dense pelage. Adult females have a yellow coat and adult males have a black coat with white cheeks. In males the fur projects into a point on the top of the head, hence the name "crested" gibbon. They are the most abundant primate in the area where I worked because most other species appear to have been extirpated by hunting. I made a preliminary trip to the field site in 2009 and located several groups whose ranges were in proximity to one another. The nearby village considers the hunting of gibbons to be taboo, and because of this, it is possible that the area reflects the natural density and behaviors of gibbons unexposed to hunting pressure and deforestation. The nearby 
villagers often walk in the forest, but because they do not represent a danger to the gibbons, the gibbons do not appear to see them as a threat, and this habituation to humans facilitated my observations of the wild groups.

I collected data on three groups. All groups had one adult male, one adult female, but group $\mathrm{A}, \mathrm{B}$, and $\mathrm{C}$ had different numbers of juveniles, numbering 3, 2, and 1 respectively. The three groups' home ranges shared common borders.

\section{2.c. Data Collection: Climate and Phenology}

Temperature and rainfall were recorded daily using a Taylor Dual-Scale Maximum Minimum Thermometer and an All Weather Rain Gauge set up in an opening in the forest. The phenological survey assessed monthly leaf, flower, and fruit abundance. To document forest phenology, I established three 100 meter transects within the known home ranges of the three study groups. At 10 meter intervals along each transect I marked all trees greater than $10 \mathrm{~cm} \mathrm{DBH} \mathrm{(diameter} \mathrm{at} \mathrm{breast} \mathrm{height)} \mathrm{within} \mathrm{a} 5$ meter radius of the point. Thus, each transect covered an area of $1000 \mathrm{~m}^{2}$ and the total area sampled covered 9000 meters $^{2}$ (> $2 \%$ of the typical home range). All of the marked trees were examined once per month by inspecting each tree crown and its associated plant life forms with binoculars and recording the presence of fruit and young leaves. Identification of tree species is dependent on export permits for the plant samples that have not yet been obtained because of stifling bureaucracy in Laos.

At each survey, every tree was listed as having either fruit, young leaves, or just leaves. Only one of the three was designated in the phenological survey and fruit was always given precedence over either leaf category because leaves were always present when fruit was present. If flowers were present, they were present only in addition to 
fruit, so fruit was designated over flowers. Many tropical species produce new leaves throughout the year, and as a result, young and mature leaves were available in all months. If young leaves and mature leaves were both present on trees, young leaves were designated over mature leaves. Of the trees that did not have fruit, trees with young leaves were recorded as a subset, differentiating them from trees with mature leaves only.

\section{2.d. Data Collection: Diet}

I followed each study group for at least 4 days per month for 12 months, which yielded 12 full days each month. Observations began at dawn ( 0500-0600 h) after the gibbons woke and ended when they reached their sleeping tree at around $1500 \mathrm{~h}$. Field assistants aided me by locating and following gibbon groups, and pointing out positions, activities, and food consumption by gibbons. Diet was determined using time point sampling with a frequency method (Struhsaker, 1975; 1978; Rudran, 1978; National Research Council, 1981). During group follows, time budget data was collected at intervals of five minutes for the whole group, meaning that group activity was designated by a single behavior. When individual differences were observed at the time point, they were recorded with all-occurrence sampling. I recorded activity as resting, traveling, feeding, or singing. Food type was recorded whenever possible when animals were observed feeding. Foods were placed into 1 of 4 categories: fruit, young leaves, mature leaves, and other, which included flowers, vine shoots, and insects. If more detail could be ascertained, such as type of fruit (fig or non-fig), that was also recorded. Frequencies of food types in the diet were estimated by dividing the number of time point records for each food category by the total number of feeding records. As all group members consistently fed together, I assume this method yielded an accurate picture of the 
importance of different items in their diet. Estimates of actual mass or energy intake could not be made during daily follows, mainly because individual gibbons went in and out of view, and because other behavioral data were being recorded at the same time.

I report data from 144 days of observation conducted from June 2011 through May 2012. In most months, all three groups were observed for more than 4 days each. However, on many days the groups were lost when they passed over high cliffs, which made it difficult to maintain contact. Here I report the data from 4 days per group per month, when I was able to follow the gibbon groups without losing them for most of the day (from dawn to when they reached their night trees).

\section{2.e. Statistical Methods}

I used Pearson product-moment correlations to compare seasonal changes in rainfall and phenology and one way analysis of variance (ANOVA) to compare the percentage of fruit, leaves, and other items in the diet of the three groups. I also used repeated measures ANOVA to compare the three groups and the percentage of fruit in their diet across months. Partial correlations were used to evaluate the effect of food availability and rainfall on diet. The dependent variables tested were frequency of fruit consumption and frequency of young leaf consumption, while the independent variables were monthly rainfall, fruit availability, and young leaf availability. I conducted general linear models (GLM) to refine differences between groups, by simultaneously evaluating all factors with a potential influence on the dependent variables. I report statistics as means \pm SE. Because my power to test hypotheses was limited because of the small sample size resulting from a single year of data collection, I opted for a $P$ value of 0.10 to 
minimize the probability of committing a type II error (i.e., accepting a false null hypothesis of no difference).

\subsection{Results}

\section{3.a. Seasonality: Climate and Phenology}

The forest at my study site was dominated by large and tall trees with an average DBH of $1.6 \mathrm{~m}, \mathrm{SE} 1.4$ (range $10 \mathrm{~cm}$ to $6 \mathrm{~m}, \mathrm{~N}=279$ ). It is a wet seasonal evergreen forest because no trees in this sample lost all of their leaves in the cool season. Fruiting availability, on the other hand, fluctuated seasonally (Fig. 7). The percentage of trees with fruit was at its lowest in the rainy season, (10\% in September) and more than four times that in the dry season (44\% in March). Overall, fruit was most abundant during the March to May transitional hot period. The percentage of trees with leaves only was lowest in March (54\%) during the dry season, and highest in the rainy season, especially August and September. Monthly leaf abundance tended to be greatest in months of high rainfall, $(r=0.49, P=0.10)$. Conversely, monthly fruit abundance tended to be lowest in months of high rainfall ( $r=-0.5, P=0.08$ ). Thus, as noted above, fruit tended to be more abundant during the drier months of the year, whereas, the rainy season was a foliage rich and fruit poor period.

\section{3.b. Diet}

Feeding and travel were highly coordinated within groups, and the gibbons rarely lost sight of each other as they traveled between feeding trees. Because individuals within a group always traveled and fed together, food types were consistent between individuals within a group (i.e., when a group was feeding, all of the individuals in the group were 
feeding on the same thing). Diet among the groups varied little (Fig. 8) because the percentage of fruit, young leaves, mature leaves, and other items in the diet of the three groups averaged over the year was remarkably similar (ANOVA: $F=<0.01, \mathrm{df}=2,11, P$ $=>0.99)$. I used a repeated measures ANOVA to evaluate the relationship among the three groups and the percentage of fruit in their diet across months (Fig. 9) which also indicated that the groups were similar $(F=0.005$, df $=2,33, P=0.995)$. In addition, after accounting for rainfall, and estimates of fruit and young leaf availability concurrently, there was no difference among the groups in the proportion of different items in the diet (Table 5).

Averaged over the annual cycle, leaves comprised most of the feeding observations (68.8\%), followed distantly by fruit (30.4\%). These two items accounted for roughly $99 \%$ of food items, the remaining $1 \%$ including insects $(0.5 \%)$ and flowers $(0.3 \%)$. Non-fig fruit was consumed more frequently $(26.9 \%)$ than fig fruit $(3.5 \%)$ but the main component of the gibbons' diet was leaves (young leaves 52\% and mature leaves $16.8 \%)$. Seasonality in food choices was quantified as changes in the frequency of feeding on particular food types over the course of the year (Fig. 10). Fruit consumption was lowest in the foliage rich, fruit poor rainy season, especially September (14\%), and more than three times higher in the fruit rich dry season, and at that time accounted for nearly $50 \%$ of feeding observations. The pattern was reversed in the case of leaf consumption, because leaf consumption was lowest in the dry season, especially April (53\%), and highest in September (85\%), during the rainy season. Young leaves comprised a minimum of $44 \%$ (in February) of all feeding observations in the dry season and was highest in October (61\%) which marks the transition from the rainy to dry 
season. The highest consumption of "other" food sources occurred in June (3\%) and decreased to $0 \%$ in August, November, and from March through May. Fig fruit was a small percentage of the total fruit eaten and never accounted for more than $6 \%$ of the diet in any month and in 8 of 12 months figs comprised $<3 \%$ of the diet.

\section{3.c. The Effect of Resource Availability and Rainfall on Diet}

Partial correlation analysis indicated that diet varied with both the availability of

fruit and young leaves in the environment as well as rainfall (Figs. 11 and 12). The partial correlation of monthly fruit consumption with fruit availability indicated that, after controlling for the influence of rainfall and young leaf availability, gibbons increased their consumption of fruit as fruit availability increased (Table 6). Likewise, after controlling statistically for the influence of fruit availability, gibbons consumed less fruit during months of high rainfall. In contrast, the time spent feeding on fig fruit alone was unrelated to fruit abundance ( $r=-0.28, P=0.32)$ and only weakly related to rainfall $(r=$ $-0.51, P=0.10)$. The partial correlations also indicated that young leaf abundance was the strongest predictor of young leaf consumption in a given month (Table 6). Rainfall was not significantly related to young leaves in the diet (Table 6 and Fig. 12). However, when controlling statistically for the influence of rainfall and young leaf availability, fruit availability was strongly negatively correlated with young leaf consumption, indicating that in months of high fruit availability the gibbons consumed fewer young leaves (Table 6). GLM analyses indicated that fruit consumption was a function of fruit availability when all other variables in both the full model and reduced model were accounted for statistically (Table 5). Young leaf consumption was not significantly associated with any of the factors in the full model of the GLM analysis (Table 5). When the analyses were 
redone without the group factor in the reduced model, young leaf availability was significantly associated with young leaves in the diet (Table 5).

\subsection{Discussion}

Folivorous species are defined as species that specialize on leaves (Davies and Oates, 1994; Fleagle, 1999). Most studies of other gibbon genera, specifically Hylobates, report leaves as constituting less than $40 \%$ of the total gibbon diet over the year (Table 7). My finding that leaves represented nearly $70 \%$ of the white-cheeked crested gibbon diet indicate that they are considerably more folivorous and less frugivorous than other species of Hylobates (Bartlett, 2007), and are slightly more folivorous than Nomascus concolor in Wuliang Mountain, China (Fan et al., 2009) and Symphalangus syndactylus (Chivers, 1974; Raemaekers, 1979; MacKinnon and MacKinnon, 1980). Strong relationships existed among rainfall, the availability of plant resources, and their consumption by gibbons in the forest of Nam Kading NPA, Laos and differences in the local flora, rather than selective differences between gibbon species, may influence diet. Less mountainous, tropical forests have more plant species that produce fleshy fruits (van der Pijl, 1969), than the forests at Nam Kading, and are therefore likely to have higher fruit availability and permit higher levels of frugivory. For instance, in tropical central Borneo, Hylobates muelleri x agilis consumed fruit from more than 167 species (McConkey et al., 2002). By contrast, Nomascus concolor consumed fruit from only 38 species in the relatively cooler climates of Wuliang Mountain, China (Fan et al., 2009).

At my study site, both young leaves and fruit were ephemeral resources compared to the stable availability of mature leaves. Plant phenology is also likely to be an important factor in comparative analyses of frugivory in gibbons. In the lowland tropical 
forests of Thailand, Malaysia, and Indonesia, fruit is likely to be more abundant yearround than in the northern, higher elevation, wet, seasonal, karst forests of Laos and the montane forests at Wuliang Mountain, China. At the more northern latitudes and higher elevations, fruiting is likely to follow a stronger seasonal pattern (Fan et al., 2009). At these locations, it is likely that gibbons turn to other food resources during periods when fruit becomes scarce (Fan et al., 2009).

Reliance on leaves during periods of food scarcity differentiates folivores from frugivores (Stanford, 1991). As field studies of anatomical folivores have accumulated, so has the recognition that fruit and seeds are major dietary components of Asian and African colobines (Davies and Oates, 1994) and Malagasy indrids (Hemingway, 1996). While the relative selectivity of young leaves over mature leaves is a consistent theme in dietary studies of folivores (Oates, 1977; Glander, 1978, Stanford, 1991), recent discussion also emphasize the fruit and seed component of the diet (Hemingway, 1996; 1998; Strier, 2004).

Folivores may consume lower quality foods in response to disruption of food resources. Studies of Propithecus diadema in continuous versus fragmented forests have shown that forest fragmentation results in divergent ecological strategies (Irwin, 2008). Continuous forest groups had higher dietary diversity and ate more fruit than fragmented forest groups, who consumed mostly mistletoe (Bakerella clavata), which is considered a lower quality fallback food (Irwin, 2008). The difference in resource utilization between sites has important implications for understanding interspecific variability in response to fragmentation. 
White-cheeked crested gibbons appear dissimilar to most of the known folivores (New World monkeys such as Alouatta palliata and Brachyteles arachnoides, Old World monkeys (subfamily Colobinae), and lemurs (genus Propithecus and Indri). Gibbons are not known to have specialized gut anatomy for digesting leaves like that of the colobines (Davies and Oates, 1994), a capacious hindgut like howler monkeys (Milton, 1981), or a particularly large gut capacity and rapid passage rate, as found in woolly spider monkeys (Milton, 1984). Behaviorally, howler monkeys (Milton, 1980) and white-cheeked crested gibbons (this study) were alike in that both consumed more leaves when energy rich food sources were scarce. In addition, white-cheeked crested gibbons exhibit some similarities with indris (Indri indri): a similar body size (Indris are $6.5 \mathrm{~kg}$, Nomascus leucogenys are $7.5 \mathrm{~kg}$ ), both species defend territories with song rather than active patrols, and both have a selective diet with an emphasis on young leaves.

Fruit is nutritionally rich, providing more carbohydrates per gram, but less fiber than leaves (Hamilton and Galdikas, 1994; Velleyan, 1981). Leaves are abundant and easily obtained, but they also usually contain tannins and other secondary plant products that reduce digestibility (Davies and Oates, 1994). Conversely, fruit commonly occurs in small, scattered sites, takes time and energy to locate, but comparatively speaking is a rich energy source. Thus, white-cheeked crested gibbons may obtain dietary bulk from accessible leaves during the rainy season's months of low fruit availability. The proportions of soluble carbohydrates, crude protein, and crude fats in native Asian plants indicated a higher percentage of protein and calcium in mature leaves, and a higher percentage of carbohydrates and lipids in fruits (Ruby et al., 2000). Mature leaves have been found to be the most important source of calcium for some primates, yielding the 
highest values found in all food samples (National Research Council, 1978; Powzyk, 1997). Thus, mature leaves could be an important dietary source of protein and calcium for crested gibbons.

Many studies of gibbons showed that they eat more fruit when availability is high (Chivers, 1974; Ahsan, 1994; Bricknell, 1999), and that leaves replace fruit in the diet when fruit is scarce (Gittins and Ramaekers, 1980; Leighton and Leighton, 1983; Leighton, 1993; Bricknell, 1999). Thus, my study adds to a growing body of data to suggest that gibbons consume fruit when it is available and replace fruit with leaves when fruit is not abundant. The higher percentage of leaves consumed compared to other gibbon species may reflect the expected positive relationship between folivory and larger body size (Peters, 1983), as white-cheeked crested gibbons are relatively large (Table 1). Alternatively, they may possess a unique gut adaptation for digesting leaves (Vellayan, 1981) that has so far been unidentified. In addition, their guts most likely contain symbiotic gut flora (Hladik, 1978; Bauchop, 1978). A third possible explanation for their high leaf consumption is that the local population in my single year of study experienced atypical climatic conditions that resulted in lower fruit abundance, forcing them to eat more leaves during my observation period. However, Fan et al. (2009) documented high leaf consumption in Chinese populations of Nomascus concolor, suggesting that my observations were not anomalous for crested gibbons. Moreover, conversations with local villagers indicated that the weather during the period of my study was not unusual. Given this, and the fact that gibbons are not hunted by local people, my data might possibly represent some of the most accurately collected data on free-ranging gibbons during what should probably be considered a typical year of fruit abundance and rainfall. 
It appears that figs are less important to white-cheeked crested gibbons compared to other gibbon species (Table 7; see MacKinnon and MacKinnon, 1980). Figs never accounted for more than $6 \%$ of the items eaten in any month and in 8 out of 12 months comprised $<3 \%$ of the diet, which is trivial compared to, for instance, the $45 \%$ that is typical of Hylobates lar (Table 7). No significant relationships were found between fig feeding and fruit availability or rainfall. Fig consumption by black crested gibbons also diverged from typical gibbon patterns in that figs, although eaten more than in my study, contributed less to diet than other gibbons in most months (Fan and Jiang, 2008; Fan et al., 2009; Table 7). Thus, decreased reliance on figs may be a unique characteristic of crested gibbons because of a lack of availability or preference for and abundance of other foods. Future research should compare Ficus density and seasonal phenology between habitats of crested gibbons and other gibbons as one explanation for the apparent difference in importance of figs for the Nam Kading NPA and other populations.

Phenology will fluctuate inevitably with variability in rainfall because of its influence on moisture availability, cloud cover, and solar radiation (van Schaik et al. 1993; Wright and van Schaik, 1994). However, without long-term data it will not be possible to determine the proximal stimuli of flowering or fruiting patterns. As suggested by my data, it is likely that subtle changes in phenology may have triggered extensive changes throughout the animal community. Rainfall seasonality in Khao Yai National Park, Thailand is associated with highly seasonal availability of fruits for gibbons much like in the present study (Brockelman, 2011). In addition considerable year-to-year variation exists in Khao Yai, which also strongly affects diet (Brockelman, 2011). I cannot evaluate year-to-year variation, but as more long-term studies are conducted, high 
inter-annual variation in fruiting is increasingly seen as the normal pattern in both the Old and New World tropics (Newstrom et al., 1994; reviewed in Brockelman, 2011). Thus, a major threat to gibbons, is that inter-annual variation is likely to cause more stress in years when fewer species fruit and when more species vary inter-annually. If we introduce into this scenario increased global warming and more variable weather patterns (START, 2011) we can predict increased threats to the survival of frugivores in seasonal environments at the margins of their ranges and in fragmented, stressed populations in anthropogenically influenced areas.

Evidence that low food availability causes stress that affects the behavior of primates is difficult to obtain, but has been found in some species (Goldizen et al., 1988; review in Hemingway and Bynum, 2005). Much like my study of white-cheeked crested gibbons, white-handed gibbons and siamangs have been found to alter their diet when there is low fruit abundance in non-seasonal rainforests (Raemaekers, 1979; 1980) as well as seasonal forests (Bartlett, 1999; 2003; 2009). Fan and Jiang (2008) found the same for Nomascus concolor in highly seasonal forests. A shift in diet that occurs along with lower fruit availability may reflect awareness that increased travel will not be rewarded and a decision is made to utilize lower quality foods. This noteworthy capacity to eat and digest a diverse range of foods gives gibbons a wide breadth of food species to choose from, and may increase survival prospects in periods when preferred foods are limited or unavailable, and allow them to occupy marginal areas. In other species, it is unclear whether food quality or changes in location of food sources is responsible for seasonal changes in diet (Terborgh, 1983; Hemingway and Bynum, 2005). 
The gibbons that I studied consumed a mixed diet of fruit and leaves so neither food is likely to be completely substitutable or expendable. Interestingly, in times of high fruit abundance, only a small amount of the fruit on the trees was harvested by the gibbons. Historically there was likely competition with other species such as macaques (genus Macaca), great hornbills (Buceros bicornis) and squirrels (Ratufa spp., Callosciurus spp., and Hylopetes spp.) for available fruit. Langurs (Trachypithecus spp. and Pygathrix spp.) are unlikely competitors with gibbons for food because they are highly folivorous and anatomically specialized for consuming mature leaves (Kool, 1992; Zhou et al., 2006). However, because of pervasive hunting in the area of all species except gibbons it is difficult to know what interactions may have taken place between competitors for food. However, approximations can be made about what it would be like if the gibbons in Nam Kading NPA lived in a full community based on information from other field sites. Interactions of gibbons (Hylobates lar) with macaques were reported during $13 \%$ of gibbon observations in Khao Yai, NP in Thailand where macaques foraged near gibbons or from shared fruit sources. However, when gibbons make their presence known, macaques do not typically enter fruit trees occupied by gibbons (Whitington, 1992). Other studies have indicated that gibbons may reduce competition with macaques by preferentially traveling in the upper canopy (Cannon and Leighton, 2005). Gibbons can travel more efficiently across canopy gaps than macaques because of their specialized anatomy and locomotion (Cannon and Leighton, 2005). These reports suggest that exploitative and interference competition exists between gibbons and other species (Whitington, 2005). It appears that the gibbons in Nam Kading NPA have been 
released from competition due to hunting. However, competitors in the recent past likely influenced their behavior and ecology.

In summary, Nomascus leucogenys is a folivore that specializes on young leaves, but will consume fruit in large quantities when it is available. Fruit availability and rainfall have strong and independent influences on diet, but the availability of fruit is the major determinant of gibbon diet across the year. Moreover, my research has shown that Nomasucs leucogenys consumes more leaves than any other gibbon species studied to date. Why this is so is unclear, but the leading hypothesis is that it is a consequence of resource availability in a highly seasonal habitat. Considering resource abundance and rainfall alone does not provide a full explanation of dietary habits of white-cheeked crested gibbons, but it clearly remains a crucial element in determining diet in particular seasons. 
Chapter 3: Seasonal Variation in Activity Budget of Nomascus leucogenys: Relationships of activity budget with rainfall, diet, and ranging over the annual cycle

\begin{abstract}
Activity budget is an important aspect of a species' ecology because it is directly related to home range use, energy investment, and diet, but it has never been studied in gibbons (Nomascus spp.) of the rainy, mountainous, forests of Laos. I studied seasonal variation in the activity budget of 3 groups of white-cheeked crested gibbons ( $N$. leucogenys) in Nam Kading National Protected Area, Bolikhamxay Province, Laos. Annually, the three groups spent nearly equal amounts of time resting (30\%), feeding (33\%), and traveling (35\%), but only a small amount of time singing (2\%). However, the proportion of time allocated to different activities showed significant seasonal variations and was associated with variation in rainfall and diet, and correlated with home range use. Gibbons increased traveling time and decreased feeding time when they ate more fruit, and they decreased traveling time and increased feeding time when they ate more leaves. When the gibbons spent more of their time traveling, they also had longer day range lengths, and used a higher percentage of their total home range. Moreover, when rainfall was high, the gibbons decreased traveling time and increased time resting and feeding. In summary, white-cheeked crested gibbons employed a high-effort foraging strategy when they ate more fruit and appeared to conserve energy when they ate more leaves and experienced high rainfall. Activity patterns thus appear to reflect the ability to exploit rich food resources during periods of food abundance, but minimize energy loss during stressful periods.
\end{abstract}




\subsection{Introduction}

The proportion of time spent in different activities at different times of the year likely reflects important aspect of a species' ecology because it is an indicator of interactions with the environment and energy investment in essential activities (Defler, 1995). Climate and available resources constrain activity budgets because maintaining energy balance is contingent upon food availability and the ability to exploit those resources. A central concept in life-history theory is that individuals must allocate their energy to competing life-history traits such as investment in growth and body maintenance, territory maintenance, reproduction, and predator avoidance (Stearns, 1992; Roff, 1992). Variations in diet, somatic growth, reproduction, and home range or territory size between species reflect different allocations of time, effort, and energy to competing life attributes.

Activity budgets vary seasonally in response to changes in the abundance, quality, or distribution of important food resources (Robinson, 1986; Altmann and Muruthi, 1988; Stanford, 1991; Isbell and Young, 1993; Doran, 1997; Passamani, 1998; Estrada et al., 1999; DiFiore and Rodman, 2001; Hanya, 2004; Vasey, 2005). Animals may adjust time spent feeding on a seasonal basis, subject to food availability, so that they maintain an optimal or tolerable energy balance to preserve biological homeostasis (Coelho, 1986). Demographic factors, such as age, sex, social rank, and reproductive condition, and environmental factors (e.g., predation pressure or the degree of human disturbance), also interact to influence primate activity budgets and behavioral trade-offs among individuals engaged (Whitten, 1983; Muruthi et al., 1991; Matsumoto-Oda and Oda, 1998; Li and Rogers, 2004; Vasey, 2005). 
The distribution of activities throughout the day and proportion of time spent in different activities in most animals is usually related predictably to body size and diet. For example, the largest of the gibbons, siamangs (Symphalangus syndactylus) are at least twice the size of most other gibbon species and they can digest leaves as a result of longer passage time down their longer digestive tract. As a result, siamangs have smaller home-ranges, have shorter day ranges, spend less time searching for food and spend more time eating than other gibbons (Gittins and Raemaekers, 1980; Palombit, 1997). By contrast, the frugivorous diets of other gibbon species requires them to invest more time traveling to scattered sites of fruit abundance (Bartlett, 1999). Finding leaves requires less traveling, but to obtain the same energy from this diet, siamangs must eat more, and spend more time feeding and digesting than other gibbons.

Similar activity patterns of anatomically specialized folivores (subfamily Colobinae) and less specialized folivores (howler monkeys (Alouatta palliata), woolly spider monkeys (Brachyteles arachnoides), sifakas (Propithecus diadema) and indris (Indri indri) indicate common solutions to problems associated with leaf eating by primates. In general, these primates have constrained energy budgets. Folivores spend a large proportion of the day resting presumably to allow time to digest fibrous leaves. All colobines (subfamily Colobinae) exhibit this typical pattern of a large proportion of time spent resting (Davies and Oates, 1994). Howler monkeys are particularly lethargic animals that may spend up to $80 \%$ of their diurnal hours resting (Milton, 1980). The physiological mechanisms that underlie these behaviors were described by Smith and Jungers (1977). Inactivity allows blood to be shunted to the digestive tract to facilitate nutrient extraction. In a study by Powzyk (1997), the folivorous indri (Indri indri) spent 
the majority of its daylight hours resting. However, the sympatric and also folivorous sifaka (Propithecus diadema) spent significantly more time traveling and socializing. The sifaka exhibited a greater number of feeding bouts and fed on more plant species than Indri. It is therefore not surprising that the species spends more time traveling, while searching for diverse food resources (Powzyk, 1997).

Primates with primarily frugivorous diets are expected to exhibit greater seasonal variation in movement patterns than folivores because frugivores are likely to be forced to travel more and spend more time searching more widely for food in seasons of low food availability. This pattern is found in gibbons (Raemaekers, 1980; Palombit, 1997) and other primates (Strier, 1987; Huang et al., 2003). Primates that spend more time feeding and traveling during seasonal food scarcity are thought to follow this strategy in order to attain equivalent nutrition from poorer quality or more widely dispersed foods (Raemaekers, 1980; Dunbar, 1988). However, the relationship between activity budgets and seasonal food availability may not be as straightforward as it seems because many primate folivores are known to follow a pattern of conserving energy by resting more during times of food scarcity (Richard, 1978; DiFiore and Rodman, 2001). Travelling raises metabolic rate and thus requires more energy than other activities. Therefore, if food is scarce, resting, which does not raise metabolic rate, may be a better option. Larger species, with their lower-mass specific metabolic rates, should be better able to reduce activity during such periods because of lower mass-specific energy requirements of large compared to small animals (Peters, 1983). .

White-cheeked crested gibbons (Nomascus leucogenys) are critically endangered and in decline. Their behavior has never been studied in the wild, and here I provide 
detailed information on the activity budget of a free-living Lao population. I first characterize the general activity budget and show how activity changes on a monthly basis. I then explore how diet, rainfall, and ranging behavior influence monthly activity budgets. Based on knowledge of this species and past studies of similar species, I predicted that (1) N. lecuogenys is more folivorous than other gibbons (Ruppell, Chapter 2), (2) variations in proportions of leaf and fruit consumption (Ruppell, Chapter 2) influence the proportion of time spent in different activities such as resting, feeding, or traveling, and (3) variations in rainfall throughout the year also influences the proportion of time spent in different activities.

\subsection{Methods}

\section{2.a. Study Area}

I conducted this study in the Nam Kading National Protected Area (NPA) in Bolikhamxay Province of Laos (1840’51 N and $\left.104^{\circ} 08^{\prime} 11 \mathrm{E}\right)$ in a wet, seasonal, evergreen forest (Fig. 1). The study area has a rugged, hilly to mountainous terrain, with elevations ranging from 400-1200 meters. The nearest village is only $2.5 \mathrm{~km}$ from the edge of the study site. However, steep slopes, cliffs, dense shrubs and bamboo, and seasonal flooding of trails, limit use of the area by people and domestic animals, and both were seldom seen. Although the presence of langurs (Trachypithecus spp.) and macaques (Macaca spp.) was reported by villagers in the past, neither was seen during my study. It is likely that all diurnal primate species, aside from gibbons, have been eliminated from the area due to hunting. 


\section{2.b. Climate}

The climate in Nam Kading NPA is hot, humid, and monsoonal. Although mean monthly rainfall was $272 \mathrm{~mm}$ from June 2011- May 2012, it ranged from 0 to 50 $\mathrm{mm} / \mathrm{month}$ during dry months (October to April) to between 200 to $918 \mathrm{~mm} / \mathrm{month}$ in rainy months (May to September). Rainfall less than $100 \mathrm{~mm}$ in a month corresponds to a"dry" month (Brockleman, 2011), and therefore, from this point forward I refer to October to April as the dry season and May to September as the rainy season (Fig. 6). Fruit availability was highest in the dry season (Fig. 7) while the rainy season was foliage rich and fruit poor (Fig. 7). The dry season became cool from October to February, with the lowest temperatures in December. In addition, there was almost no rain from November to January. Daily temperature averaged $26^{\circ}$ Celsius, but was highly seasonal varying from $20^{\circ}$ to $30^{\circ} \mathrm{C}$ across months. Temperature varied throughout the day with cool mornings (average $22^{\circ} \mathrm{C}$ ) and hot afternoons (average $29^{\circ} \mathrm{C}$ ).

\section{2.c. Study species and Groups}

I made a preliminary trip to the field site in 2009 and during that time, I located several groups whose ranges were in proximity to one another. Because hunting of gibbons has historically been taboo in the nearby village and because the habitat has been preserved, it is possible that the area represents the density and behaviors of gibbons not exposed to hunting pressure and deforestation. The gibbons in the area were somewhat habituated to the presence of humans because villagers live nearby and often walk in the forest, but do not hunt them. Historically, predation by tigers (Panthera tigris), clouded leopards (Neofelis nebulosa), and raptors (Falco spp.) likely influenced the behavior of 
gibbons. However, hunting has eliminated these predators from the area and therefore predators are no longer likely to be a heavy influence on gibbon behavior.

The northern white-cheeked crested gibbon ranges from north Vietnam and northern Laos to central Vietnam and central Laos and from the eastern border of Vietnam to the western boarder of Laos (Geissmann et al., 2000). Northern whitecheeked crested gibbons are a territorial species that actively defend home ranges against encroachment by other groups (Burt, 1943). Body mass (between 7.3-7.4 kg), (Smith and Jungers, 1997), morphology, and dense pelage are essentially identical across the sexes. On the other hand, adult females have a yellow coat and adult males have a black coat with white cheeks. I collected data on three groups, each with one adult male, one adult female, and between one and three juveniles. The home ranges of the three groups were adjacent and contiguous with one another.

\section{2.d. Data Collection}

I followed each study group for 4-8 days per month for 12 months. Each day I attempted to locate the group by visiting the sleeping site of the previous day, listening for the loud morning songs, and by searching where I heard the songs. Once I located the group, I attempted to follow group members until they entered a sleeping site. Field assistants helped locate and follow gibbon groups, and pointed out positions, activities, and food consumption by gibbons at 5 minute intervals. On several days the gibbons often passed over high cliffs or deep valleys which made it difficult to maintain contact. Data collection was terminated during such days, but I was nonetheless able to collect 12 full days of observations total (4 days per group) each month for the groups in this analysis. Standardized observations were made over the entire period that groups were 
visible and ended when they reached their sleeping tree. During group follows, location was entered into a GPS (Garmin 60CSx) and time budget data were collected at intervals of five minutes. I recorded group activity as resting, traveling, feeding, or singing.

Resting included any inactive posture (sitting, lying, or hanging). Grooming, playing, and copulations always occurred during bouts of rest and were recorded with all occurrence sampling. Traveling comprised movement between locations (brachiating, climbing, and jumping). This activity primarily involved brachiating as a group to new trees. Singing included production of the duet with mate or solo song. Feeding involved manipulating, picking, chewing, or swallowing food. Whenever animals were observed feeding, the food type was noted. Foods were categorized as: fruit, young leaves, mature leaves, and other, which included flowers, vine shoots, and insects.

To determine the activity pattern, data for each 5 minute interval were pooled monthly by social group. Because individuals within a group are almost always together, gibbons within a social unit were typically all engaged in the same activity at a given time. The only exception was for brief bouts of grooming or play that were recorded with all occurrence sampling. For each group the percentage of time devoted to each behavior, such as feeding, resting, or travel is the number of 5-minute time point samples for which that behavior was recorded divided by the total number of samples for the group in a given month.

The GPS readings had an error range between 5 and 20 meters. The outer limits of ranging during the study (cumulative day range limits) were plotted manually for the groups to determine total home range size. Using Google Earth Pro the distance traveled by the group each day (day range length), was calculated by measuring the sum of the 
distance $(\mathrm{m})$ between each travel starting point and ending point. The total range area each month was calculated using Google Earth Pro by creating minimum convex polygons around the gibbon group's recorded locations. The percentage of the total home range used each month was calculated by dividing the area used by the total home range area.

Temperature and rainfall were recorded daily using a Taylor Dual-Scale Maximum Minimum Thermometer and an All Weather Rain Gauge in an opening in the forest.

\section{2.e. Statistical Methods}

I conducted one-way analyses of variance (ANOVA) to evaluate the relationship between the three groups and the average percentage of time spent in each activity. I conducted repeated measures ANOVA to evaluate the relationship between the three groups and the percentage of time spent in different activities across months. I used Pearson-product-moment correlations to compare seasonal changes in rainfall and diet with the different aspects of time budget, such as proportion of time spent traveling, resting, or feeding. I used general linear models (GLM) will full and reduced models to simultaneously evaluate the possible influences of group, rainfall, fruit availability, young leaf availability, fruit in diet, and young leaves in diet, on activity budget concurrently. I report statistics as means $\pm \mathrm{SE}$, and used a $P$ of 0.10 to establish significance. A limited sample size resulting from a single year of data collection reduced my power to test hypotheses, and therefore, in the desire to minimize the probability of committing a type II error, I opted for a critical $P$ value of 0.10 . 


\subsection{Results}

\section{3.a. General Activity Patterns}

Daily activities of gibbons all occurred between 0600 and 1600 hours, but often ended at 1500 when they arrived at their sleeping tree. Morning songs typically began at dawn (between 0600 and 0700 hours). The groups' daily activity budgets were very similar (Fig. 13) and the percentage of time spent in different activities averaged over the year for the three groups did not differ among groups $(F=<0.01$, $\mathrm{df}=2,9 P>0.99$ for all comparisons). I used repeated measures ANOVA to evaluate the relationship among the three groups and the percentage of time spent in different activities across months, which also indicated that the groups were similar (feeding $F=0.005$, df $=2,33 P=0.9$; traveling $F=0.004, \mathrm{df}=2,33 P=0.95 ;$ resting $F=0.008, \mathrm{df}=2,33 P=0.89 ;$ singing $F$ $=0.009, \mathrm{df}=2,33 P=0.87)$. In addition, GLM analyses found no group effect on activity budget supporting the result of lack of differences between the three groups (Table 8). The gibbons spent much of the early morning and mid-day feeding, and much of the morning and afternoon resting. By contrast, traveling occurred mainly from midmorning to early afternoon (Fig. 14).

Averaged over the annual cycle, nearly equal amounts of time were spent traveling (35.1\%), resting (29.9\%), and feeding (32.9\%), followed distantly by singing (2.1\%). However, the amount of time spent in each activity varied throughout the year according to season (Fig. 15). Feeding time showed less variation over the annual cycle than did either travel or resting time (Fig. 15) and was lowest in the dry season $(25.5 \%)$ and highest in the foliage rich rainy season $(38 \%)$. The pattern was reversed in the case of travel, with travel time lowest in the fruit poor, foliage rich rainy season, especially 
August (21\%), and more than twice that in the fruit rich dry season, up to $45 \%$ of activity time. Resting was lowest in the dry season (21\%) and almost twice that in the rainy season $(40 \%)$. The most singing occurred in the transitional period between the dry and rainy season in May and June (4-4.5\%) and decreased to around 1\% of total activity time (around 10 minutes per day) in October-November and January- March.

\section{3.b. Diet, Rainfall, and Activity Budgets}

Mature leaves comprised a nearly constant proportion (9-10\%) of the gibbon's diet over the course of the day (Fig. 16). On the other hand, gibbons spent much of the early morning feeding on fruits when available, while the afternoon was most often spent feeding on young leaves (Fig. 16). Across months, there was a significant positive correlation between fruit eating and percent of time spent travelling and significant negative correlations between fruit eating and resting and feeding (Table 9). There was also a significant correlation between leaf eating and time spent feeding and a significant negative correlation between leaf eating and time spent traveling. The consumption of other dietary items was significantly negatively correlated with traveling and positively correlated with feeding. It appears that when the gibbons ate more fruit they also spent more time traveling (Fig. 17), and less time feeding and resting. When the gibbons ate more leaves (both young and mature) they spent more time resting and feeding, and less time traveling (Fig. 18). When the gibbons ate other dietary items, they spent more time feeding and less time traveling (Fig. 19).

GLM analyses indicated that rainfall was the only variable to be associated with resting and traveling when accounting for all other variables in the full model, while feeding was only affected by fruit availability in both the full and reduced models (Table 
8). In the reduced model fruit in diet, as well as rainfall, were associated with variation in time spent resting. In follow up tests, significant correlations were found between rainfall and traveling $(r=-0.93)$ and rainfall and resting $(r=0.91)$ indicating that gibbons spent more time resting and less time traveling during periods of heavy rain (Fig. 20).

\section{3.c. Ranging and Activity Budgets}

Many aspects of ranging and activity budget were understandably and unavoidably correlated (Table 10). There were significant positive correlations between travelling and day range length and percent of home range used. There were also significant negative correlations between time spent resting and day range length and percent of home range used, and time spent feeding and day range length and percent of home range used. Thus, when the gibbons travelled more they also traveled a greater distance and used a larger portion of their range (Fig. 21), and when they fed and rested more they had shorter day range lengths and used less of their home range (Fig. 22).

\subsection{Discussion}

\section{4.a. Activity Rhythm and Activity Budget}

The activity budget of white-cheeked crested gibbons varied diurnally, was highly seasonal and was strongly related to diet, rainfall, and home range use. Throughout their active period there were temporal modifications in activity demonstrating a distinct activity rhythm. Fruit was eaten commonly during the early morning hours before animals began to move at my study site (Fig. 16) and elsewhere (Chivers, 1974; Powzyk, 1997). The timing of fruit eating may allow gibbons to undertake energetically expensive activities in the morning and mid-day because fruit is a rich source of energy that is 
readily and rapidly absorbed (Raemaekers, 1978; Vasey, 2004). By contrast, leaf eating usually preceded resting or sleeping when an animal's system can be fully devoted to lengthy fermentation (Figs. 14 and 16). Leaf consumption in the late afternoon allows time for digestion of proteins and fiber overnight (Milton, 1979; Glander, 1982).

Overall, gibbons in this study spent more time traveling than other gibbons (Table 11). The corresponding time spent resting (30\%) is atypical for primate folivores where rest normally accounts for $>50 \%$ of the activity budget (Milton, 1980; Davies and Oates, 1994; Powzyk, 1997). Sifakas (Propithecus diadema) spend a larger proportion of their time traveling compared to indris (Powzyk, 1997). However, sifakas still rest much more (43\% of activity budget), and travel less (6.8\% of activity budget) (Powzyk, 1997) than white-cheeked crested gibbons. Several possible explanations exist for the low proportion of time spent resting and high proportion of time spent traveling by white-cheeked crested gibbons and these are discussed below.

Frugivory by the Nam Kading NPA gibbons was high when the proportion of time spent traveling was high (up to $45 \%$ of the activity budget in the fruit rich dry season). The percent of time spent traveling was below $26 \%$ of the activity budget in the fruit poor, foliage rich rainy season in this study, and as low as $21 \%$ in August. Therefore, the high proportion of time spent travelling occurred when the gibbons consumed fruit, and at that time they did not need to spend large amounts of their time resting to digest leaves. Studies of primate activity budgets often use different methods and rely heavily on focal animals sampling, raising the possibility that the behavioral differences observed between genera (Table 11) may be inflated. For example, several studies recorded a fifth variable, other (see Table 11), for activity budget which could 
also elevate or decrease reported percentage of different activities. However, "other" never accounts for more than $5 \%$ of time and therefore has minimal influence. This being said, I doubt that differences in methods can account for large differences in behavior between resting and traveling in studies of Nomascus (Table 11).

Indeed, despite possible influences of methodical differences on reported behaviors, the large differences in activity budgets of crested gibbons in this study compared to those reported for other gibbons is noteworthy. Most prominent is time spent traveling compared to other species, which I argue is a real difference related to their unique locomotor adaptations. Crested gibbons brachiate and have longer forelimbs than other gibbons, which should enable them to move faster and more efficiently through the trees (Jungers, 1984). My personal observations of gibbons brachiating indicates to me that crested gibbons are the fastest, most agile, and have the best hand-eye coordination, although this has not been rigorously tested. Their ability for fast, efficient travel likely plays a role in their ranging behavior. For example, they could spend more time travelling than other species of gibbons because they use less total energy in the process. If motivated, they can traverse their home range in one hour, and thus may have a better ability to monitor the distribution of fruiting trees and potentially defend large territories from intruders.

\section{4.b. Effects of Diet on Monthly Variation in Activity Budget}

The search for and acquisition of food is one of the most important determinants of activity budgets (Hanya, 2004; Kurup and Kumar, 1993; Menon and Poirier, 1996; O'Brien and Kinniard, 1997). My results indicate significant monthly variation in the activity budgets of the study groups, and document that monthly changes in diet drive 
activity patterns. The high energy density of fruit make it a valuable food, but the proportion of fruit in the diet varied widely from $14 \%$ in the fruit poor, foliage rich rainy season to $47 \%$ in the fruit rich dry season. Compared to leaves, fruits contain a lower content of indigestible fiber and high content of free sugars, which individuals can absorb directly and convert to energy (Raemaekers, 1978). Also, the proportion of digestible matter per unit volume of fruits is generally higher than leaves (Raemaekers, 1978). When the gibbons ate nutritionally high quality fruit, they decreased their feeding time, but increased traveling time in search of it because it is distributed more sparsely than other foods. The pattern of increasing travel time and decreasing feeding time when eating more fruits has been reported for other species of gibbons, Nomascus concolor (Fan et al., 2008) and Hylobates lar (Bartlett, 2009), and Japanese macaques (Agetsuma and Nakagawa, 1998; Hanya, 2004).

The time period with the lowest percentage of traveling in the activity budget was also when the most leaves were consumed, during the rainy season (May-September). Leaves contain fewer available calories and more indigestible fiber than fruits (Raemaekers, 1978), and when the gibbons ate mostly leaves, they traveled less and rested more. Fibrous food requires more time to digest, but the increase in resting time may have also helped to conserve energy at a time when foods of low energy density were being consumed (Raemaekers, 1978). That, and the abundance and even distribution of leaves in the forest make it possible and profitable to travel little when eating leaves. On the other hand, more time had to be spent feeding when eating leaves to keep their energy intake at an adequate level (Nakagawa, 1989). 
"Other" food types contributed <3\% to gibbon diets in any given month, but when these were consumed, the gibbons also spent more time feeding and less time traveling. Leaves and "other" thus exhibited the same pattern of being associated with little travel and more time spent feeding. The intrinsic value of the other food items is unknown, but perhaps they provide supplements of micronutrients or de-toxicants when the gibbon diet was mostly energy-poor leaves. This is supported by the fact that the months with $0 \%$ of the diet being "other" were also the months of highest fruit availability (March-May) (Fig. 7).

Song was the only aspect of the gibbons' activity budget that was unrelated to diet. Singing varied throughout the year but accounted for only $1 \%$ to $4.5 \%$ of activity time, and appeared to be independent of all the measured factors, yet appeared to be directly related to the amount of singing by other groups. When nearby gibbon groups were heard, the gibbons sang more (Ruppell, pers. obs.). On days, when no other groups could be heard due to distance, wind, or other sounds like cicadas, the gibbons seemed to spend less time singing. Singing was most intense in May when there was high fruit availability (Fig. 7) suggesting that singing was possibly associated with maintenance and defense of territories when fruit availability was high. Nonetheless, singing was not statistically associated with fruit availability.

\section{4.c. Effects of Rainfall on Monthly Variation}

Rainfall also affected monthly variation in the activity budget of the gibbons such that feeding and resting time increased, but travel decreased, during high rainfall. The decline in travel was perhaps an adaptive response to reduce energy consumption and risk of injury. Folivorous indris and sifakas also reduce their activity during rainfall (Powzyk, 
1997). Traveling is energetically demanding (Coehlo et al., 1976) and could be risky during times of high rainfall because branches are very slippery. Even though gibbons are highly dexterous and agile, it is possible they could slip when branches are very wet and be seriously injured or die in a fall. Travel during periods of rain would also wet pelages and increase heat loss and therefore sheltering under heavy tree canopies may reduce unnecessary heat loss. Rainfall is also strongly negatively correlated with fruit availability (Fig. 7). Thus, using energy to travel more in periods of heavy rain would have no dietary benefit.

\section{4.d. Activity Budget and Ranging}

Gibbon ranging behavior exhibited seasonal variation that was associated with the activity budget. The ability of gibbon species to change their diet throughout the year appears to strongly influence home-range use (MacKinnon and MacKinnon, 1977). Fruit consumption entailed more travel, greater home range use, and longer day range lengths. Conversely, when they were eating more leaves, the gibbons traveled less, used less of their home range and had shorter day range lengths. These findings are consistent with the idea that the gibbons are most likely following an energy conservation strategy. The gibbons have knowledge of the food resources in their home range, including the spatiotemporal pattern of fruiting, which allows them to efficiently range over increasingly large areas when fruit is available. Gibbon ranging behavior may be constrained during periods when resource abundance is low (Bartlett, 2009).

In summary, the activity budget of white-cheeked crested gibbons reflects adaptations related to seasonal shifts in diet and rainfall. They employed high-effort activities when they ate more fruit because eating fruit necessitated that they spend more 
time traveling to known fruiting trees, which resulted in greater use of their total range, and longer distances traveled per day. Conversely, they employed a pattern of energyconservation when they ate more leaves and in high rainfall periods because they spent more time resting and feeding, used less of their total range, and traveled shorter distances per day. 
Chapter 4: Ranging behavior of Nomascus leucogenys

\begin{abstract}
The endangered white-cheeked crested gibbon (Nomascus leucogenys), native to Laos, Vietnam, and likely extirpated in China, remains little known and highly threatened. The home range size of three groups of white-cheeked crested gibbons was measured in the Nam Kading National Protected Area, Bolikhamxay Province, Laos. Average home range size was 37.9 hectares and daily average distance over which they ranged over the 12 month study was $1.48 \mathrm{~km}$. Differences existed among the three groups, possibly related to differences in topography of the sites used by the three groups. Overall, white-cheeked crested gibbons have a home range similar in size or larger than frugivorous gibbons and larger than the folivorous siamang. Ranging was highly seasonal with shorter day ranges during times of low fruit availability and consumption. During times of high fruit availability and low rainfall, the gibbons took on an energy maximizing strategy where they maintained large home ranges, traveled longer distances and consumed larger quantities of fruit.
\end{abstract}




\subsection{Introduction}

Most primates maintain reasonably stable home ranges and patterns of intergroup spacing throughout the year (Carpenter, 1958; Boinski, 1997; Cowlishaw and Dunbar, 2000; Chivers, 2001). By contrast, other taxa, such as ungulates or birds, often pass through multifarious seasonal changes in both home range and intergroup relations. However, ranging patterns also depend on geographic location. Most primates live in tropical areas, and tropical breeding birds likewise show stable territories and home ranges (Greenburg and Gradwohl, 1986). At its most basic level, the size of an animal's home range is determined by its energy needs and the distribution and density of resources. Territory refers to a socio-geographical area that an animal of a particular species defends against conspecifics, and occasionally animals of other species (Mitani and Rodman, 1979). Animals that defend territories in this way are referred to as territorial (Carpenter, 1958). Ecological optimization theory predicts that territorial behavior will evolve only when resources are limited and defendable (Carpenter, 1958; Mitani and Rodman, 1979), and when the benefits of defending resources exceed the costs of territorial defense.

On a larger scale, interspecific variation in home range size is best explained as directly reflecting metabolic needs determined by body size and diet (Harvey and Clutton-Brock, 1981). Home range area increases with body size in small mammals (McNab, 1963), lizards (Turner et al., 1969), birds (Schoener, 1968), and primates (Milton and May, 1976). A longstanding view is that home range size varies directly with body size, because basal metabolic rate increases with body weight (Milton and May, 1976). However, basal metabolic rate is not always a realistic estimate of metabolic needs 
because it fails to take into account energy consuming behaviors, such as territory defense, mating, and abundance of food resources, which vary greatly among species (Clutton-Brock, 1977). We now know, for instance, that the determinants of ranging patterns (and therefore home range) in primates are multifaceted and include a complex association of diet, seasonality, locomotion, and group size (Boinski, 1997; Doran, 1997; McConkey et al., 2003; Hemingway and Bynum, 2005; Fan and Jiang, 2008).

Diet has a significant influence on home range size regardless of taxonomic affinity. Carnivores have particularly large home-ranges because prey is often thinly distributed (Gittleman and Harvey, 1982; McNab, 2002); plants are generally more densely distributed and thus primary consumers range over smaller areas. Nonetheless, primary consumers (herbivores) have home ranges that vary with respect to the dominant food type; fruit eating species (frugivores) generally having the largest home ranges (Robinson and Redford, 1986), while folivorous animals (leaf eaters) inhabit smaller home range areas for their body weight than do frugivores and omnivores (Milton and May, 1976; McNab, 2002).

The smaller size-specific home ranges of folivores compared to frugivores reflects the more uniform distribution of foliage compared to fruits (Oates, 1986). Folivores are inclined to have shorter day ranges for the same reason. For example, siamangs (Symphalangus), weighing around $11 \mathrm{~kg}$ (Table 1), spends over $50 \%$ of its feeding time on foliage and has a home range below 23 ha (Palombit, 1997). By contrast, home ranges of the lighter (5.5 kg) frugivorous white-handed gibbon (Hylobates lar) can exceed 44 ha (McConkey et al., 2003). 
Body size differences also appear to place restrictions on diet because of the interaction between basal metabolic needs and energy density of different food types. The body size of Nomascus falls between that of the larger Symphalangus $(11 \mathrm{~kg})$ and the smaller Hylobates genus (5.5 kg) (Table 1). Allometric relationships between primate body size and ecology suggest that without highly specialized digestive anatomy, only larger species can be folivorous, with enables then to occupy a smaller home range and move less (Peters, 1983; McNab, 2002). Fruits are a higher-quality food item because they contain large quantities of sugar, but tend to be patchily distributed. Primarily fruiteating species require larger ranges and therefore, increased metabolic requirements. Larger animals, which are more likely to eat leaves, will need to travel less to obtain enough food because leaves are typically an abundant food source in tropical forests. Smaller animals, which require higher energy foods (fruit) which are more widely dispersed, must travel more to feed. Thus body size is greatly intertwined with diet and daily movement patterns.

All extant gibbon species appear to be characterized by small territorial groups, long term monogamous pairing, and loud songs which in most species are structured duets (Chivers, 2001; Groves, 2005). Strong defense of territories by small cohesive groups is likely an adaptation to exploit and defend preferred food trees that fruit asynchronously over a wide area (Chivers, 2001). Gibbon territories are thought to be routinely maintained through loud morning song bouts which are highly structured duets in crested gibbons (Geissmann 1984; 2002; 2003).

Chivers (1974) was the first to compare ecological strategies in different gibbon species and genera. He was particularly interested in whether generic level distinctions 
were defensible on behavioral as well as morphological grounds. He found that the frugivorous Hylobates has a much larger home range than the folivorous Symphalangus. The ecological differences between these two gibbon genera suggest that there could be major differences among other genera as well. Chivers' predictions about differing adaptations between genera reveal the need for cross-genera comparisons of behavior and ecology. Siamangs, on average, live in smaller territories (9-23 ha) than white-handed gibbons (23-44 ha) (Bartlett, 2009; Chivers, 1974; Gittins and Raemaekers, 1980; McConkey et al., 2003). Siamangs also have shorter day ranges (800 m) than whitehanded gibbons (1300 m) (Chivers, 1974; Gittins and Raemaekers, 1980; MacKinnon and MacKinnon, 1980). Palombit's (1997) study of sympatric siamang and white-handed gibbons indicated that siamangs rely heavily on immature foliage while white-handed gibbons mainly exploit the pulpy fruit of trees. Gibbon dietary composition may, however, exhibit strong seasonal and local fluctuations (Palombit, 1997). Where siamangs and Hylobates lar gibbons occur in sympatry, siamangs can more easily include a higher proportion of low-energy leaves in their diet. Thus, siamangs may be more flexible because of their larger body size (Palombit, 1997).

Crested gibbons are found in Vietnam, Laos, Cambodia, and southern China including Hainan Island. Although crested gibbon taxonomy is disputed and requires further study (Konrad and Geissmann, 2006; Ruppell, 2009), up to six species of crested gibbons are currently recognized. Other than a few reports on vocalizations and distribution (Ruppell, 2007a; b; 2008; 2009), neither the northern (Nomascus leucogenys), or the southern (Nomascus siki) white-cheeked crested gibbons has been studied in the wild. During previous fieldwork I made home range estimates for $N$. 
leucogenys based on observations of gibbon groups, which indicated that their home ranges are up to 40 ha.

I spent a year in the field documenting ranging behavior of $N$. leucogenys with the goal to (1) determine home range size (2) estimate day range length, and (3) evaluate the relationships between ranging behavior and food availability, rainfall, and diet so that I could test the predictions that (a) rainfall and food availability affect ranging, and (b) crested gibbons have home ranges larger than expected for a folivore. Larger body sizes, reduced energy needs, and highly folivorous diets, are normally associated with smaller home ranges in primates.

\subsection{Methods}

\section{2.a. Study Area}

This study was conducted in the Nam Kading National Protected Area (NPA) in Bolikhamxay Province of Laos (1840’51 N and 10408'11 E) (Fig. 1). The nearest village is only $2.5 \mathrm{~km}$ from the edge of the study site, but, steep slopes, cliffs, nearly impenetrable shrub and bamboo thickets, and seasonal flooding of trails, limit use of the area by people and domestic animals. Both were rarely seen. Although the presence of langurs (Trachypithecus spp.) and macaques (Macaca spp.) was reported by villagers in the past, neither was seen during this study. Aside from gibbons, it is likely that hunting has eliminated all other diurnal primate and predator species from the area. The area has a rugged, hilly to mountainous terrain, with elevation ranging from 400-1200 meters. 


\section{2.b. Climate}

The climate in Nam Kading NPA is hot, humid, and monsoonal. Although mean monthly rainfall was $272 \mathrm{~mm}$ from June 2011- May 2012, it ranged from 0 to 50 $\mathrm{mm} / \mathrm{month}$ during dry months (October to April) to between 200 to $918 \mathrm{~mm} / \mathrm{month}$ in rainy months (May to September). Rainfall less than $100 \mathrm{~mm}$ in a month roughly indicates a "dry" month (Brockleman, 2011), and based on this, I refer to October to April as the dry season and May to September as the rainy season (Fig. 6). The dry season became cool from October to February, with the lowest temperatures in December. In addition, there was almost no rain from November to January. Fruit availability was highest in the dry season (Fig. 7) while the rainy season was foliage rich and fruit poor (Fig. 7). Daily temperature averaged $26^{\circ}$ Celsius, but was highly seasonal varying from $20^{\circ}$ to $30^{\circ} \mathrm{C}$ across months. Temperature varied throughout the day with cool mornings (average $22^{\circ} \mathrm{C}$ ) and hot afternoons (average $29^{\circ} \mathrm{C}$ ).

\section{2.c. Study species and Groups}

The northern white-cheeked crested gibbon ranges from northern Vietnam and northern Laos to central Vietnam and central Laos and from the eastern border of Vietnam to the western boarder of Laos (Geissmann et al., 2000). Males and females are of nearly equal weight (7.3-7.4 kg) (Smith and Jungers, 1997) and both have long limbs and dense pelage. Adult females have a yellow coat and adult males have a black coat

with white cheeks. White-cheeked crested gibbons are territorial and early statements by Delacour (1933) suggested that they will journey over only about one hundred acres (40 ha) if they have no reason to range further in search of resources or escape from hunting 
pressure. I collected data on three groups, each with an adult male, adult female, and 1-3 juveniles. The home ranges of the three groups were adjacent and contiguous.

The density of gibbons in the Nam Kading NPA is extremely high compared to sites that I visited in Vietnam (Ruppell 2007a; b; 2008), most likely because of village hunting taboos related to gibbons in the area. In addition, gibbon behavior at this site is in all probability little influenced by predators because large predators appear to have been locally extirpated by hunting pressures. Hence, gibbon behavior is most likely a consequence of resource distributions and intraspecific behavioral interactions.

\section{2.d. Data Collection}

I followed each study group for 4-8 days per month for 12 months. Field assistants aided me by pursuing gibbon groups when they were on the move, and pointing out positions, activities, and food consumption by gibbons at 5 minute intervals. Each day I attempted to locate the group by visiting the sleeping site of the previous day, listening for the loud morning songs, and by searching where I heard the songs. Once I located the group, I attempted to follow members until they entered a sleeping site, generally around 1500. On some days it was not possible to follow the group for the entire day because they passed over high cliffs or into deep valleys. I was able to collect 12 full days of observations total ( 8 hours per day, 4 days per group, 144 days total) each month and these form the basis for this analysis. Observations began after the gibbons woke and finished when they reached their sleeping tree. During group follows, location was entered into a GPS (Garmin 60CSx) and activity budget data were collected at intervals of five minutes. I positioned myself under the gibbon group when I took the GPS reading. The error reading range was between 5 and 20 meters. 
Using Google Earth Pro the distance traveled by the group each day (day range length), was calculated by measuring the sum of the distance (m) between each travel starting point and ending point. The range area each month was calculated using Google Earth Pro by creating minimum convex polygons around the gibbon group's recorded locations. The outer limits of ranging during the study (cumulative day range limits) were mapped for the groups to determine total home range size. The percentage of the total home range used each month was calculated by dividing the area used each month by the area used over the entire annual cycle.

\section{2.e. Statistical Methods}

Home range size for groups $\mathrm{A}, \mathrm{B}$, and $\mathrm{C}$ was calculated from the cumulative day range map of each group with Google Earth Pro software. Most studies of ranging in primates have used minimum convex polygon methods. Thus to facilitate comparisons with other studies, I likewise estimated home range using minimum convex polygons. I used one-way ANOVA and repeated measures ANOVA to compare the day range length (i.e., distance moved over the course of one day), and monthly home range area to seasonal changes in rainfall, fruit availability, and diet. Partial correlations were used to evaluate the individual effects of food availability and rainfall on ranging. I conducted general linear models (GLM) to refine differences between groups and incorporate all of the possible influencing factors at the same time. I used a P of 0.10 to establish significance because a limited sample size resulting from a single year of data collection reduced power to test hypotheses. 


\subsection{Results}

\section{3.a. Range}

Repeated measures analysis of variance showed that average day range lengths across months differed among the three groups (Fig. 23: $F=6.8055, \mathrm{df}=2,33, P<0.05$ ). In addition, GLM analyses indicated that there was a significant group effect (Table 12). However, compared across months, there were strong correlations in average day range lengths between groups $\mathrm{A}$ and $\mathrm{C}(r=0.60, P<0.05), \mathrm{A}$ and $\mathrm{B}(r=0.75, P<0.05)$, and $\mathrm{B}$ and $\mathrm{C}(r=0.64, P<0.05)$. On average, groups moved $1.48 \mathrm{~km}$ over the course of the day, but this varied from a low of $1.09 \mathrm{~km}$ in the foliage rich, fruit poor rainy season to a high of $1.94 \mathrm{~km}$ in the fruit rich dry season.

Mean home range size was 37.9 ha. However, at 29.0 ha, group A's home range was noticeably smaller than group B's (40.8 ha) and group C's (43.9 ha). Like day range length, home range size varied seasonally (Fig. 24 and Table 12). The average range area for the three groups was greatest in the fruit rich dry season (highest monthly average was $32.5 \mathrm{ha}$ ) and lowest in the foliage rich, fruit poor rainy season (lowest monthly average was $15.7 \mathrm{ha}$ ). The percentage of the total home range used varied across months and seasons for the three groups (Fig. 25). On average, it was greatest in May. This was the transitional month between the dry and rainy season and one of the months of highest fruit availability (Fig. 7), and gibbons used $85 \%$ of the total home range (Fig. 25). The percentage of the total home range used was lowest in June (40\%), which was the beginning of the rainy season where fruit availability appeared to drop off substantially. 
4.3.b. Relationships of Ranging with Diet, Fruit Availability, and Rainfall

GLM analyses did not find any factor other than group to have a significant association with day range length when accounting for all other factors (Table 12). The reduced GLM model, which in stepwise fashion eliminated non-significant variables, detected significant associations between day range length and group, rainfall, and percentage of fruit in the diet. Over the annual cycle, the gibbons' day range lengths were longer when they ate more fruit (Table 13 and Fig. 26). In addition, when more fruit was available, the gibbons had longer day range lengths (Table 13; Fig. 26) and when there was more rainfall, the gibbons had shorter day range lengths (Table 13 and Fig. 27).

GLM analyses indicated that home range area was only affected by group, fruit availability and fruit in diet when accounting for all other potential influencing factors in the full model (Table 12). The same three variables were retained in the reduced model (Table 12). Over the annual cycle, there was a strong positive correlation between the percentage of the total home range used and the percentage of fruit in the gibbon's diet (Table 13). Thus, when fruit was more abundant and when gibbons ate more fruit, they used more of their home range (Table 13 and Fig. 28). Lastly, the gibbons used less of their range when rainfall was high (Table 13 and Fig. 27).

\subsection{Discussion}

4.4.a. Range

Crested gibbons (Nomascus) are distinctly larger than Hylobates (Smith and Jungers, 1997), and both are smaller than Symphalangus (Table 1).Variation in home range size and diet was expected for crested gibbons because of allometric relationships between ecology and body size (Peters, 1983; McNab 2002). My own observations 
(Chapter 2, Ruppell in Nam Kading NPA) and preliminary studies in China (Bleisch and Chen, 1991; Chen, 1995, Fan and Jiang, 2008) revealed extensive folivory and low frugivory in Nomascus compared to other gibbons. Based on the results reported in the present study, past studies (Ruppell, 2007a; 2008) and the work of others (Bleisch and Chen, 1991; Chen, 1995; Fan and Jiang, 2008), the home range size of crested gibbons is large (Table 14), especially when body size and diet are taken into account (Fig. 29). The white-cheeked crested gibbon home range is roughly similar to frugivorous gibbons and much larger on average than folivorous siamangs, even during the foliage rich, fruit poor rainy season (Fig. 29).

The ranging patterns of white-cheeked crested gibbons are comparable with other folivorous species. Folivorous sifakas (Propithecus species) and indris (Indri), weighing $6.5 \mathrm{~kg}$ on average, have home ranges that average 37.5 and 37 ha respectively (Richard, 1974; Pollock, 1979; Wright, 1995, Powzyk, 1997), similar to the 37.8 ha average found for Nomascus leucogenys in this study. Interestingly, Propithecus diadema diadema exhibits much longer day range lengths on average $(1.63 \mathrm{~km})$ than Indri indri $(0.77 \mathrm{~km})$ (Powzyk, 1997). Even though they have a similar sized home range, Propithecus diadema diadema monitors all of their boundaries within 3-4 days, while Indri indri spends most of its time in the interior of its range and takes up to 14 days to visit their territorial boundaries (Powzyk, 1997). Howler monkeys (Aloutta palliata) follow a strategy similar to Indri with a home range of 39 ha, but an average day range length of only $0.43 \mathrm{~km}$ (Milton, 1980). The mean day range length for the 3 groups of Nomascus leucogenys in the present study was $1.48 \mathrm{~km}$ per day, closer to the values found for sifakas. Although sifakas and white-cheeked crested gibbons are folivores (Table 4), they 
travel long distances to locate fruit when it was available, unlike indris whose year-round diet is comprised of a uniformly high proportion of young leaves (Powzyk, 1997; Powzyk and Mowry, 2003).

It is unknown why crested gibbon home ranges are loosely equivalent to frugivorous gibbons, even though they are more folivorous (Ruppell, Chapter 2). However, several possibilities exist, such as efficiency of locomotion (i.e., speed of brachiation), differences in song, and differences in habitat.

The forelimbs of Nomascus are "elongate even for a lesser ape" (Jungers, 1984:167). Nomascus species have longer skeletal trunk length and forelimb length and shorter hindlimb length than the average among the hylobatids (Napier, 1963; Jungers, 1984). The intermembral index is a strong indicator of locomotion in primates. For scores lower than 100, the forelimbs are shorter than the hind limbs, which is common in leaping primates and bipedal hominids (Jungers, 1984). Quadrupedal primates have scores around 100, while brachiating primates have scores significantly higher than 100 . The intermembral index of $N$. leucogenys (arm length x 100/leg length) averaged 140 (Groves and Wang, 1990), which is longer than other apes; with examples 116 (Gorilla), 102 (Pan), 126 (Hylobates), and 129 (Hoolock): (Fleagle, 1999). The slender elongated forelimbs of gibbons are adaptations for brachiation, and the longer forelimbs of Nomascus indicate the potential for faster travel than other gibbons. My personal observations of gibbons brachiating suggest that crested gibbons are the fastest and most agile, and have the best hand-eye coordination, although this has not been rigorously tested. Their capacity for fast, efficient travel likely plays a role in their ranging behavior 
because they are probably more energetically efficient than other gibbons, making it easier to maintain a large home range.

In terms of singing behavior, crested gibbons also exhibit a number of unique characteristics that set them apart from other gibbons. Song bouts of mated pairs of the genus Nomascus are highly stereotyped and male-dominated, whereas solo songs appear to be produced by non-mated individuals only. In addition, crested gibbons exhibit the highest degree of sex-specificity in their songs, as there is typically no overlap between the sexes in either note repertoire or phrase repertoire. The song of crested gibbons reaches the highest frequencies of all gibbons at up to $4 \mathrm{kHz}$ (Ruppell, 2009). The high frequencies and sex-specificity of their songs may allow crested gibbon song to communicate with other nearby gibbon groups without actually seeing them and thus contributes to the ability to maintain large territories. Crested gibbon song sounds like a siren, and is a signal to adjacent groups to stay out of their territory. However, although high frequency song might help to maintain territorial boundaries, song by itself cannot be the driver for why this species defends an unusually large territory; it is an enabler, not a driver.

In addition to differences in singing behavior and body size, the habitat of crested gibbons varies from other gibbons. Crested gibbons live primarily in mountainous forests with a karst limestone landscape. In fact, the countries that crested gibbons inhabit (China, Laos, Vietnam and Cambodia) contain the most mountainous terrain in Southeast Asia (Singh, 2008). Crested gibbons are almost solely found at higher elevations (from 400 to 1,900 meters) than other gibbons (typically from sea level to 500 meters). When 
crested gibbons travel perhaps they can move rapidly along peaks and cover more ground than other gibbons, allowing them to maintain a large home range.

Nomascus concolor gibbons at the northern extreme of gibbon distribution in subtropical China appear to be truly exceptional in their ranging behavior (Table 14; Fan et al. 2009). Fan's estimate of more than 100 ha home ranges might be typical for crested gibbons that live near the edge of the species range in marginal areas that require animals to cover greater distance to obtain adequate resources. In conjunction with my results, these findings suggest that environment and population density may play a larger role than taxonomy in determining home range size. The ranging patterns of $N$. concolor in China shifted slightly month by month to different parts of their large home ranges, which is not consistent with the prediction that territorial species should regularly use all parts of their range (Mitani and Rodman, 1979). In contrast, N. leucogenys in Laos did not shift and they regularly used much of their home range, especially in the fruit rich dry season. Tree diversity in the montane forests of central Yunnan, China is lower than in warm tropical forests, and food trees appear to be patchier in distribution (Fan et al. 2009). The harsher climate and reduced availability of food in the habitat of $N$. concolor compared to potentially relative abundance of food for $N$. leucogenys may explain the differences in home range size between these two closely related and similar sized species.

Because hunting of gibbons has traditionally been taboo around the research site, it is likely that the area represents the density and home range sizes of gibbons unexposed to hunting pressure. However, potential effects of inter-specific competition and threats of predation have been eliminated because hunting of all other species except gibbons 
have eliminated potential competitors and predators. The remaining crested gibbon populations, especially in the northern regions of China are generally only found at higher elevations as most forests below 2200 meters have been cleared for agriculture through generations of selective logging (Bleisch et al., 2008). Even in the areas of high quality primary forest with continuous canopy, gibbon densities are low, likely because at this elevation tree diversity is reduced (Bleisch et al. 2008; Fan et al., 2008). The surviving populations confined to higher elevations have been considered a natural "sink" (Cowlishaw and Dunbar, 2000). It is possible that previous range estimates for crested gibbons (Fan et al., 2009, see Table 14) are based on populations kept at extremely low density by hunting pressure and what are essentially high elevation "island" habitats surrounded by farms. Low density populations may allow large territories to be acquired with little effort because of artificially limited intra-specific competition. Thus, although representative of the remaining populations in China, it is possible they are not representative of the original distribution and ecology of crested gibbons before forest loss and hunting pressure.

Home range size of the three groups that I studied differed. The argument that home range size of a large group would be larger than that of a small group (MacKinnon and Mackinnon, 1977) does not provide an explanation because the largest group (Group $\mathrm{A}=5$ individuals) also had the smallest home range (29.0 ha). Groups B (4 individuals) and C (3 individuals) each had home ranges above 40 hectares. Group size probably does not have implications for home range size in gibbons because generally, if there is enough food for one gibbon, there is enough for five (Whitten, 1982). A reasonable alternative explanation for the smaller home range in Group A is that their home range 
encompassed an especially rich area with a high density of food trees. A third possibility is that Group A is an older, more well-established group, while Group B and C are younger. If a group has more recently formed, it could take some time for them to establish their range which could be provisionally larger than an older group. The adults from Group C appeared to be a "young couple" given that they had only one offspring. Anecdotally their duet seemed less fluid and practiced compared to groups A and B, suggesting that their group may have formed more recently. In general, the three groups' home ranges were found on mountain peaks that formed somewhat of a plateau and were isolated from one another by valleys with streams running through them. Therefore, natural barriers may have helped to determine home range boundaries, and because they facilitated boundary defense, been a primary factor determining the size of an easily defended area.

A shortcoming of my study, and most similar studies that preceded mine, is that calculation of day range lengths and use of standard minimum convex polygons to measure home range do not take topography into account. Use of GPS to measure distance does not reflect the true linear distance between a high ridge and a deep valley, but is instead approximated by shortest distance between points on a two dimensional map. Therefore, my approach may have underestimated range area for gibbons in this region of highly irregular terrain. On the ground measurements, which account for variation in slope and topography would likely have yielded higher estimates of home range. However, my estimates are probably reasonably close to the actual because the gibbon home ranges that I studied were located primarily on mountain plateaus separated 
from one another by deep valleys. Topographic extremes within home ranges were not great.

\section{4.b. Ranging, Diet, Fruit availability, and Rainfall}

The gibbon groups did not have specific sleeping trees or group of trees to which they returned each afternoon. Instead, they settled down for the night in whatever trees were most suitable in the area where they had been feeding prior to dusk. I also never recorded movements to obtain water as they apparently obtained sufficient water from their food. As all groups had mated pairs, I also never observed movements to find mates. The main reason for traveling was thus to locate and monitor food sources.

Not surprisingly, therefore, fruit availability emerged as an important factor influencing the distance over which a group ranged and their total monthly home range use (Table 13). All three groups traveled less when fruit was scarce. By contrast, even though young leaf abundance varied throughout the year (Fig. 12), and young leaves were an important component of the diet (Ruppell, Chapter 2), young leaf availability was not a significant predictor of range area or day range length (Table 12). The finding that gibbons alter their movement patterns in response to resource abundance is similar to observations made by Raemaekers (1980) who studied white-handed gibbons and siamangs, and Bartlett (2009) who studied white-handed gibbons. Raemaekers (1980) concluded that the strong correlation between fruit abundance and ranging suggests that gibbons follow a "loss-cutting policy" in their home range use. With the reduced availability of preferred foods, the best strategy is to limit movements. For the gibbons in the present study, the positive correlation between day range length, home range use, and the quantity of fruit in the diet is consistent with this conclusion. Reduction in travel 
distance with lower fruit availability may reflect awareness that increased travel will not be rewarded and a decision is made to utilize lower quality foods. Evidence that ranging is reduced in months of fruit shortage comes from other territorial (mantled howler monkeys [Alouatta palliata]: Milton, 1980; Verreaaux's sifaka [Propithecus verreauxi]: Norscia et al., 2006; chimpanzees [Pan troglodytes]: Doran, 1997) and non-territorial (capped langurs [Trachypithecus pileatus]: Stanford, 1991; white-bellied spider monkeys [Ateles belzebuth]: Nunes, 1996; lowland gorillas [Gorilla gorilla]: Yamagiwa and Mwanza, 1994) primates as well. Many species cope with reduced food availability through selective occupation of different portions of their home range (Kinzey, 1977; Leighton and Leighton, 1983; Boinski, 1987; Overdorff, 1993; Soini, 1993; Peres, 1994; Zhang, 1995). Hemingway and Bynum (2005) reported fifteen instances of seasonal "habitat shifting" occurring in their survey of 157 studies reporting seasonal data for one hundred primate species.

Evidence suggests that gibbons reduce their movements in the rain and therefore seemingly avoid traveling during these periods. Thus, rainfall was negatively correlated with day range length and proportion of the home range that was used. However, during times of high rainfall there was also low fruit availability (Fig. 7), which indicates that the gibbons are also limiting ranging to conserve energy when fruit is not widely available. Fruit availability was a stronger predictor of range area and day range length than rainfall (Table 12) and fruit availability was a stronger predictor than rainfall of diet in any given month (Table 5). 


\section{4.c. Ecological Strategies}

Optimal foraging theory predicts that organisms forage in a way that maximizes their net energy intake per unit time (MacArthur and Pianka, 1966). This theory predicts that animals will make foraging decisions to either minimize time spent foraging or maximize energy acquisition over a foraging period. Time minimization implies that animals forage such that they use the least amount of time possible to acquire some given amount of energy. A potential primate example is Howler monkeys (Alouatta palliata). Howler monkeys are extremely folivorous, have limited ranges, and 50-79\% of their time is spent resting (Milton, 1980). Howler monkeys can thus subsist on a relatively lowquality diet that requires little time to be spent traveling to acquire food. By contrast, energy maximization implies that animals attempt to gain as much energy as possible in a given amount of time. Common chimpanzees (Pan troglodytes) provide a potential primate example. Chimpanzees are highly frugivorous, live in fission-fusion social communities, and spend a large proportion of their time traveling in search of food (Goodall, 1986). Flexibility in chimpanzee social organization appears to be associated with seasonal changes in fruit availability, and thus fruit consumption can be maximized (Isabirye-Basuta, 1989).

Primates may exhibit divergent ecological strategies when they are exposed to forest fragmentation. Studies of Propithecus diadema in continuous and fragmented forests have shown that groups in continuous forest appear to be energy maximizers that maintain large ranges and feed preferentially in rare fruiting trees, while groups occupying fragmented habitat appear to be time minimizers that use small home ranges and feed primarily on mistletoe (Bakerella clavata), which is considered a lower quality 
fallback food (Irwin, 2008). The difference in resource utilization strategies between sites has important implications for understanding how primates respond to fragmentation.

The primary constraints on gibbon diet are the availability and quality of different food resources. My data seem to suggest that Nomascus leucogenys is a time minimizer during the season of low fruit availability and high rainfall. During this time, they traveled infrequently and fed on nearby leaves, presumably because looking for fruiting trees would be energetically costly and would yield little reward. During times of high fruit availability and low rainfall (the dry season), the gibbons took on an energy maximizing strategy where they traveled long distances to locate and consume large quantities of fruit. These results indicate that the gibbons were behaving more as energy maximizers rather than time minimizers because they responded to seasonal changes that made fruit less available at certain times of year. Future studies will hopefully be able to expand on these conclusions by examining gibbons in a more diverse array of habitat, and also by evaluation how groups forage when faced with increasing energetic needs associated with gestation and/or feeding depending young by lactating females. 


\section{Chapter 5: Discussion}

The picture that has emerged from my study is that Nomascus leucogenys is a folivorous ape that specializes on young leaves, whose home range is larger and spends more time traveling than expected for a folivore. Environmental influences on behavior are important, and activity budget, ranging patterns, and diet are all strongly affected by rainfall and fruit availability.

\subsection{Seasonality: Climate and Phenology}

My phenological studies showed that a consistent year- round supply of palatable young leaves were available to the gibbons. To a lesser degree, fruit mirrors this year round availability, but the total number of trees with edible fruits each month was far fewer than those bearing edible leaves. Forests in Laos are highly seasonal but the gibbons were able to locate food and feed every day that they were observed, independent of month or season.

Identifying the plants in this study was problematic. No plant or animal studies had ever been conducted in the region and village guides were unable to identify even fairly common plants (i.e. out of 10 seemingly different plants they only had two possible names for them).

The monthly changes in weather observed in this study demonstrate that Nomascus leucogenys lives in a highly seasonal habitat with an extremely wet rainy season, and exceptionally little rain in the dry season (Fig. 6). The dramatic seasonal changes effected plant phenology in the forest and the behavior and ecology of gibbons. The most important factors influencing gibbon behavior were fruit availability and rainfall. 
Weather records do not exist for my study area, but discussions with villagers indicated that my year of study was not unusual with respect to rainfall and fruit availability. Examining yearly data for other areas in Laos, such as the lowland capital of Vientiane, suggest that 2011 (during this study) was extremely wet with widespread floods that caused catastrophic damage in nearly all Southeast Asian countries, including Thailand, Cambodia, Laos, Malaysia, Myanmar, and the Philippines. The OctoberNovember 2011 flooding of the Chao Phraya River in Thailand was labeled the country's worst since 1942, when flood waters inundated much of Bangkok for more than 3 months (The Bangkok Post, 2011). However, weather can vary dramatically across Laos because of varying elevations and distance from the ocean (i.e. source of moisture) and comparisons of my study site to low elevation sites likely meaningless. To some, the 2011 flooding was evidence of a changing climate that will ultimately produce dramatic increases in rainfall, stream flow, and sea level, changes that will certainly bring more flooding (START, 2011). Bangkok's location on floodplains where natural waterways and wetlands have been drained, filled, and replaced with urban structures makes the city especially vulnerable to flooding (Engkagul, 1993), and Laos, being less developed, is currently less susceptible to damage from flooding. In addition, flood devastation such as in Thailand in 2011, or throughout southern Asia in prior years, is not simply the result of extreme rainfall. It results from failure to prepare for recurrent floods and continued unregulated development (Ziegler et al., 2012). Therefore, at my study site, the amount of rainfall may not have been out of the ordinary, as was expressed by the local villagers. 


\subsection{Diet}

The white-cheeked crested gibbons dietary profile indicates that leaves and fruit are the major constituents, but averaged over the year, young leaves were their most important food source. A comparison with other gibbon genera indicates that whitecheeked crested gibbons have a more folivorous diet than any gibbon species previously documented.

Ecological theory predicts that animals select food resources on the basis of nutrients or energy content, and as determined by the animal's ability to extract said resources through the possession (or not ) of specialized digestive physiology. Studies have shown that a slower gut passage rate (GPR) is associated with larger body size (Parra, 1978; Milton, 1980; Estrada et al., 1999) and when two primate species are similar in size, GPR is expected to be slower in folivorous compared to frugivorous species because folivores must ferment and digest tough plant fiber (Milton, 1981). Experiments to determine gut passage rates were performed on guenons (Cercopithecus spp.) and mangabeys (Cercocebus spp.) that preferentially eat fruit when available but consume substantial leaf material when fruit is scarce (Maisels, 1993). Indeed GPR in these primates was slower than in similar sized primate species that were more frugivorous. Perhaps, white-cheeked crested gibbons have a slower gut passage rate than other gibbons, allowing them to consume larger quantities of leaves. However, Nomascus does not have known digestive system specializations compared to other gibbons and their GPR has not been determined. The name Hylobates was used to describe all gibbons before generic level distinctions were made, and it is used in anatomical literature to describe gibbons without species specifications or provenance (Hill, 1966). 
At this point, it is not known whether patterns that I detected in white-cheeked crested gibbons reflect adaption to their environment, or represent constraints imposed by a low quality environment. Low plant productivity in the forest could mean they are just doing what they can to survive, and if they were in a different forest they might possibly alter their diet. For example, white-handed gibbons in Khao Yai NP, Thailand are highly frugivorous (Bartlett, 2009), but current studies nearby are investigating differing diets in lower quality habitats where the same species is found (Overbaugh, pers.comm). In addition, the habitat of folivorous black crested gibbons is highly seasonal with fewer fruiting trees than Khao Yai NP, Thailand (Fan and Jiang, 2008). It could be that gibbons are highly flexible and will eat whatever is available in their habitat. In the mountainous habitat where I worked, there were probably not as many succulent fruits available year round as in other gibbon habitats. Indeed, I would predict that populations of whitecheeked crested gibbons occurred in lowlands their diet would likely include a higher percentage of fruit.

\subsection{Activity Budget and Activity Rhythm}

Results indicated that white-cheeked crested gibbons spent more time traveling than other gibbons and that the proportion of time spent in different activities throughout the year varied seasonally. The physiological attributes of a primate together with the content of different food types are two important factors that result in the expression of species-specific activity budgets. Thus, food choice and activity patterns are clearly related. A negative correlation between the amount of active time spent moving and the proportion of foliage in a primate's diet has been found in this and several other studies (Clutton-Brock, 1977; Davies and Oates, 1994; Powzyck, 1997). This finding was 
attributed to the relative abundance of leaves in a primate's environment as opposed to the more patchy distribution of fruit. In addition, animals that consume a diet richer in simple sugars have more readily available energy for traveling and engaging in social behaviors than those that do not. However, a close examination of the foods eaten by white-cheeked crested gibbons must also be undertaken to fully address the issue of whether the proportion of leaves in the diet is the primary driver for the seasonal increase in time spent resting in the rainy season. Primates also have differing gut morphologies that help dictate their diet and activity budget (Davies and Oates, 1994), yet the gut morphology of Nomascus has not been described.

The present and other studies have shown than primates travel farther when they are eating fruit rather than leaves (Milton, 1980; Bartlett, 1999). Fruit also tended to be eaten during early morning hours before animals begin to move, as has also been observed in other studies (Chivers, 1974; Powzyck, 1997). Temporal resource partitioning by gibbons, with high energy density fruits being consumed in the first half of the day, may provide for quick energy after nighttime rest and allow them to accomplish energetically expensive activities (Clutton-Brock, 1977; Raemaekers, 1978). By contrast, leaf eating often preceded resting or sleeping when an animal's system can be fully devoted to lengthy fermentation. Leaves being naturally high in fiber and secondary compounds make their consumption late in the day advantageous because nutrients can be extracted slowly during nighttime inactivity (Milton, 1979; Glander, 1982). In addition, soluble carbohydrates in leaves may increase throughout the day (Ganzhorn and Wright, 1994). Therefore, by eating leaves late in the day, gibbons may be optimizing their energy intake by consuming leaves when they are highest in 
carbohydrate value. Hence, the timing of leaf eating may be dictated by plant circadian rhythms (Vasey, 2004). Temporal separation of resource consumption thus seems optimized to maximize energy use and extraction.

White-cheeked crested gibbons may spend a large amount of their time awake travelling because they must patrol a large home range, which may be facilitated by their especially long forelimbs and fast brachiation through the trees. Based on personal observations of gibbons brachiating it seems quite clear that crested gibbons are the fastest and most agile, although this has not been empirically tested. Their capacity for fast travel likely plays a role in their ranging behavior because it may enable them to easily determine fruiting times of widely separate fruit trees so that travel time and distance is ultimately minimized.

Another possibility for the large amount of time spent traveling in white-cheeked crested gibbons (compared to other gibbons) is that predation/hunting pressures has selectively favored wariness and frequent movement to reduce detectability. Gibbons in areas of intense hunting may increase their survival and reproductive success by traveling often and being hyper-vigilant while feeding and resting. Even though gibbons were not hunted by the villagers near my field site, it is likely that they are adaptable to situations where hunting of gibbons and other species is common. Gibbons are highly intelligent primates so if they observed other species being shot or caught in traps, such as macaques or langurs (both are popular hunting targets) they might increase their vigilance.

\subsection{Ranging}

Home ranges for folilvores tend to be smaller than those of frugivores (CluttonBrock, 1977), and the siamang (Symphalangus), for instance, which spends over $50 \%$ of 
its feeding time on foliage, has a smaller home range than the frugivorous white-handed gibbon (Hylobates lar; Milton and May, 1976) even though the siamang are twice the size of white-handed gibbons. Surprisingly, my results show that folivorous whitecheeked crested gibbons have home ranges similar in size to frugivorous gibbons (Fig. 29). The smaller home ranges of folivores have been attributed to the high availability of leaves compared to fruit, the latter of which is usually widely dispersed and a less temporally predictable resource. Although white-cheeked crested gibbons are folivores, their diet is flexible and they searched for fruit and traveled long distances to locate it. Hence, the availability of fruit appears to be the main driver of their ranging ecology. White-cheeked crested gibbon home ranges contracted during the rainy season when fruit availability was low (Fig. 24 and 29). A similar pattern of decreased ranging resulting in smaller home ranges during periods of reduced food availability has been observed in many other folivorous primates such as sifakas (Richard, 1978), woolly spider monkeys (Strier, 2004), gorillas (McNeilage, 2001), and colobine moneys (Davies and Oates, 1994). This consistency among species indicates that ranging is directly influenced by seasonal changes in food availability. Comparative studies of ranging behavior rarely account for this seasonal effect, but standardization of comparisons across similar seasons should be an objective for future studies.

The remaining crested gibbon populations, especially in the northern regions of China, are generally only found at higher elevations as most forests below 2200 meters have been cleared through generations of selective logging and for agriculture (Bleisch et $a l ., 2008)$. At this elevation tree diversity is reduced, so even in the areas of high quality primary forest with continuous canopy, gibbon are not found at high densities (Bleisch et 
al. 2008; Fan et al., 2008). The surviving populations confined to higher elevations in China have been considered a natural "sink" (Cowlishaw and Dunbar, 2000) because they have persisted in these habitats for many years without the possibility of dispersers arriving from lower elevations. In addition, it is possible that most previous home range estimates for crested gibbons are based on populations of extremely low density due to hunting pressure. Low density populations may allow large territories to be acquired without much dispute.

Large home ranges may be an adaptation to highly seasonal environments. Smaller home ranges would pose a greater risk to the gibbons in times of extreme weather events or food scarcity. Species that occupy larger home ranges include a greater range of habitats and resources within their defended space, which can buffer them against events such as drought or food scarcity (Fan et al., 2008).

\subsection{Conservation Recommendations}

Very little research has been conducted in Laos. Few resources and little biological training within the country have led to a shortage of information regarding Lao wildlife. My study is one of the first in Laos to forge relationships with the National University, with local people, and a non-government organization (The Wildlife Conservation Society) and it will hopefully lead to more similar efforts because data to develop conservation strategies in Laos are urgently needed. Such efforts will hopefully also promote biological and conservation research training so that Lao nationals will be empowered to participate in future research on the extensive biodiversity present in their country. Tenure of local people over their resources must also be fostered because without it there is little hope for sustainable use of resources. Establishing research 
programs in Laos will hopefully also open doors for future non-nationals to conduct biological research in the area.

One of the biggest dangers for white-cheeked crested gibbons and other endangered gibbons is encapsulated by what conservation biologists have characterized as the "extinction vortex" (Soule, 1986). The extinction vortex begins with small population size. The latter are prone to demographic stochasticity, sex ratio drift, inbreeding depression, low dispersal distance, and Allee effects (i.e., difficulty of finding a mate), all of which contribute to an increased probability of extinction. Combined with anticipated increased population fragmentation because of deforestation and development, and associated increased hunting pressures, edge effects, human encroachment, weak protection, plus lack of attention and urgency, we have a species at extreme risk for extinction over the next few years.

Conservation strategies based on attempts to identify "flagship species" have been questioned (Simberloff, 1998), but it seems possible that a single species can help to define the landscape and scale of conservation. I would therefore argue that there is value in focusing conservation efforts on one species if others are conserved in the process. Recent taxonomies (e.g. Groves, 2005) indicate that Laos has at least 15 species of primates, of which 13 are threatened with extinction (IUCN, 2011), including whitecheeked crested gibbons. Conservation strategies to protect the forest habitat of one taboo species (gibbons) will not help to conserve these others, unless other steps are also taken to decrease hunting pressure.

In the past 20 years, Laos has realized several large-scale development projects (Singh, 2008), including hydroelectric dams and large mining projects. With about $70 \%$ 
of Lao people relying on natural resources for their livelihood and on wildlife as a protein resource (UNDP, 2010), such projects, which involve movement of villagers into areas with lower agricultural potential (McNeely, 1987; Ruppell, pers. obs. 2012), increase the risk of overhunting. Within National Protected Areas (NPAs), wildlife extraction is prohibited but local villagers are allowed to take some species for subsistence use (National Assembly Lao PDR, 2007). Dead gibbons are heavily traded in Vietnam (Tran Thu Hang, 2010), which suggests that in Lao villages, hunting gibbons for trade with Vietnam could potentially be a lucrative activity. Because most of the remaining gibbon habitat in Laos is in the eastern half of the country, it is at particular risk of Vietnamesedriven hunting, and this is likely to increase as wildlife populations in Vietnam continue to dwindle. Both Vietnamese and local villagers have been found hunting in protected areas of Laos, for either local consumption or trade (Ruppell, 2008; Phiapalath, 2009; Johnston, 2011). Gibbons are classified under the Prohibition category of the Lao hunting regulations, which groups species as "rare, near extinct, high value and of special importance in the development of social-economic, environmental, educational, and scientific research" (National Assembly Lao PDR, 2007: Article 11). Species in this category should be "managed, inspected, and preserved" (National Assembly, Lao PDR, 2007). However, this declaration has had little effect on activities in rural areas. For example, villagers reported using tree snares to catch gibbons and douc langurs (Lippold et al., 2011). One villager claimed he had caught seven individuals with this technique in one year (Lippold et al., 2011). At this rate, gibbons, which live in small groups (2-6 individuals), have late sexual maturity (7+ years), long gestation periods (6-7 months), 
and long inter-birth intervals (2-3 years), face risks of rapid extinction in areas where hunting is not managed (Rawson and Ruppell, 2012).

The largest ever reported population of white-cheeked crested gibbons is in PuMat National Park, Vietnam based on a recent survey by Conservation International (2011). However, the quantification of individuals was based on extrapolation from very few encounters by nonrandom surveys clustered in one area along trails. Accordingly, I believe that the Lao population of white-cheeked crested gibbons unquestionably remains the largest in the world. With the species reported as extinct in China (Fan, pers.comm., 2012) and dwindling in Vietnam (Ruppell, 2007; 2008), the Lao population represents the strongest and most diverse option for conserving genetic and ecological diversity.

It is clear from surveys and populations estimates (Duckworth et al., 1999) that gibbons have been reduced to very low densities, even to local extinction, in many forests of Laos. This is especially true in smaller, more fragmented, and easily reached habitat blocks. Fragmentation increasingly typifies forest areas in the country and this trend is likely to continue if no action is taken. Timmins and Duckworth (1999) concluded that "inaccessibility" of remote forest areas was the best protection for gibbons and other primates in Laos. However, development has increasingly opened up all previously isolated areas. Thus, we need immediate identification of what active conservation programs and policies stand the highest chance of success.

The largest hydroelectric dam in Laos, recently constructed beside Nakai-Nam Theun NPA, has fueled massive increases in wildlife removal from the NPA because of the expansion of the road network that has permitted greater access and trading opportunities (Johnston, 2011; McDowell et al., 2010). I could not initially reach my 
research site without taking a 2-hour boat ride and then hiking for several hours. Over the period of my study, a highway was constructed alongside the protected area to support the construction of a hydroelectric dam that began while I was conducting fieldwork. Unfortunately, access to the site is now much easier, but it came at the expense of the local village which was forcibly moved from inside the forest to alongside the road so that they would not be in the way of dam construction. Villagers must now travel two hours (as opposed to 5 minutes previously) each way to get to their fields and crops. Dam construction is led by Vietnamese companies and personnel who do not have the same taboo against hunting as local villagers. The gibbon groups that I studied may soon disappear, leaving only those in the most remote and still inaccessible areas (Duckworth et al., 1999).

Extremely small populations are unlikely to survive in the long term. For example, the Hainan gibbon (Nomascus hainanus) on Hainan Island, China has dwindled from 1000 to 100 to 10 gibbons over the past twenty years (Zhang, 1992; IUCN, 2011). They are protected but the population continues to decline, likely because of effects of inbreeding depression (Zhang and Sheeren, 1994). The white-cheeked crested gibbon must avoid the extinction vortex if it is to survive. While I laud Conservation International's attempts to extrapolate population numbers from limited encounters (see report on Pu Mat NP, Vietnam, 2011), population estimates must be based on proper sampling efforts with extensive field sampling. Extrapolation, which relies on very few actual gibbon encounters, can grossly exaggerate population numbers. Conservation priorities and risks could be determined by layering species distribution data in GIS and observing how it changes over time. 
Despite their dwindling numbers in the wild, white-cheeked crested gibbons are common in captivity because they appear to be the favored gibbon species in American and European zoos. Many forests in Laos are intact but devoid of wildlife because of hunting. Thus, an important avenue to consider is establishing release sites where gibbons could repopulate empty forests and ultimately breed in the wild. Nomascus spp. breeds well in captivity but exhibit biased sex ratios, with very few females being born in captivity (American Zoo Association database and Baconnais pers.comm., 2012). Bacconais of the Parc zoologique et botanique in France is trying to link the diet in captivity to the male biased sex-ratio observed in zoos. The captive diet has been established using field studies carried out almost exclusively on Hylobates, and it is unclear whether this diet is appropriate for Nomascus spp. Observations of both Nomascus and Hylobates in captivity have shown that Nomascus prefers more leafy greens than Hylobates, and it will consume them first when presented with a mixture of fruit and greens.

On the basis of my study, I estimate that 40 ha is the minimum area requirement for a white-cheeked crested gibbon group. If forest quality and minimal disturbance can be demonstrated, then the approximate number of groups that could live in an area can be estimated. For example, about 75 groups of gibbons could survive in a forest patch of 3,000 ha, given adequate tree diversity and density, and protection from hunting. Assuming this is a reasonable estimate of density, it might be possible to use such estimates for at least two purposes. First, natural areas that currently yield gibbon density estimates well below this value should be considered sites where mortality, possibly because of hunting, is unusually high and in need of protection. Second, assuming the 
probability of local extinction declines exponentially with increasing population size, then estimation of potential population size in different forest fragments can help to identify the highest quality sites for potential gibbon reintroduction.

The chances of survival of gibbon populations in Laos will be made possible first and foremost by saving habitat from exploitation from outside forces (e.g., China and Vietnam) and enhanced by (1) increasing training and motivation of management staff in protected areas, (2) ensuring the primacy of biodiversity conservation in management aims where land has been declared to be protected, (3) enforcing laws against illegal wildlife collection, (4) increasing the number of patrols throughout protected areas, (5) discussing species conservation with local people and developing and encouraging consumption of other sources of protein, such as duck eggs. It may be possible to educate the population to the globally unique features of gibbons and thereby elevate it to a flagship species. Ideally, we should find ways for local communities to benefit from conservation of gibbons. (6) Training students in conservation biology in order to increase the number of conservationists in the country. (7) Facilitating internationally collaborative scientific research in Laos. This will serve to raise the awareness of the scientific community and to obtain funding for research and conservation project implementation. Future research addressing the effects of road/highway development on gibbon populations, the need for wildlife corridors, and whether or not they can survive in fragmented forests is imperative.

Precise needs at each site where gibbons still remain need to be determined, and this must include the people who will undertake the project execution along with local residents. 


\subsection{Remaining Questions}

Gibbons pose some interesting evolutionary problems that remain to be answered. Based on genetic and fossil records, gibbons split from other apes around 14 million years ago (Stauffer et al., 2001). However, there has been little evolutionary change documented since their split. Humans have undergone rapid evolution in a relatively short time span but gibbons have not. Why? The genera and species within the family Hylobatidae differ little in morphology and ecology when compared to the diversity within other primate families. All gibbon species are allopatric except for siamangs, which overlap with some species of Hylobates in distribution. All gibbons are adapted to terminal branch-feeding and are arboreal, brachiating, territorial, mostly fruit eating singers. It seems likely that at similar latitudes, all genera and species could survive in a similar habitat. There has been no major shift in habitat preference with the diversification and dispersal of species. Why have gibbon species and genera not diverged more ecologically and why is there so little sympatry? In addition, why do all gibbon species exhibit a very similar pattern of small territorial groups, and how do new groups get established? Gibbon researchers have never documented enforced departure from natal groups but young adults must leave natal groups to find new territories. Whether they travel far to find a new territory or disperse into neighboring territories and take over is unclear. Despite much research, the function of gibbon duets is still not fully understood. It's function could be territory defense, mate guarding, pair-bond advertisement, or some combination of functions that serves to increase survival and reproductive success of the singers. What exactly is the adaptive function of the duets? If 
territory defense is the function of the song, do they defend territories against other species or just individuals within their species?

Because of the strong connection between feeding activity, diet and energy allocation, it is vital to understand how behavioral decisions are influenced by environmental conditions and the physiological state of the animal (McNamara and Houston, 1996; Houston and McNamara, 1999). Endocrine mechanisms deserve specific attention because of their role in mediating interactions between environment, physiology and behavior (Sinervo and Svensson,1998; Ricklefs and Wikelski, 2002). It is unknown how hormones affect feeding and other behavior in gibbons across the seasons, but the topic should provide an interesting avenue of further research.

\subsection{Closing}

The diversity and unique attributes of gibbons have occupied my mind for at least 10 years. With the end of this book, I recognize that there are virtually endless projects that could be conducted on white-cheeked crested gibbons, a truly distinctive, irreplaceable and fascinating species. The uncertain future for crested gibbons and other species in Southeast Asia means that many questions may go unanswered and that much of this research may never be conducted. Determination, skill, and creativity will be needed from the people who recognize the intrinsic value of gibbons in order to save them. It is with hope and optimism that I look forward to reading about the results of these studies in years to come. 
Tables

Table 1. Gibbon body weights (after Smith and Jungers, 1997).

\begin{tabular}{llll}
\hline Genus & Species & Male Body Mass & Female Body Mass \\
\hline Hoolock & H. hoolock & $6.87 \mathrm{~kg}$ & $6.88 \mathrm{~kg}$ \\
\hline Nomascus & N. concolor & $7.79 \mathrm{~kg}$ & $7.62 \mathrm{~kg}$ \\
& N. nasutus & Data deficient & Data deficient \\
& N. gabriellae & $7.65 \mathrm{~kg}$ & $7.64 \mathrm{~kg}$ \\
& N. leucogenys & $7.41 \mathrm{~kg}$ & $7.32 \mathrm{~kg}$ \\
& N. siki & $7.41 \mathrm{~kg}$ & $7.32 \mathrm{~kg}$ \\
\hline Hylobates & H. agilis & $5.88 \mathrm{~kg}$ & $5.82 \mathrm{~kg}$ \\
& H. klossii & $5.67 \mathrm{~kg}$ & $5.92 \mathrm{~kg}$ \\
& H. lar & $5.90 \mathrm{~kg}$ & $5.34 \mathrm{~kg}$ \\
& H. moloch & $6.58 \mathrm{~kg}$ & $6.25 \mathrm{~kg}$ \\
& H. muelleri & $5.71 \mathrm{~kg}$ & $5.35 \mathrm{~kg}$ \\
& H. pileatus & $5.50 \mathrm{~kg}$ & $5.44 \mathrm{~kg}$ \\
\hline Symphalangus & S. syndactylus & $11.9 \mathrm{~kg}$ & $10.7 \mathrm{~kg}$ \\
\hline${ }^{\mathrm{a}}$ including N. hainanus & & \\
b including H. agilis albibaris & & \\
${ }^{\circ}$ including H. muelleri abotti and H. muelleri funereus \\
kg = kilograms
\end{tabular}

Table 2. Classification of the Hylobatidae, showing scientific, English, and common names (after Geissmann, 2002).

\begin{tabular}{|c|c|c|c|}
\hline Genus & Group name & Species & Common Name \\
\hline Hoolock & Hoolocks & H. hoolock & Hoolock \\
\hline Nomascus & $\begin{array}{l}\text { Crested gibbons, } \\
\text { concolor group }\end{array}$ & $\begin{array}{l}\text { N. concolor } \\
\text { N. nasutus } \\
\text { N. gabriellae } \\
\text { N. leucogenys } \\
\text { N. siki }\end{array}$ & $\begin{array}{l}\text { Western black crested gibbon } \\
\text { Eastern black crested gibbon (Cao } \\
\text { Vit) } \\
\text { Yellow-cheeked crested gibbon } \\
\text { Northern white-cheeked crested } \\
\text { gibbon } \\
\text { Southern white-cheeked crested } \\
\text { gibbon }\end{array}$ \\
\hline Hylobates & $\begin{array}{l}\text { Dwarf gibbons } \\
\text { Lar group }\end{array}$ & $\begin{array}{l}\text { H. agilis } \\
\text { H. klossii } \\
\text { H. lar } \\
\text { H. moloch } \\
\text { H. muelleri } \\
\text { H. pileatus } \\
\end{array}$ & $\begin{array}{l}\text { Black handed gibbon } \\
\text { Kloss's gibbon } \\
\text { White handed gibbon } \\
\text { Silvery gibbon } \\
\text { Muller's Bornean gibbon } \\
\text { Pileated gibbon }\end{array}$ \\
\hline Symphalangus & Siamangs & S. syndactylus & Siamang \\
\hline
\end{tabular}


Table 3. Divisions of Hylobatidae based on chromosome number

\begin{tabular}{llll}
\hline Genus & Group name & $\begin{array}{l}\text { Diploid Number } \\
\text { of } \\
\text { Chromosomes }\end{array}$ & Species \\
\hline Hoolock & Hoolocks & 38 & H. hoolock \\
\hline Nomascus & Crested gibbons, & 52 & N. concolor \\
& concolor group & & N. nasutus \\
& & N. gabriellae \\
& D. leucogenys \\
& Lar group & N. siki \\
\hline Hylobates & & H. agilis \\
& & H. klossii \\
& & H. lar \\
& & H. moloch \\
& & H. muelleri \\
& & H. pileatus \\
\hline Symphalangus & Siamangs & S. syndactylus \\
\hline${ }^{2}$ including $N$. hainanus & 50 & \\
bincluding $H$. agilis albibaris & & \\
${ }^{c}$ including $H$. muelleri abotti and $H$. muelleri funereus &
\end{tabular}

Table 4. Diet, \% folivory and body mass of selected folivorous primates

\begin{tabular}{|c|c|c|c|c|}
\hline Taxon & Diet & $\%$ folivory & $\begin{array}{l}\text { Body } \\
\text { mass }(k g)\end{array}$ & References \\
\hline Indri indri & $Y L$ & 72 & 6.5 & Powyzk and Mowry, 2003 \\
\hline Propithecus diadema & $Y L$ & 42 & 6.5 & Powzyk and Mowry, 2003 \\
\hline Aloutta palliata & $Y L$ & 48 & 8 & Milton, 1980 \\
\hline Nomascus leucogenys & $Y L$ & 68 & 7.5 & Present Study \\
\hline Symphalangus syndactylus & $Y L$ & 48 & 11 & Chivers, 1974; Palombit, 1997 \\
\hline Colobinae & $M L$ & 70 & 11 & Davies and Oates, 1994 \\
\hline Gorilla & $Y L$ & 82 & $68-180$ & McNeilage, 2001 \\
\hline
\end{tabular}


Table 5. Results of General Linear Models for diet for gibbons in Nam Kading NPA, Laos, June 2011- May 2012 evaluating all of the possible influences concurrently.

\begin{tabular}{lllll}
\hline & Source & & Full Model & $\begin{array}{l}\text { Reduced } \\
\text { Model }\end{array}$ \\
\hline Dependent Variable & Group & $d f$ & $\boldsymbol{F}(\boldsymbol{P})$ & $\boldsymbol{F}(\boldsymbol{P})$ \\
\hline & Rainfall & 2 & $2.34(0.18)$ & \\
& Fruit Availability & 35 & $0.02(0.90)$ & \\
& Young leaf Availability & 35 & $9.64(\mathbf{0 . 0 2})$ & $34.17(\mathbf{0 . 0 0})$ \\
& Group & $35(0.18)$ & \\
Young leaves in Diet & Rainfall & 2 & $0.22(0.80)$ & \\
& Fruit Availability & 35 & $1.35(0.29)$ & \\
& Young leaf Availability & 35 & $3.21(0.12)$ & $63.9(\mathbf{0 . 0 0})$ \\
\hline
\end{tabular}

Table 6. Results of partial correlations on the diet of gibbon groups in Nam Kading NPA, Laos, June 2011-May 2012.

\begin{tabular}{llll}
\hline $\begin{array}{l}\text { Feeding item } \\
\text { (dependent } \\
\text { variable) }\end{array}$ & $\begin{array}{l}\text { Independent } \\
\text { variables }\end{array}$ & $\boldsymbol{r}$ & $\boldsymbol{P}$ \\
\hline Fruit & Fruit Availability & 0.59 & 0.03 \\
& Rainfall & -0.50 & 0.04 \\
& YL Availability & -0.23 & $n s$ \\
Young leaves & Fruit Availability & -0.68 & 0.01 \\
& Rainfall & 0.13 & $n s$ \\
& YL Availability & 0.78 & 0.01 \\
\hline
\end{tabular}


Table 7. Diet of different gibbon species (adapted from Bartlett, 2009).

\begin{tabular}{|c|c|c|c|c|}
\hline Species & $\begin{array}{l}\% \text { Diet } \\
\text { Fruit (Fig) }\end{array}$ & $\begin{array}{l}\% \\
\text { Leaves }\end{array}$ & $\begin{array}{l}\% \\
\text { Other }\end{array}$ & References \\
\hline Hylobates klossii & $72(23)$ & 2 & 25 & Whitten, 1984 \\
\hline Hylobates pileatus & $71(26)$ & 13 & 15 & $\begin{array}{l}\text { Srikosamatara, } \\
1984\end{array}$ \\
\hline Hylobates agilis & $57(17)$ & 39 & 4 & Gittins, 1982 \\
\hline Hylobates moloch & $61(*)$ & 38 & 1 & Kappeler, 1984 \\
\hline Hylobates lar & $\begin{array}{l}50(22) \\
71(45) \\
66(19)\end{array}$ & $\begin{array}{l}29 \\
4 \\
24\end{array}$ & $\begin{array}{l}20 \\
25 \\
10\end{array}$ & $\begin{array}{l}\text { Raemaekers, } \\
\text { 1979; } 1980 \\
\text { Palombit, } 1997 \\
\text { Bartlett, } 2009\end{array}$ \\
\hline Hylobates muelleri & $62(24)$ & 32 & 6 & Leighton, 1987 \\
\hline Nomascus leucogenys & $30.4(3.5)$ & 68.8 & 0.8 & Present study \\
\hline Nomascus concolor & $44.1(18.6)$ & 46.5 & 9.4 & Fan et al., 2009 \\
\hline Symphalangus syndactylus & $\begin{array}{l}29-44(19- \\
31)\end{array}$ & $30-65$ & $1-13$ & $\begin{array}{l}\text { Chivers, } 1974 \\
\text { Palombit, } 1997\end{array}$ \\
\hline
\end{tabular}


Table 8. Results of General Linear Models for Activity Budget for gibbons in Nam Kading NPA, Laos, June 2011- May 2012 evaluating all of the possible influences concurrently.

\begin{tabular}{|c|c|c|c|c|}
\hline & & & Full Model & Reduced Model \\
\hline Dependent Variable & Source & $d f$ & $F(P)$ & $F(P)$ \\
\hline \multirow[t]{6}{*}{ Resting } & Group & 2 & $0.85(0.49)$ & \\
\hline & Rainfall & 35 & $30.1(\mathbf{0 . 0 0})$ & $20.6(\mathbf{0 . 0 0})$ \\
\hline & Fruit Availability & 35 & $1.15(0.34)$ & \\
\hline & Young leaf Availability & 35 & $0.75(0.43)$ & \\
\hline & Fruit in Diet & 35 & $3.07(0.15)$ & $48.0(\mathbf{0 . 0 0})$ \\
\hline & Young leaves in Diet & 35 & $0.79(0.42)$ & \\
\hline \multirow[t]{6}{*}{ Feeding } & Group & 2 & $1.16(0.40)$ & \\
\hline & Rainfall & 35 & $0.63(0.47)$ & \\
\hline & Fruit Availability & 35 & $9.02(\mathbf{0 . 0 3})$ & $8.32(\mathbf{0 . 0 0})$ \\
\hline & Young leaf Availability & 35 & $0.25(0.64)$ & \\
\hline & Fruit in Diet & 35 & $2.14(0.21)$ & \\
\hline & Young leaves in Diet & 35 & $0.02(0.90)$ & \\
\hline \multirow[t]{6}{*}{ Traveling } & Group & 2 & $1.46(0.33)$ & \\
\hline & Rainfall & 35 & $78.28(\mathbf{0 . 0 0})$ & $5.9(\mathbf{0 . 0 2})$ \\
\hline & Fruit Availability & 35 & $1.19(0.34)$ & \\
\hline & Young leaf Availability & 35 & $3.09(0.15)$ & \\
\hline & Fruit in Diet & 35 & $1.22(0.33)$ & \\
\hline & Young leaves in Diet & 35 & $1.49(0.28)$ & \\
\hline \multirow[t]{3}{*}{ Singing } & Group & 2 & $0.04(0.96)$ & \\
\hline & Rainfall & 35 & $1.99(0.23)$ & \\
\hline & Fruit Availability & 35 & $0.46(0.53)$ & \\
\hline
\end{tabular}


Young leaf Availability $35 \quad 0.04(0.85)$

Fruit in Diet $\quad 35 \quad 0.02(0.67)$

Young leaves in Diet $\quad 35 \quad 0.00(0.97)$

Table 9. Results of correlations between monthly activity budget and dietary proportions

\begin{tabular}{llll}
\hline & Fruit & Leaves & Other \\
\hline Activity & $\mathbf{r}(\boldsymbol{P})$ & $\mathbf{r}(\boldsymbol{P})$ & $\mathbf{r}(\boldsymbol{P})$ \\
Traveling & $0.67(0.01)$ & $-0.65(0.01)$ & $-0.52(0.04)$ \\
Resting & $-0.54(0.03)$ & $0.46(\mathrm{~ns})$ & $0.42(\mathrm{~ns})$ \\
Feeding & $-0.72(0.00)$ & $0.84(0.00)$ & $0.5(0.05)$ \\
Singing & $0.09(\mathrm{~ns})$ & $-0.20(\mathrm{~ns})$ & $0.13(\mathrm{~ns})$ \\
\hline
\end{tabular}

${ }^{*}$ ns $=$ not significant

Table 10. Results of correlations between monthly variations in activity budget and ranging

\begin{tabular}{lll}
\hline & Day Range Length $(\mathbf{k m})$ & \% Home Range \\
\hline Activity & $\mathbf{r}(\boldsymbol{P})$ & $\mathbf{r}(\boldsymbol{P})$ \\
Traveling & $0.82(0.00)$ & $0.79(0.00)$ \\
Resting & $-0.71(0.00)$ & $-0.68(0.00)$ \\
Feeding & $-0.77(0.00)$ & $-0.81(0.00)$ \\
Singing & $-0.01(\mathrm{~ns})$ & $0.14(\mathrm{~ns})$ \\
\hline${ }^{*} \mathrm{~ns}=$ not significant & &
\end{tabular}


Table 11. Activity budgets of gibbon species in different study areas (adapted from Fan $e t$ al., 2008).

\begin{tabular}{|c|c|c|c|c|c|c|}
\hline \multirow[t]{2}{*}{ Species } & \multicolumn{5}{|l|}{$\%$} & \multirow[t]{2}{*}{ References } \\
\hline & Feeding & Traveling & Resting & Singing & Other & \\
\hline Hoolock hoolock & 30.8 & 7.4 & 27.5 & 3.0 & 5.5 & Ahsan, 2001 \\
\hline \multirow[t]{2}{*}{ Hylobates lar } & 34 & 16 & 45 & 3.0 & 2.0 & Palombit, 1997 \\
\hline & 41.8 & 32.6 & 25.6 & $*$ & $*$ & Raemaekers, 1979 \\
\hline Hylobates agilis & 39 & 10 & 29 & 5 & $*$ & Gittins, 1982 \\
\hline Hylobates moloch & 22.7 & 30 & $*$ & $*$ & $*$ & Kappeler, 1981 \\
\hline \multirow[t]{3}{*}{ Symphalangus syndactylus } & 40 & 12 & 44 & 1 & 3 & \multirow{3}{*}{$\begin{array}{l}\text { Palombit, } \\
\text { 1997;Chivers, } \\
\text { 1974; Raemaekers, } \\
1979\end{array}$} \\
\hline & 44 & 26 & 30 & $*$ & $*$ & \\
\hline & 50.4 & 22.3 & 27.3 & $*$ & $*$ & \\
\hline \multirow{2}{*}{ Nomscus concolor } & 33 & 14 & 50 & 3 & $*$ & \multirow{2}{*}{$\begin{array}{l}\text { Lan, } 1989 \\
\text { Fan } \text { et al., } 2008\end{array}$} \\
\hline & 35.1 & 19.9 & 40 & 2.6 & 1.5 & \\
\hline Nomascus leucogenys & $32.9\left(3.5^{* *}\right)$ & $35.1(8.4)$ & $29.9(5.8)$ & $2.1(1.1)$ & * & $\begin{array}{l}\text { Present study } \\
(\mathrm{N}=3)\end{array}$ \\
\hline
\end{tabular}

*indicates data not collected

${ }^{* *}$ numbers in parentheses represent standard deviation 
Table 12. Results of General Linear Models for range area and day range length for gibbons in Nam Kading NPA, Laos, June 2011- May 2012 evaluating all of the possible influences concurrently.

\begin{tabular}{|c|c|c|c|c|}
\hline & & & Full Model & $\begin{array}{l}\text { Reduced } \\
\text { Model }\end{array}$ \\
\hline Dependent Variable & Source & $d f$ & $F(P)$ & $F(P)$ \\
\hline \multirow[t]{6}{*}{ Range Area } & Group & 2 & $76.5(.00)$ & $82.63(\mathbf{0 . 0 0})$ \\
\hline & Rainfall & 35 & $0.00(.99)$ & \\
\hline & Fruit Availability & 35 & $10.4(.00)$ & $25.52(\mathbf{0 . 0 0})$ \\
\hline & Young leaf Availability & 35 & $0.64(.43)$ & \\
\hline & Fruit in Diet & 35 & $11.1(.00)$ & $110.8(\mathbf{0 . 0 0})$ \\
\hline & Young leaves in Diet & 35 & $0.25(.61)$ & \\
\hline \multirow[t]{6}{*}{ Day Range Length } & Group & 2 & $15.4(.00)$ & $15.84(\mathbf{0 . 0 0})$ \\
\hline & Rainfall & 35 & $1.87(.18)$ & $6.07(\mathbf{0 . 0 2})$ \\
\hline & Fruit Availability & 35 & $0.05(.81)$ & \\
\hline & Young leaf Availability & 35 & $0.68(.41)$ & \\
\hline & Fruit in Diet & 35 & $1.68(.20)$ & $18.19(\mathbf{0 . 0 0})$ \\
\hline & Young leaves in Diet & 35 & $1.78(.19)$ & \\
\hline
\end{tabular}

Table 13. Results of correlations between ranging and fruit in diet, fruit availability, and rainfall for gibbons in Nam Kading NPA, Laos, June 2011-May 2012.

\begin{tabular}{lll}
\hline & Day Range Length $(\mathbf{k m})$ & \% Home Range \\
\hline Fruit in diet & $\mathbf{r}(\boldsymbol{P})$ & $\mathbf{r}(\boldsymbol{P})$ \\
Fruit availability & $0.81(0.05)$ & $0.86(0.05)$ \\
Rainfall & $0.82(0.05)$ & $0.88(0.03)$ \\
\hline
\end{tabular}


Table 14. Home range size of selected gibbon species

\begin{tabular}{llll}
\hline Genus & Species & $\begin{array}{l}\text { Home Range Size } \\
\text { (ha) }\end{array}$ & References \\
\hline Hoolock & H. hoolock & $30-35$ & $\begin{array}{l}\text { Islam and Feeroz, } \\
1992\end{array}$ \\
\hline Nomascus & N. concolor & 129 & Fan and Jiang, 2008 \\
& N. nasutus & $*$ & \\
& N. gabriellae & $*$ & Present study \\
& N. leucogenys & 37.87 & Whitten, 1982 \\
& N. siki & $*$ & Bartlett, 2009 \\
& H. klossii & 34 & McConkey et al.,2003 \\
\hline Hylobates & H. lar & 23.4 & Palombit, 1997, \\
& H. muelleri & 44.5 & O'Brien et al.,2004 \\
\hline Symphalangus & S. syndactylus & 9.1 &
\end{tabular}


Figures

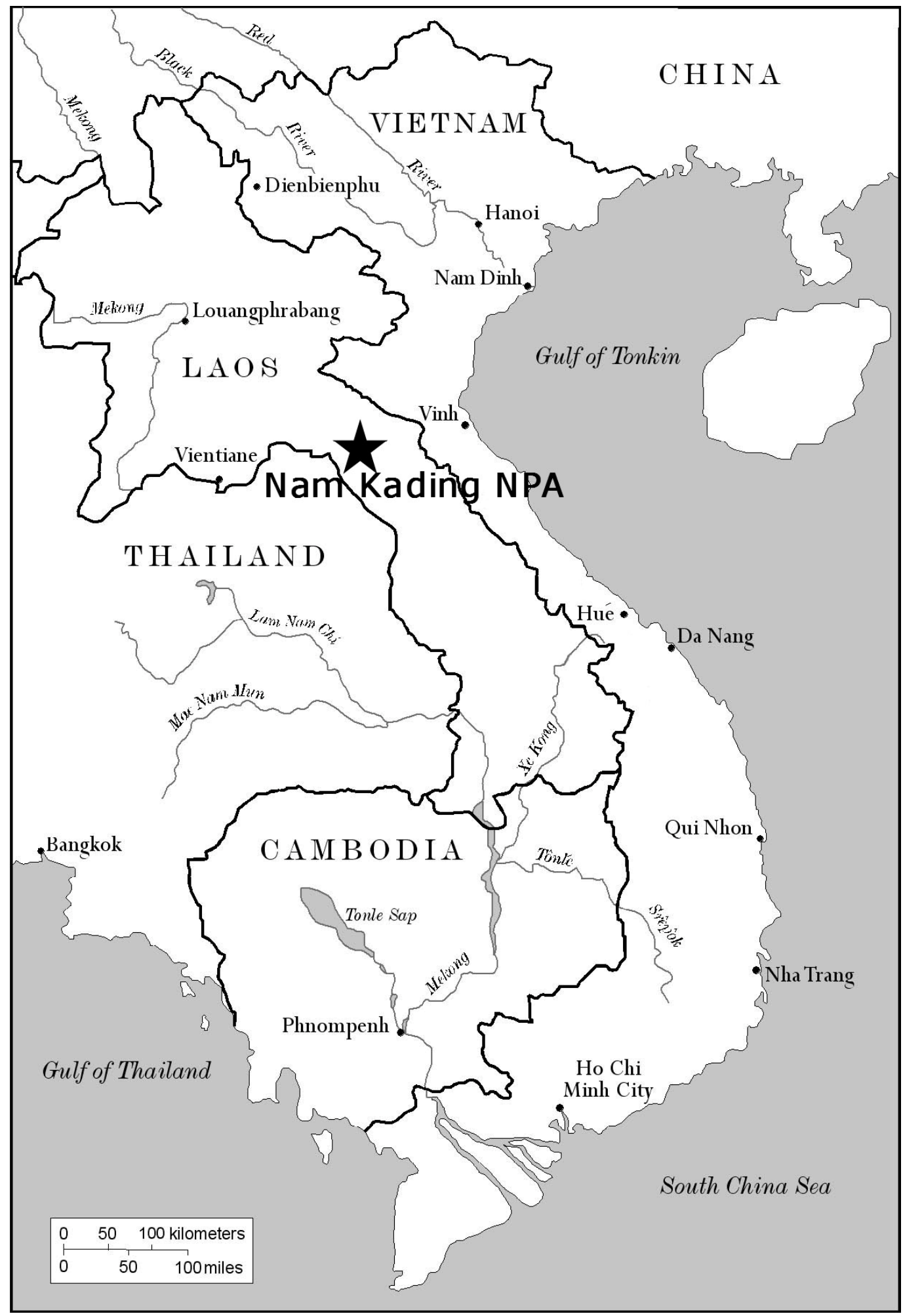

Figure 1. Map of Southeast Asia with location of field site: Nam Kading NPA. 


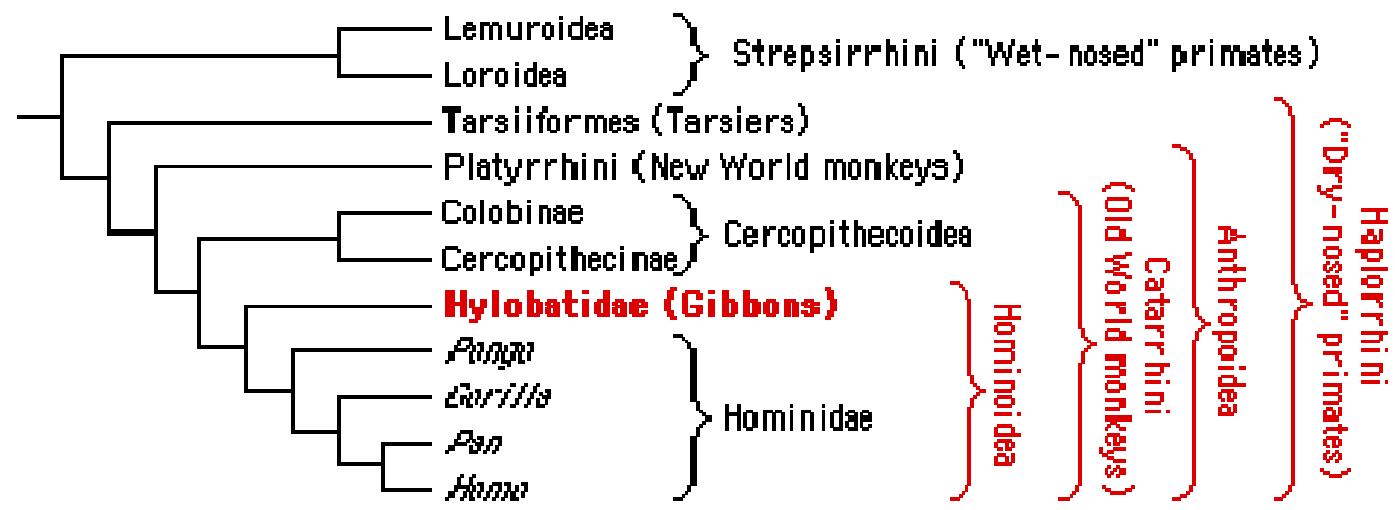

Figure 2. Systematic position of the gibbons within the primate order.

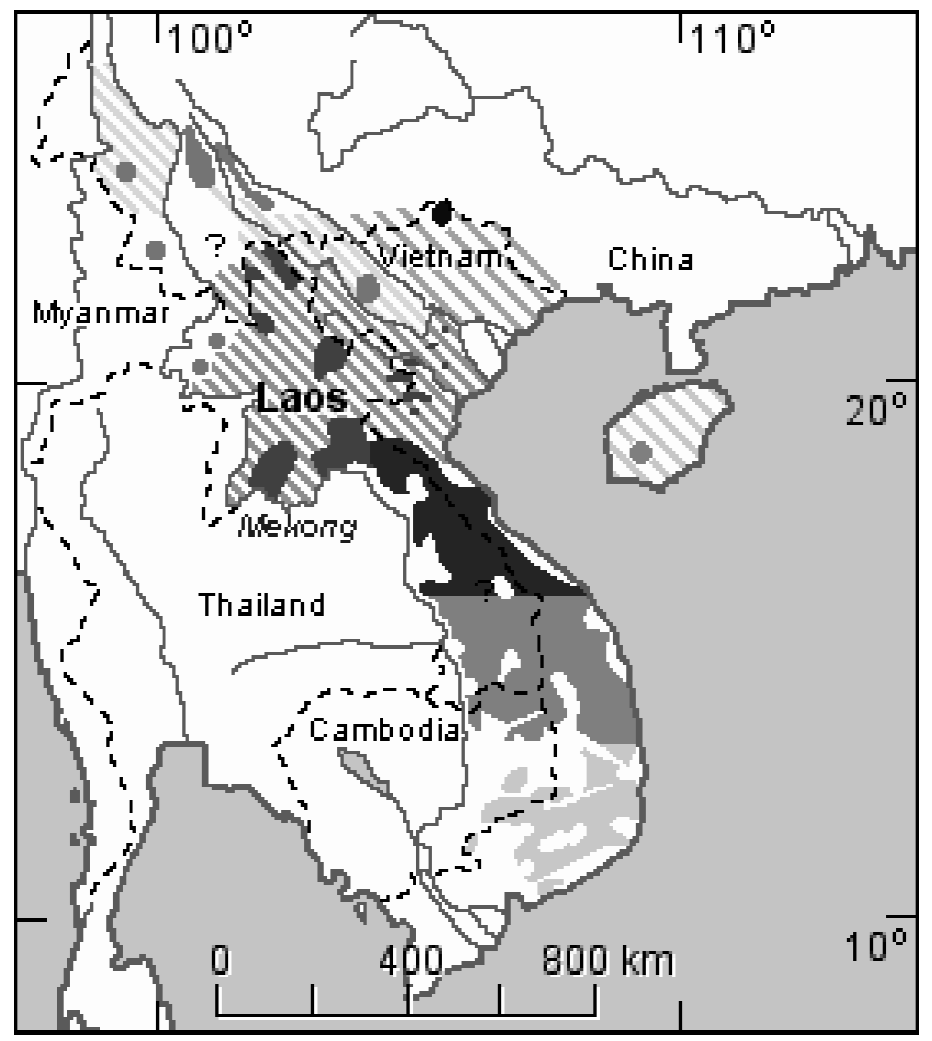

\begin{tabular}{|c|}
\hline Nomascus concolor \\
\hline N nasutus \\
\hline N. hamands \\
\hline N iencogenys \\
\hline Niki \\
\hline M. sp. (unknown taxon) \\
\hline N gabrialla \\
\hline
\end{tabular}

Figure 3.The species distribution for the genus Nomascus. Striped areas indicate assumed original distribution areas of the respective species. 


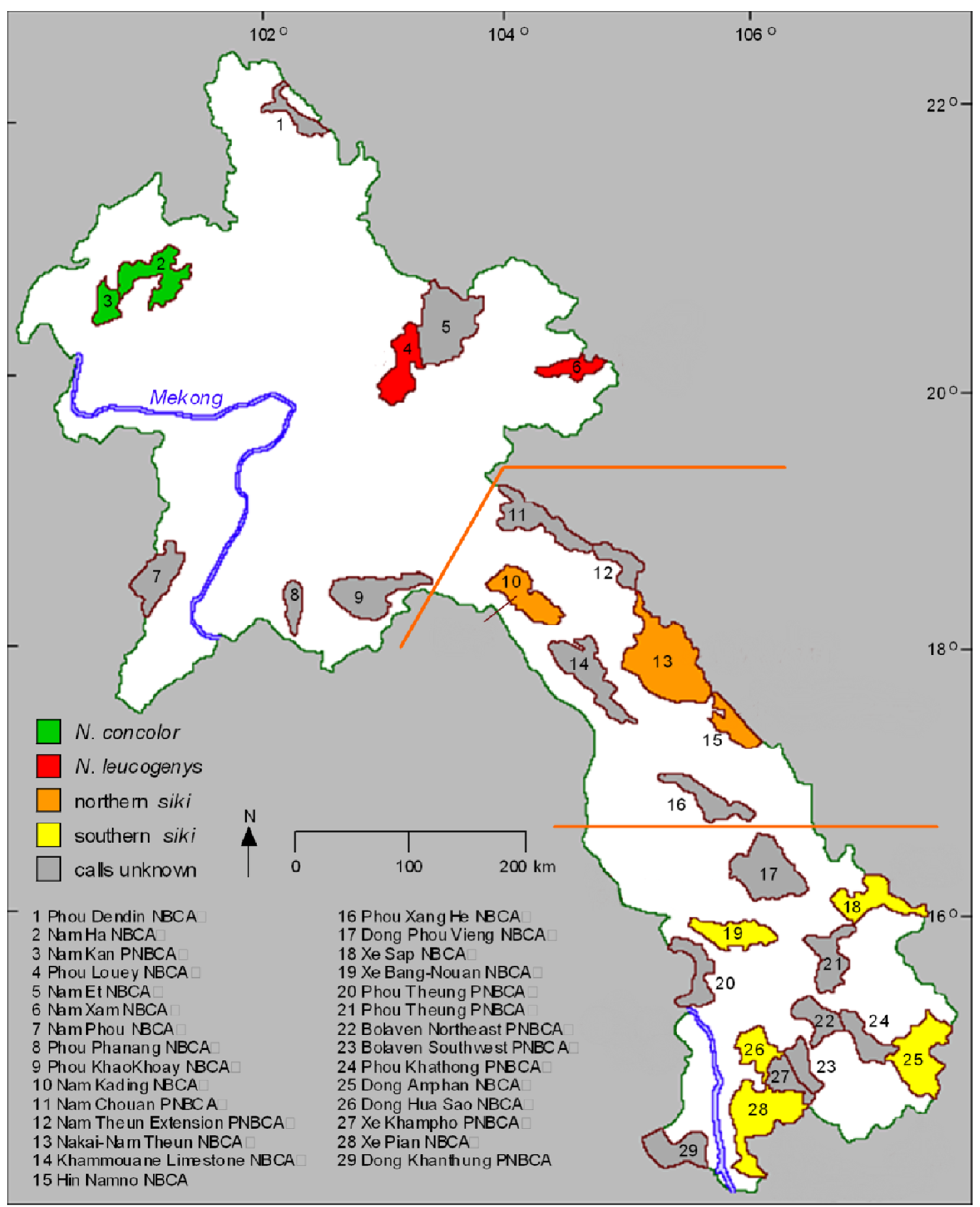

Figure 4. Crested gibbon occurrence in Laos. Lines represent approximate locations of taxonomic boundaries for Nomascus leucogenys, and northern and southern Nomascus siki. Map from Duckworth et al. (1999), modified. The distribution of Nomascus leucogenys likely extends south into Nam Kading NPA. The likely boundary between Nomascus leucogenys and Nomascus siki in Nam Kading NPA is indicated by a line (Rawson and Ruppell, 2012). 

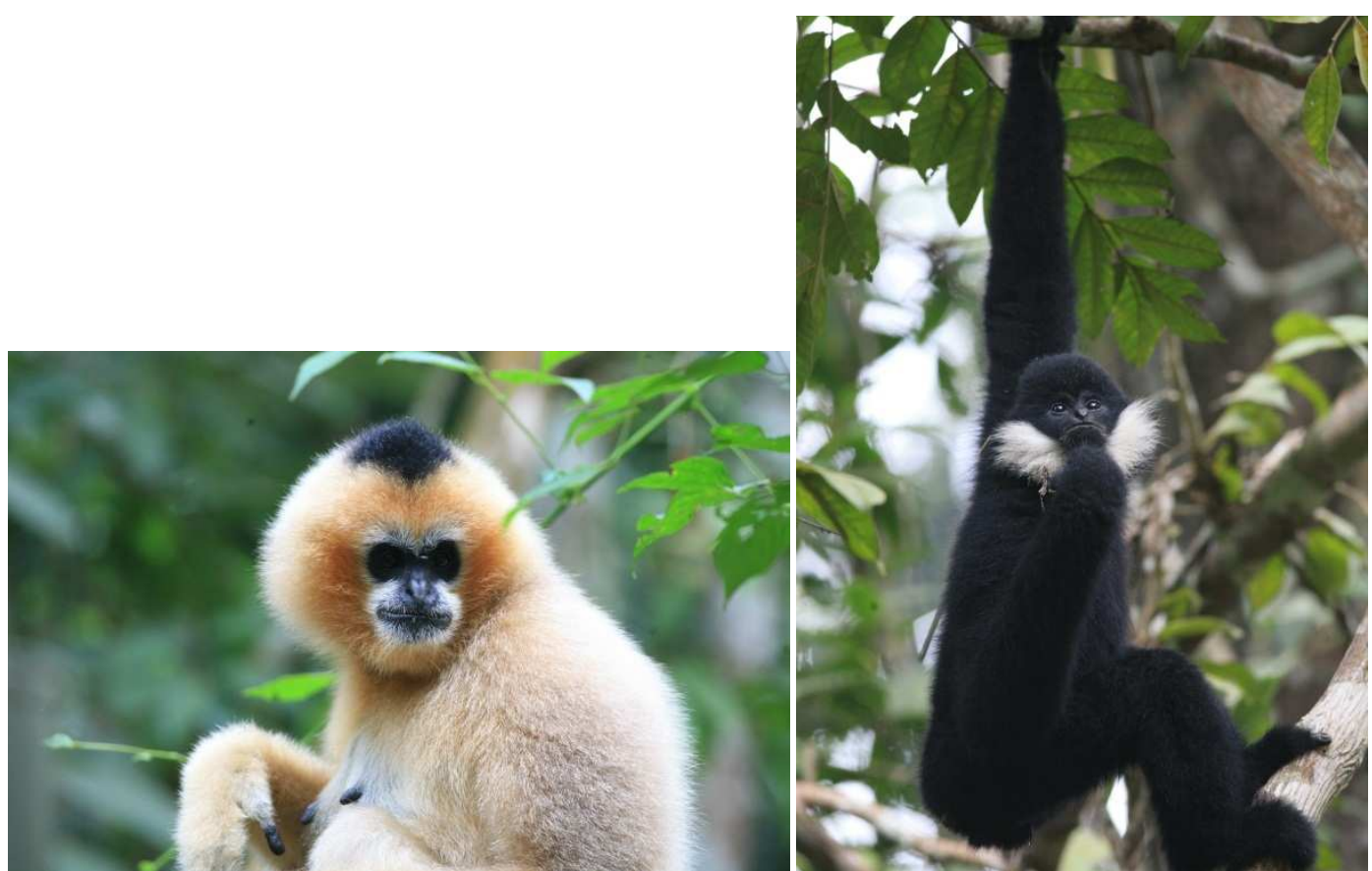

Figure 5. Female Nomascus leucogenys and male Nomascus leucogenys showing white cheek pattern characteristic of adult males. Photos: Fan Peng Fei

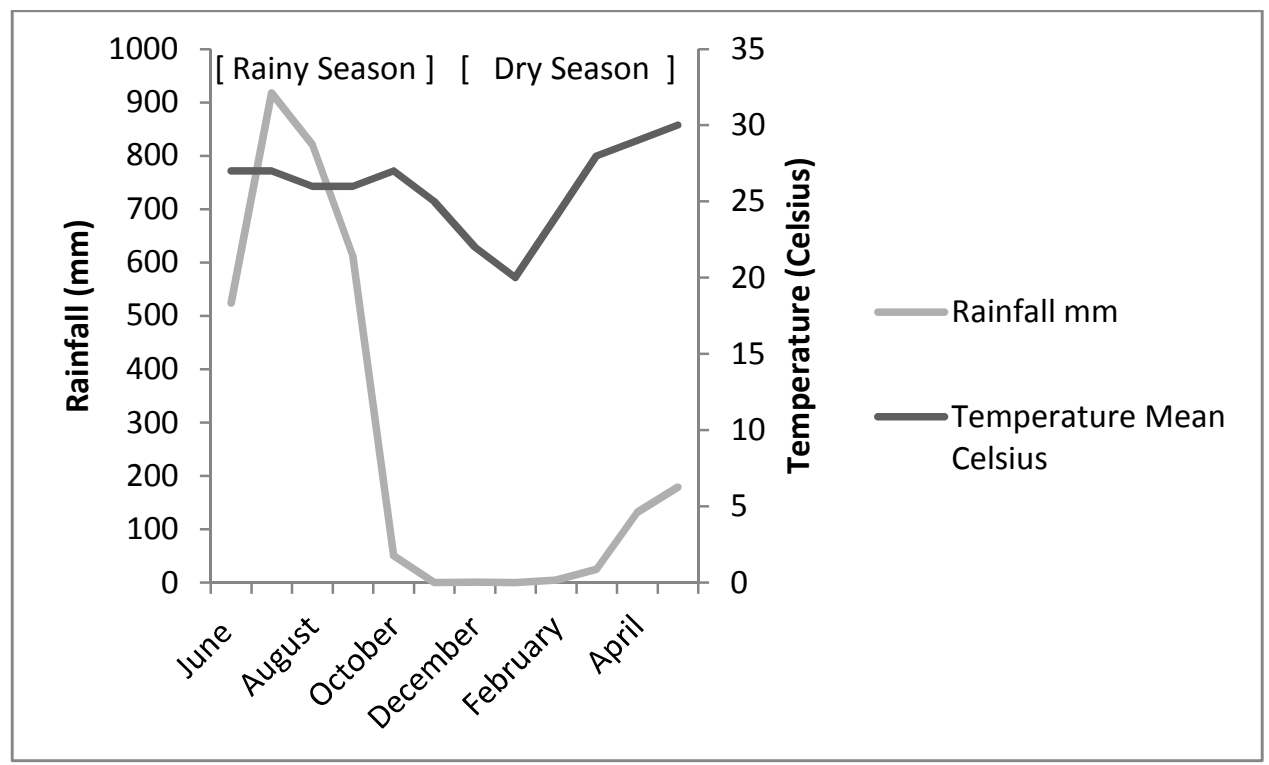

Figure 6. Total rainfall $(\mathrm{mm})$ and Average daily temperature $(\mathrm{C})$ in Nam Kading NPA, Laos, June 2011- May 2012. 


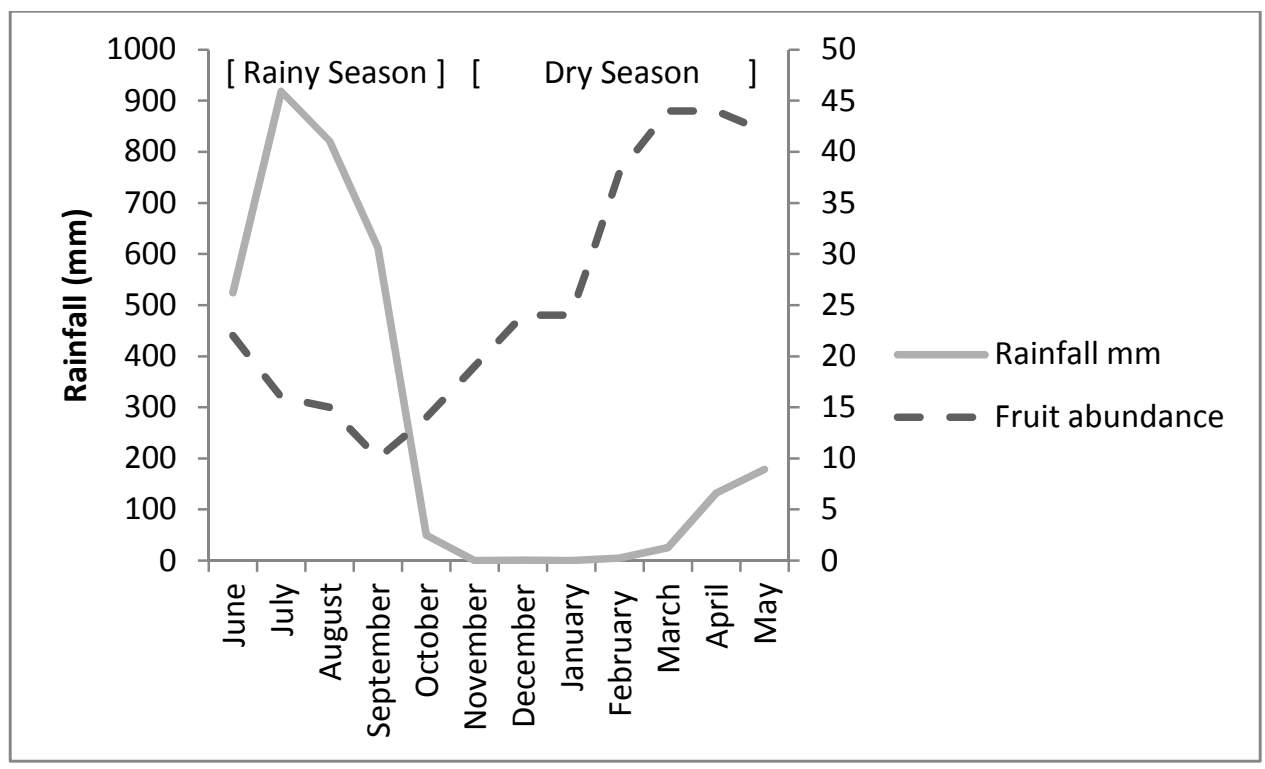

Figure 7. Percentage of phenology trees with fruit each month and rainfall in Nam Kading NPA, Laos, June 2011- May 2012.

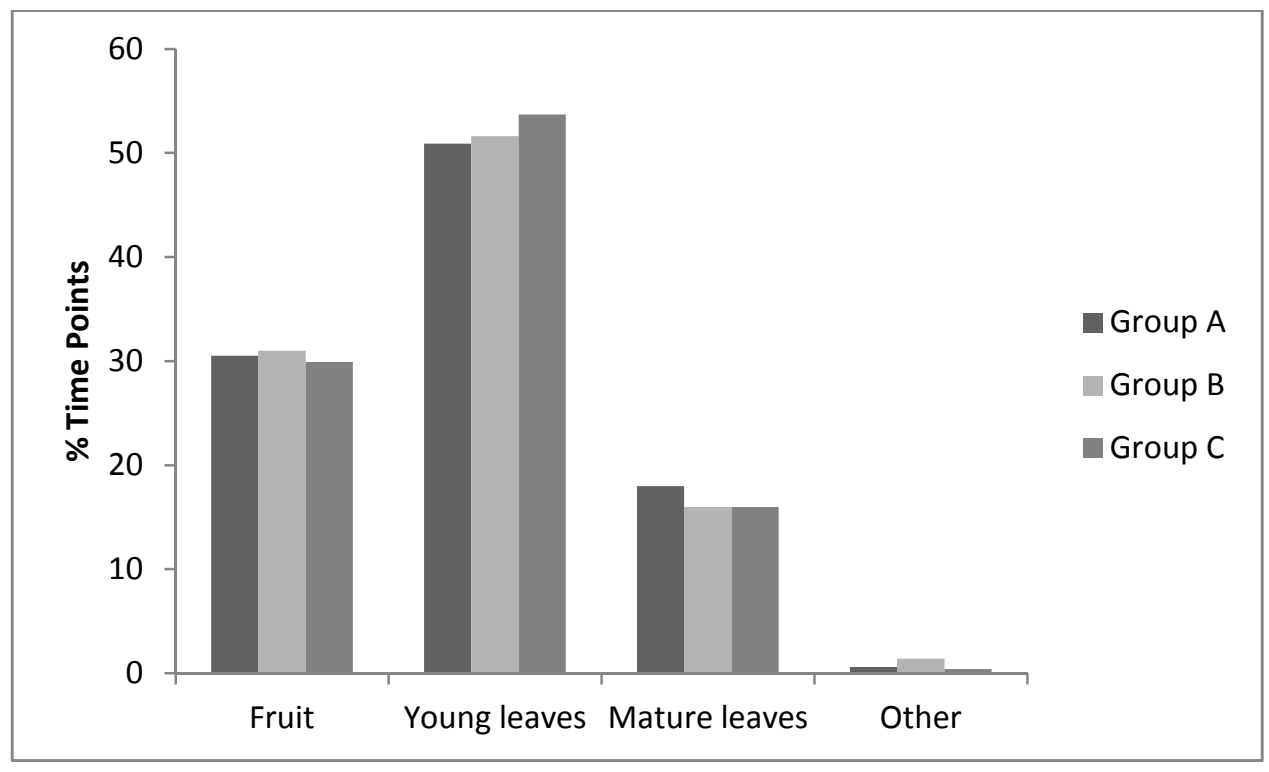

Figure 8. Diets of Groups A, B, and C in Nam Kading NPA, Laos, June 2011- May 2012. 


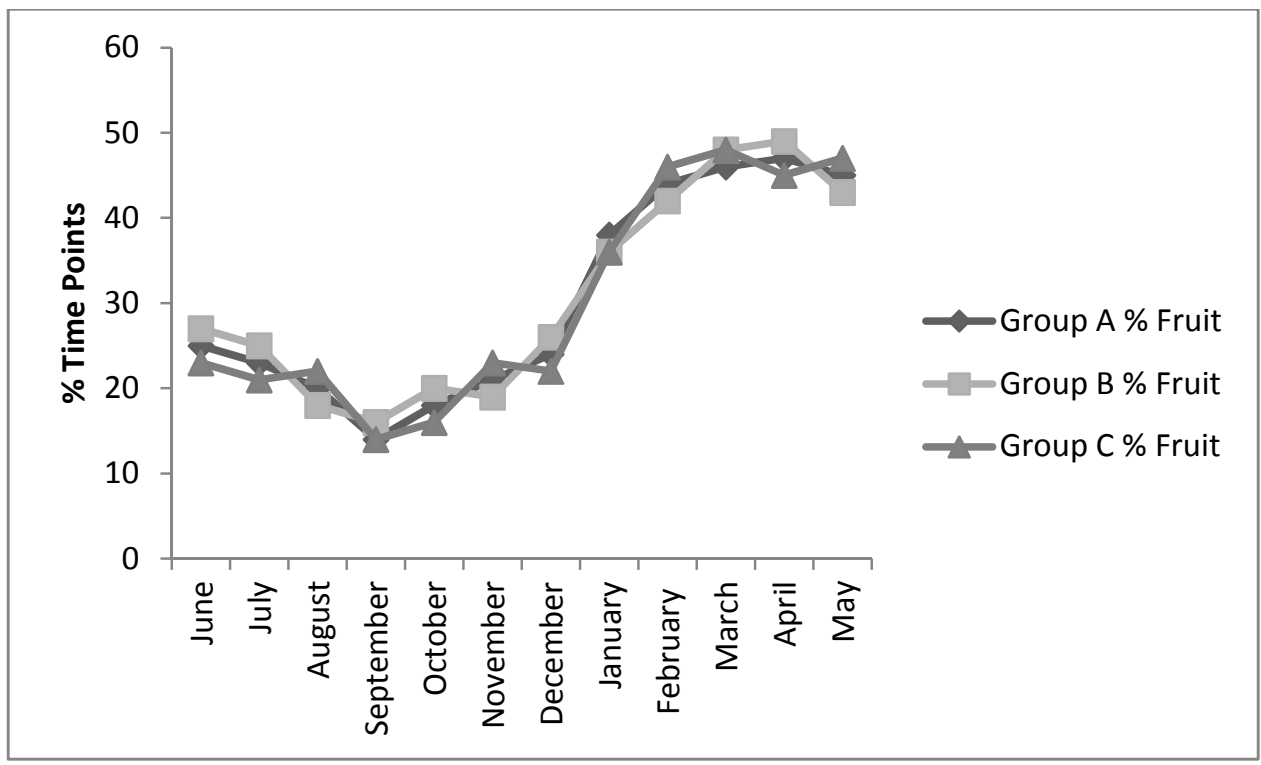

Figure 9. Monthly fruit consumption of Groups A, B, and C in Nam Kading NPA, Laos, June 2011- May 2012.

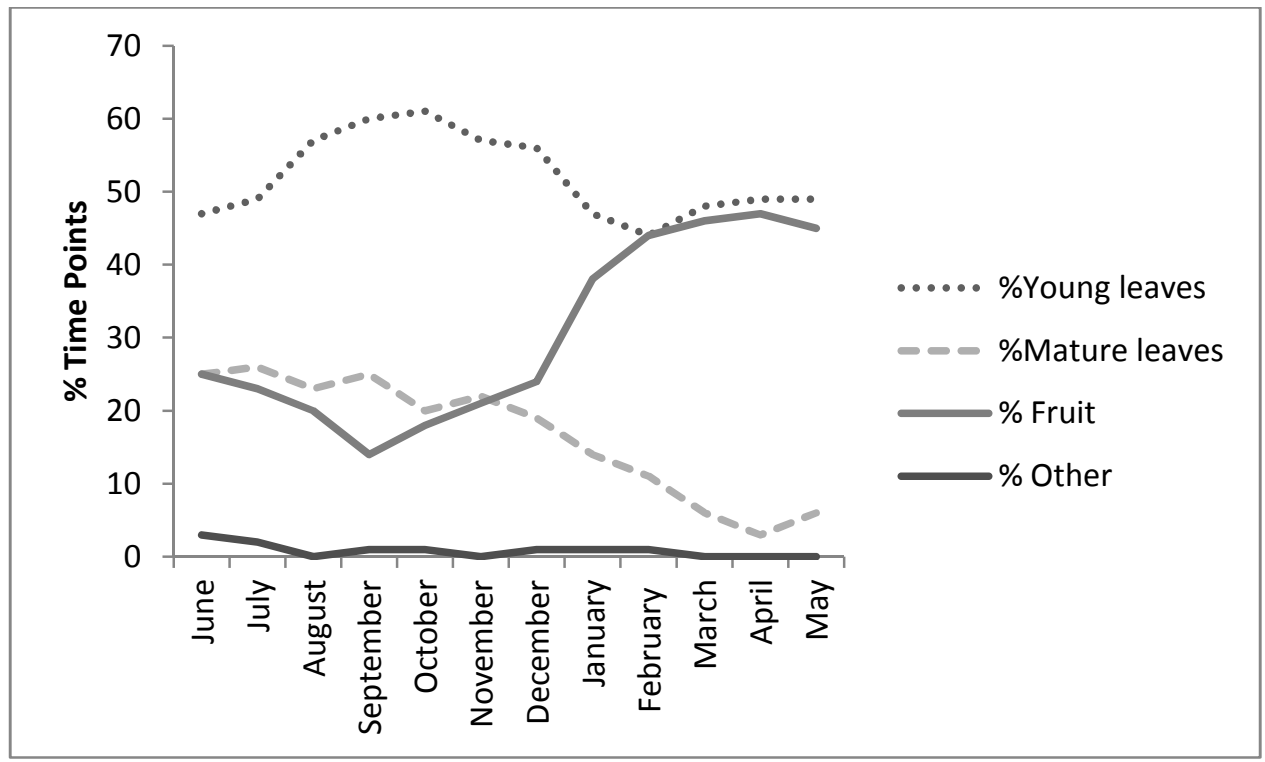

Figure 10. Seasonal variation in gibbon diet in Nam Kading NPA, Laos, June 2011- May 2012. 


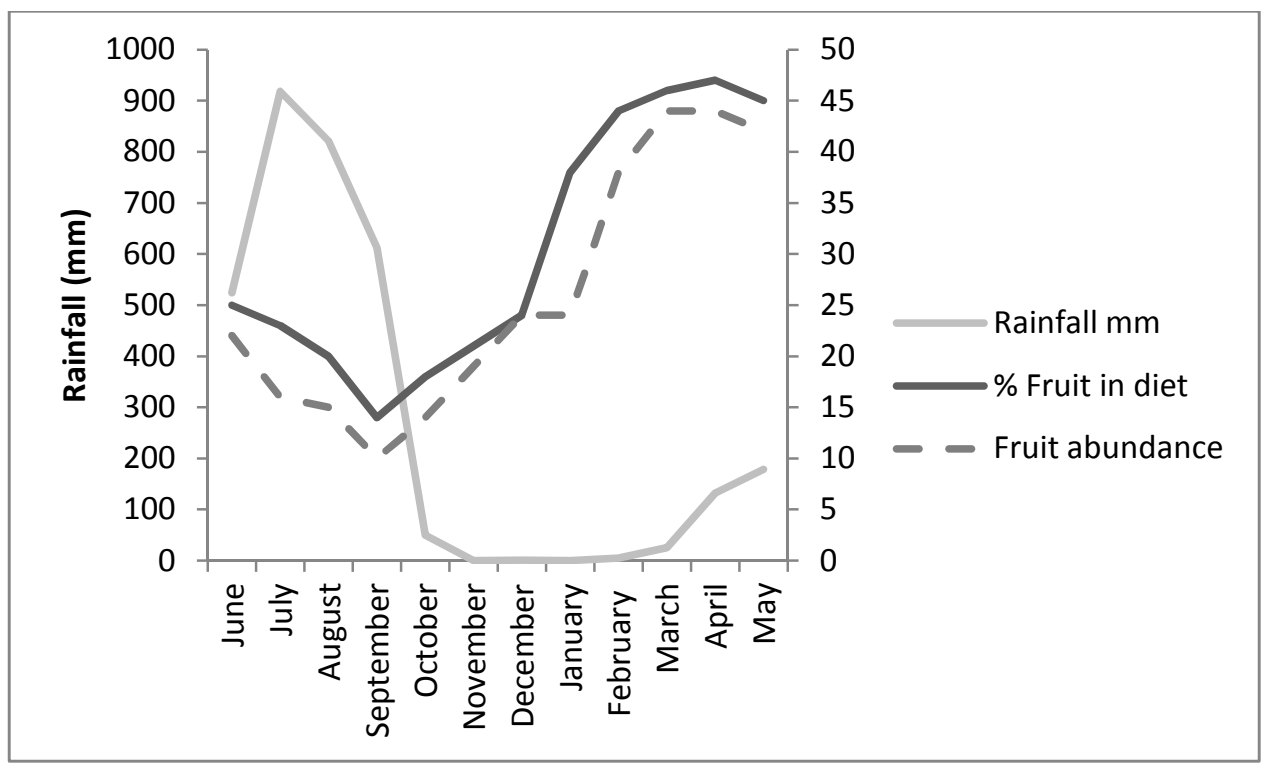

Figure 11. The monthly percentage of fruit consumed compared to the percentage of trees with fruit and rainfall in Nam Kading NPA, Laos, June 2011- May 2012.

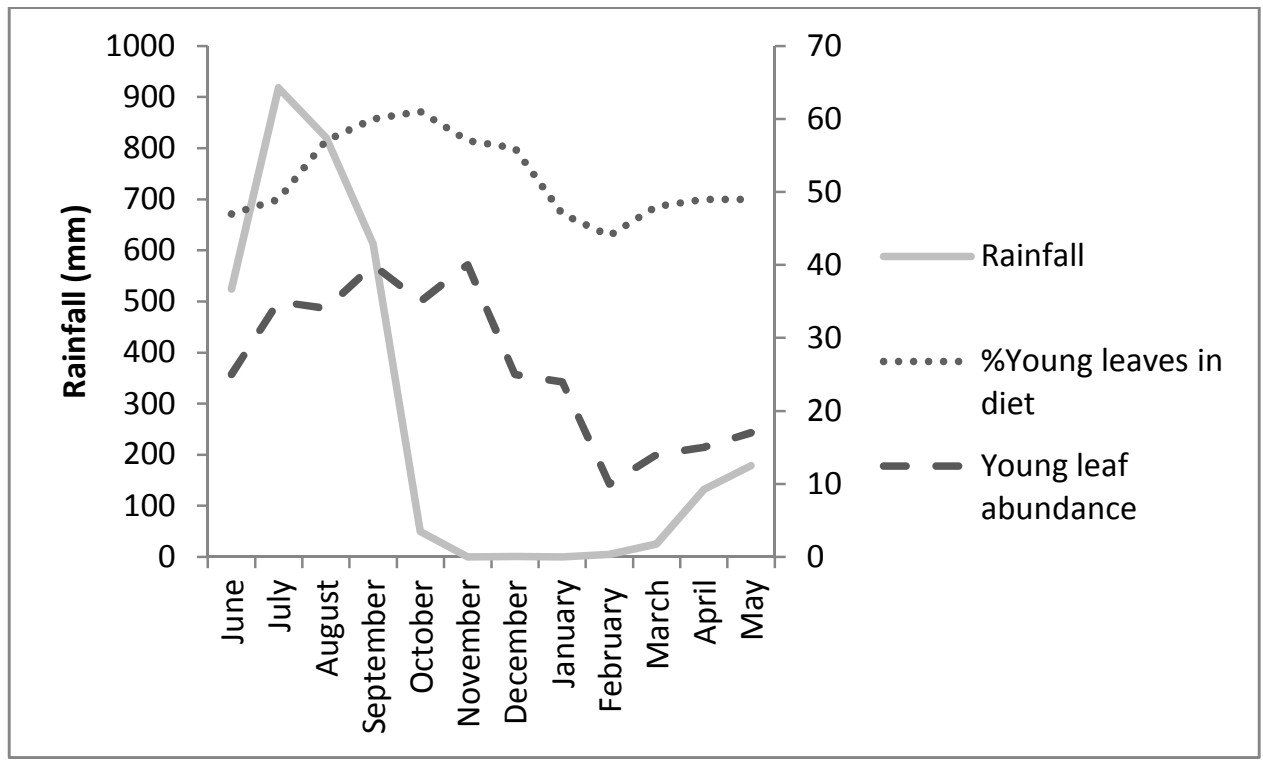

Figure 12. The monthly percentage of young leaves consumed compared to the percentage of trees with young leaves and rainfall in Nam Kading NPA, Laos, June 2011- May 2012. 


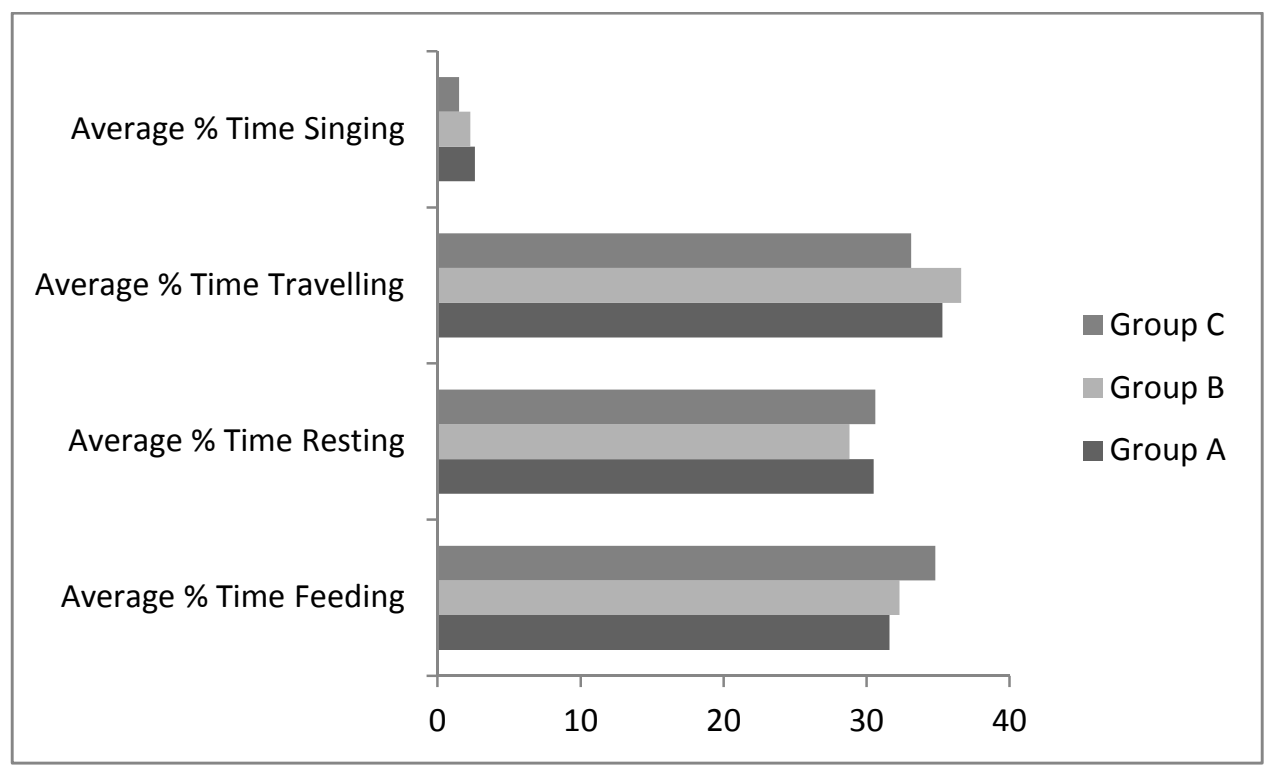

Figure 13. Time spent in different activities by gibbon groups $\mathrm{A}, \mathrm{B}$, and $\mathrm{C}$ in Nam Kading NPA, Laos, June 2011- May 2012.

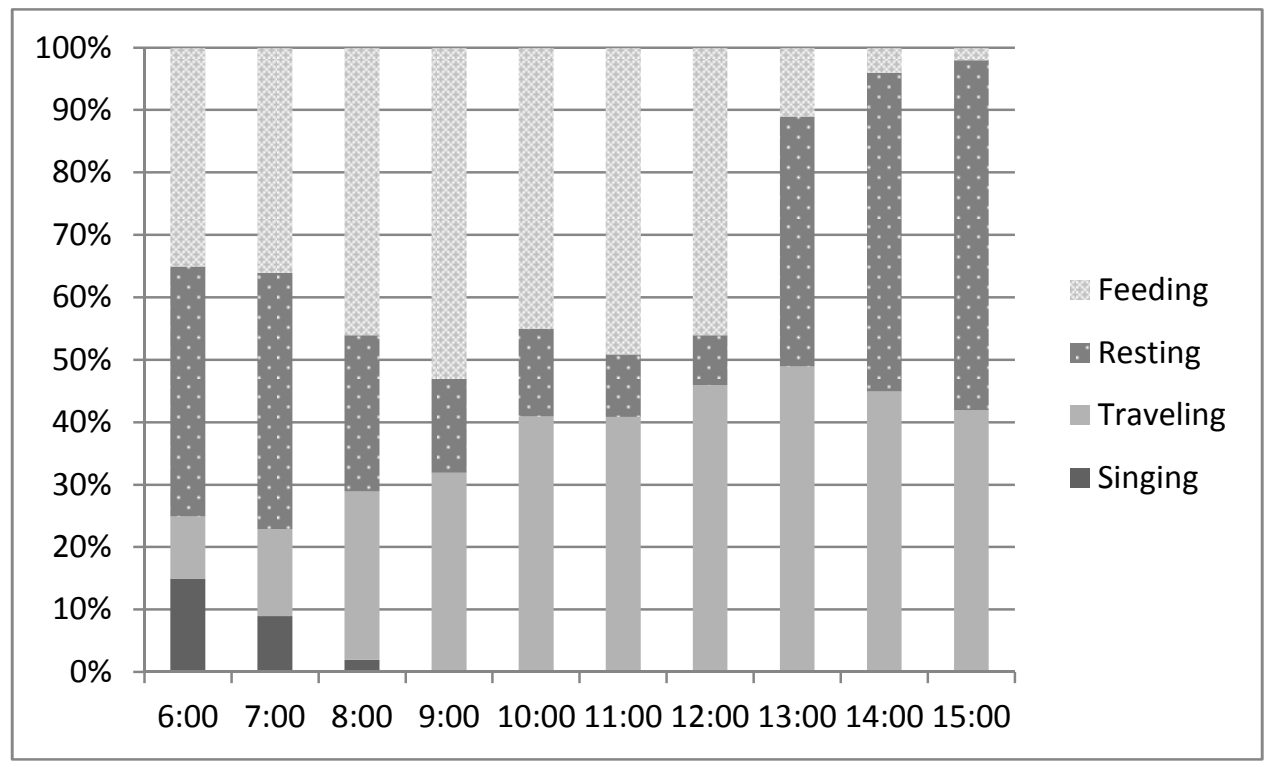

Figure 14. Daily activity rhythm of gibbons in Nam Kading NPA, Laos, June 2011- May 2012. 


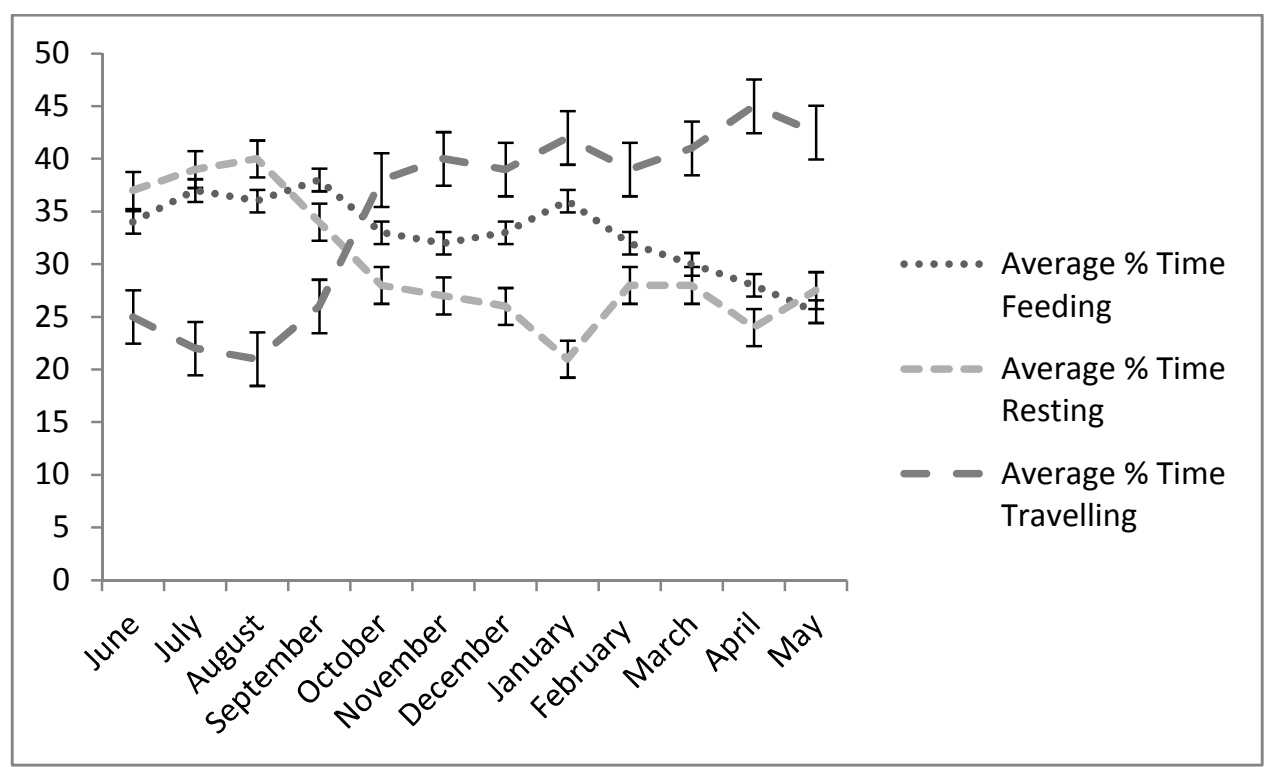

Figure 15. Time gibbons spent in different activities in Nam Kading NPA, Laos, June 2011May 2012.

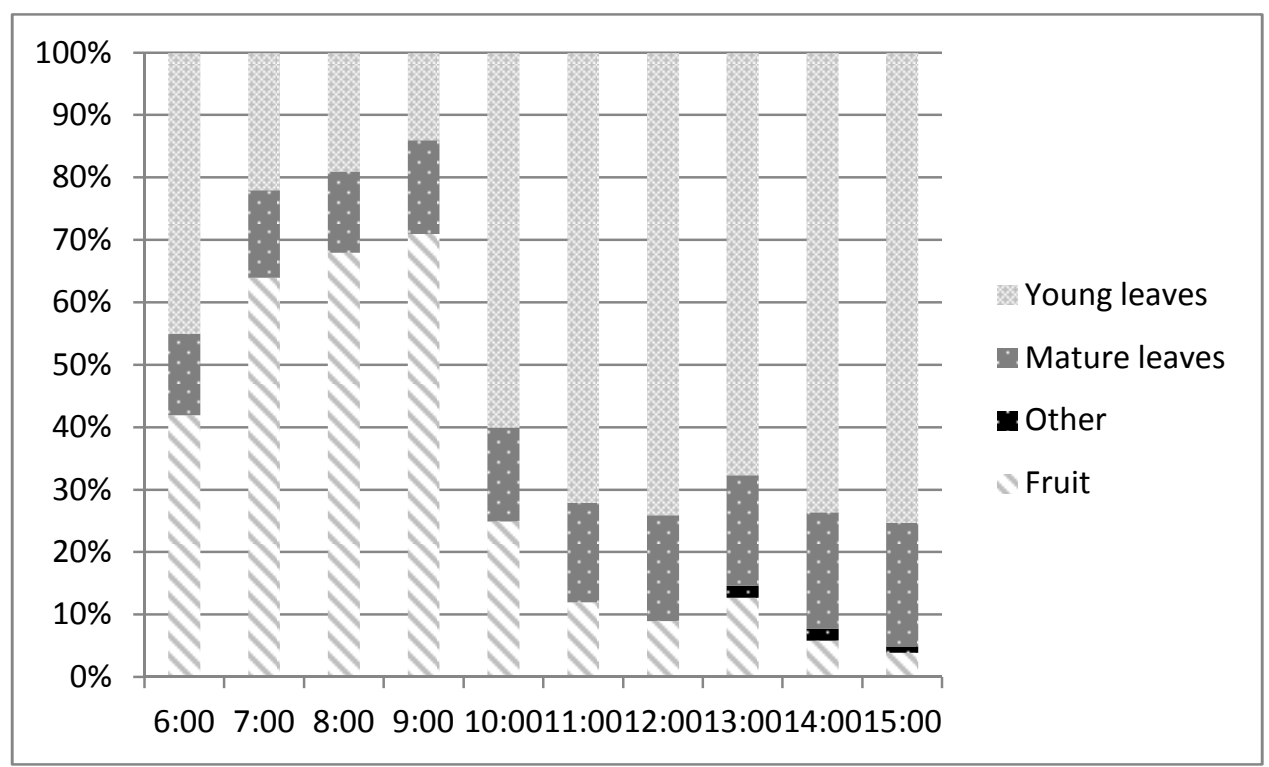

Figure 16. The percentage of fruit and leaves consumed over the course of the day by gibbons in Nam Kading NPA, Laos, June 2011- May 2012. 


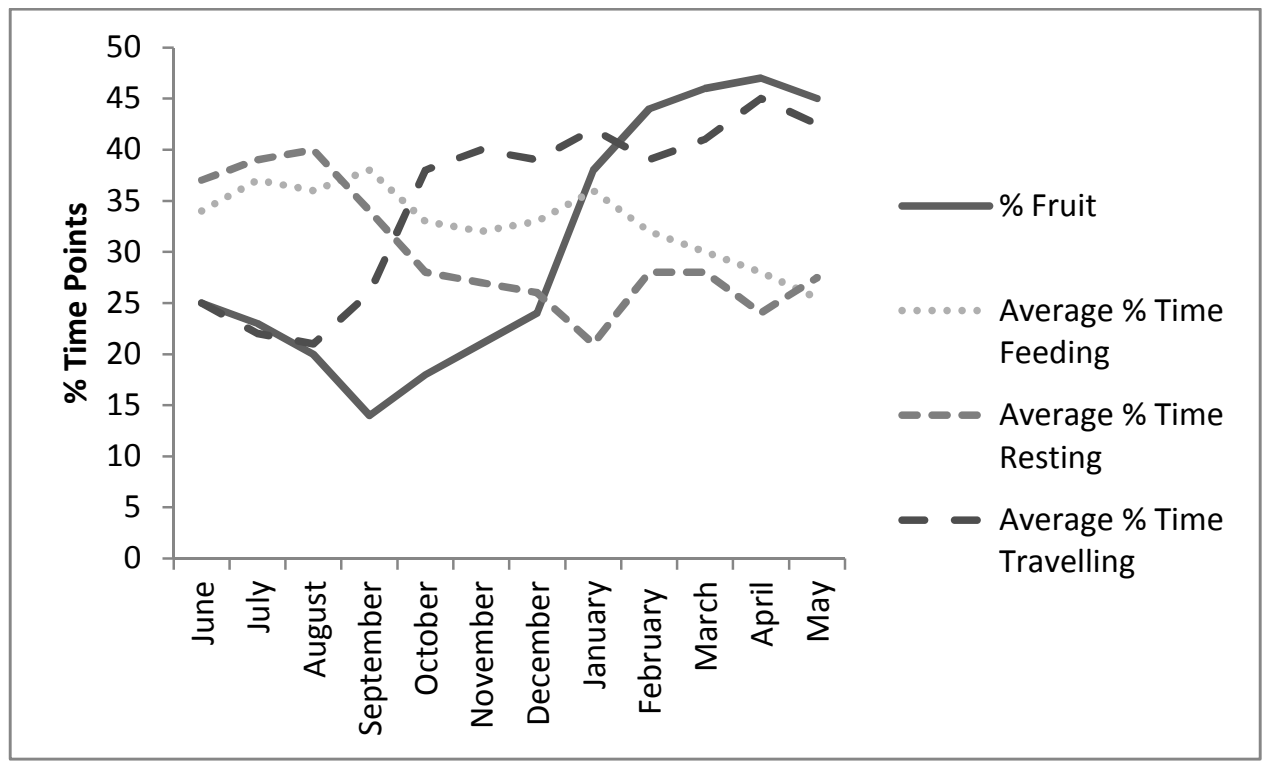

Figure 17. The percentage of fruit consumed by gibbons compared to the percent of time spent feeding, resting, and travelling in Nam Kading NPA, Laos, June 2011- May 2012.

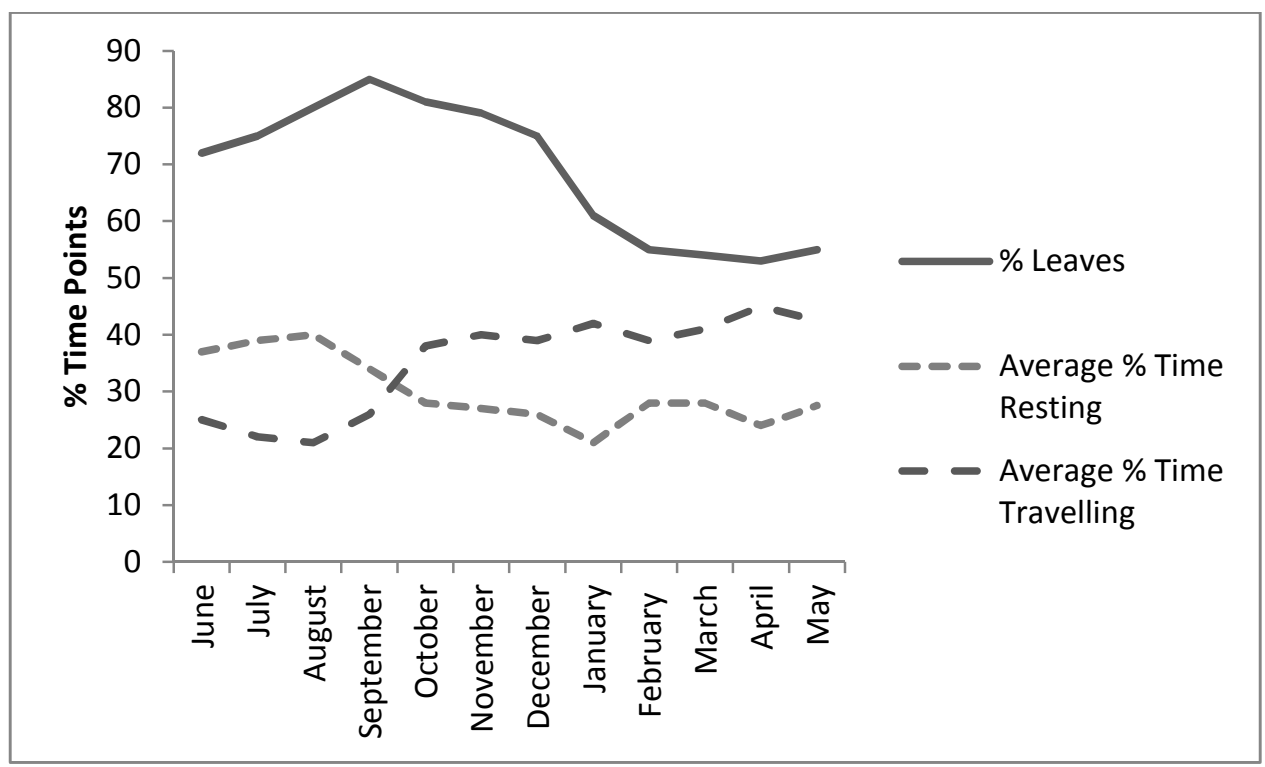

Figure 18. The percentage of leaves consumed by gibbons compared to the percentage of time spent resting and traveling in Nam Kading NPA, Laos, June 2011- May 2012. 


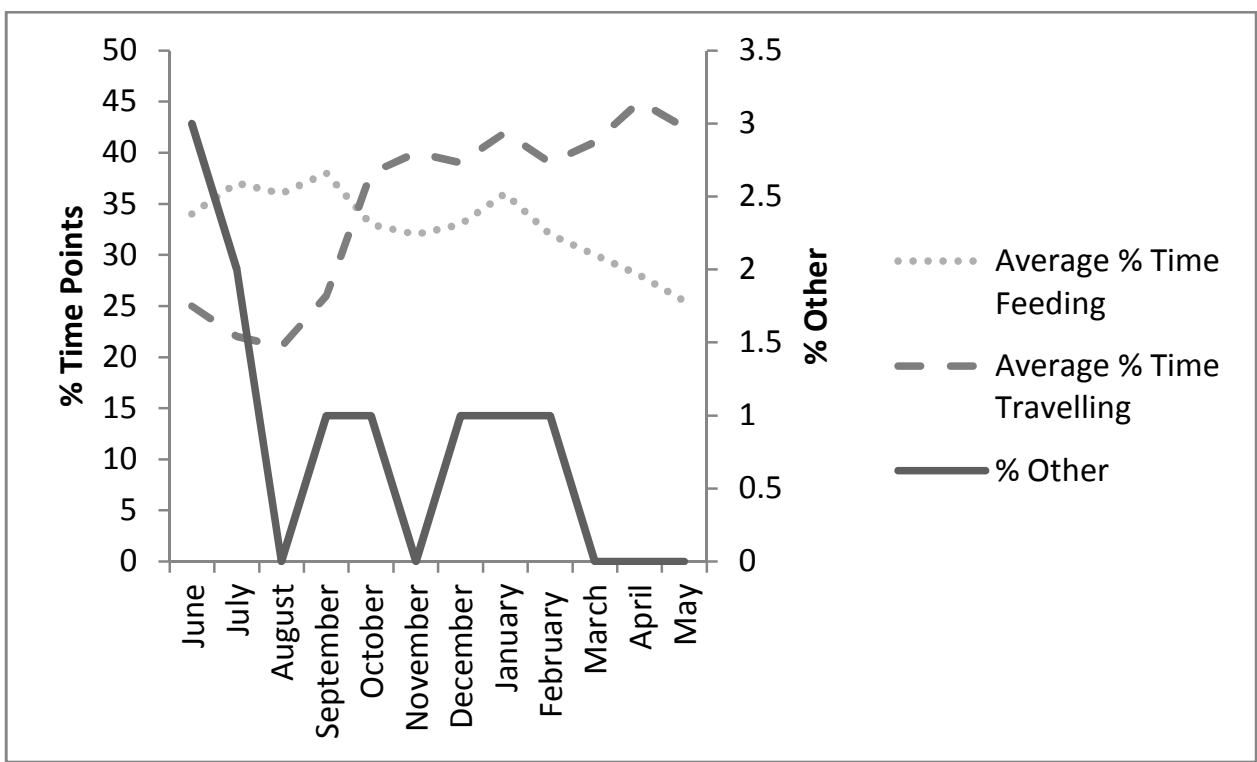

Figure 19. The percentage of other items consumed by gibbons compared to the percentage of time spent feeding and traveling in Nam Kading NPA, Laos, June 2011- May 2012.

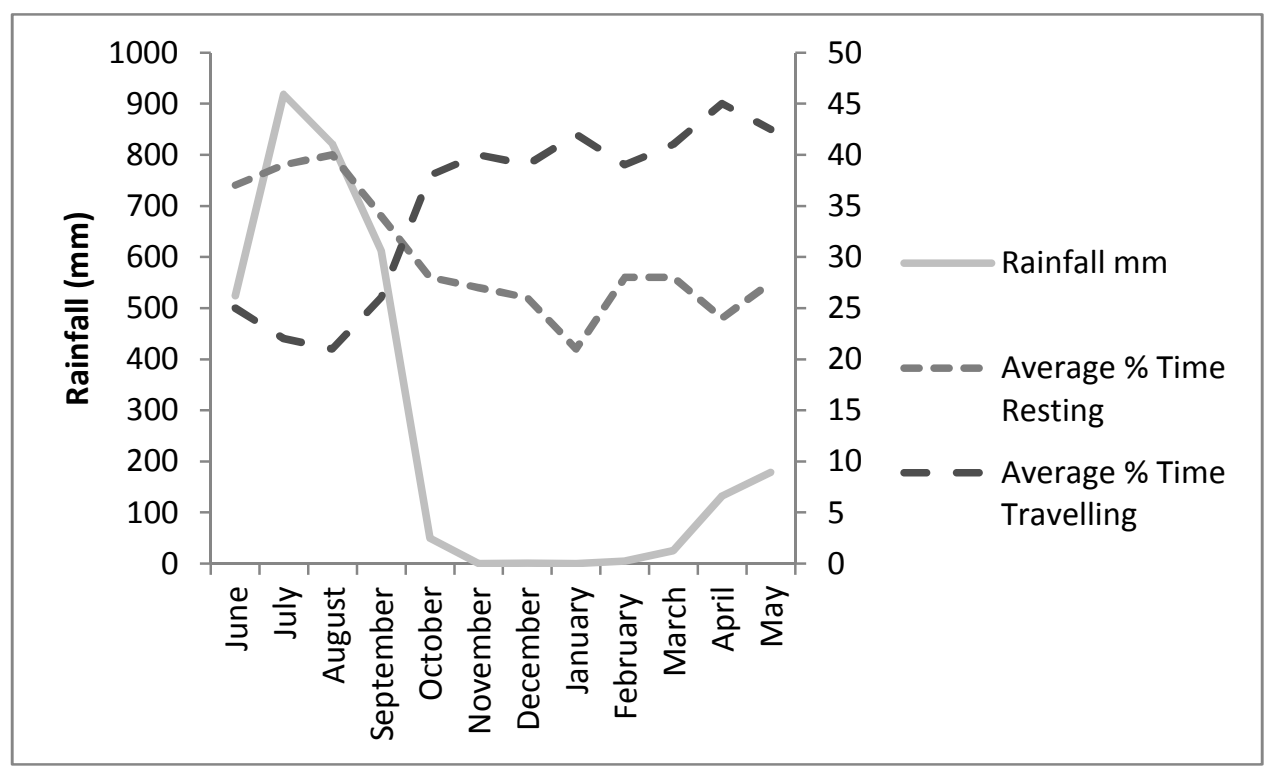

Figure 20. Rainfall compared to the percentage of time spent resting and traveling by gibbons in Nam Kading NPA, Laos, June 2011- May 2012. 


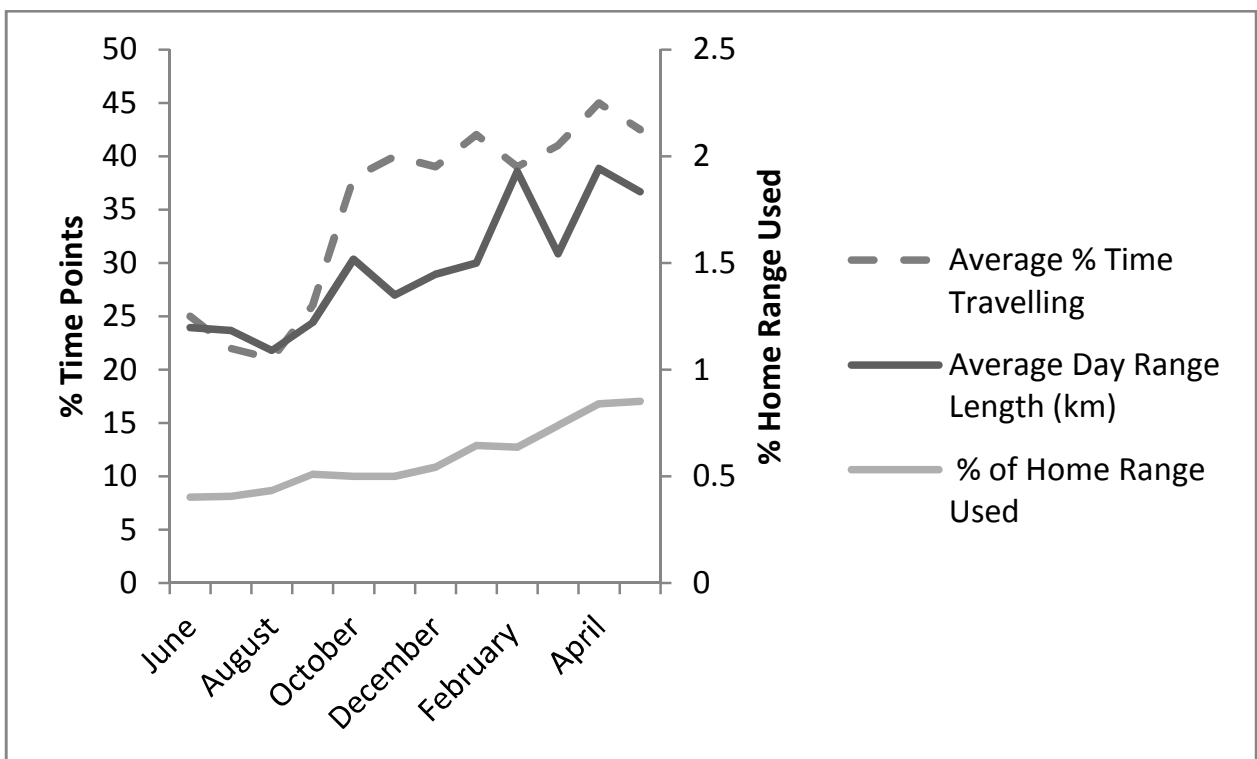

Figure 21. Average day range length and percentage of home range used by gibbons compared to the percentage of time spent traveling in Nam Kading NPA, Laos, June 2011May 2012.

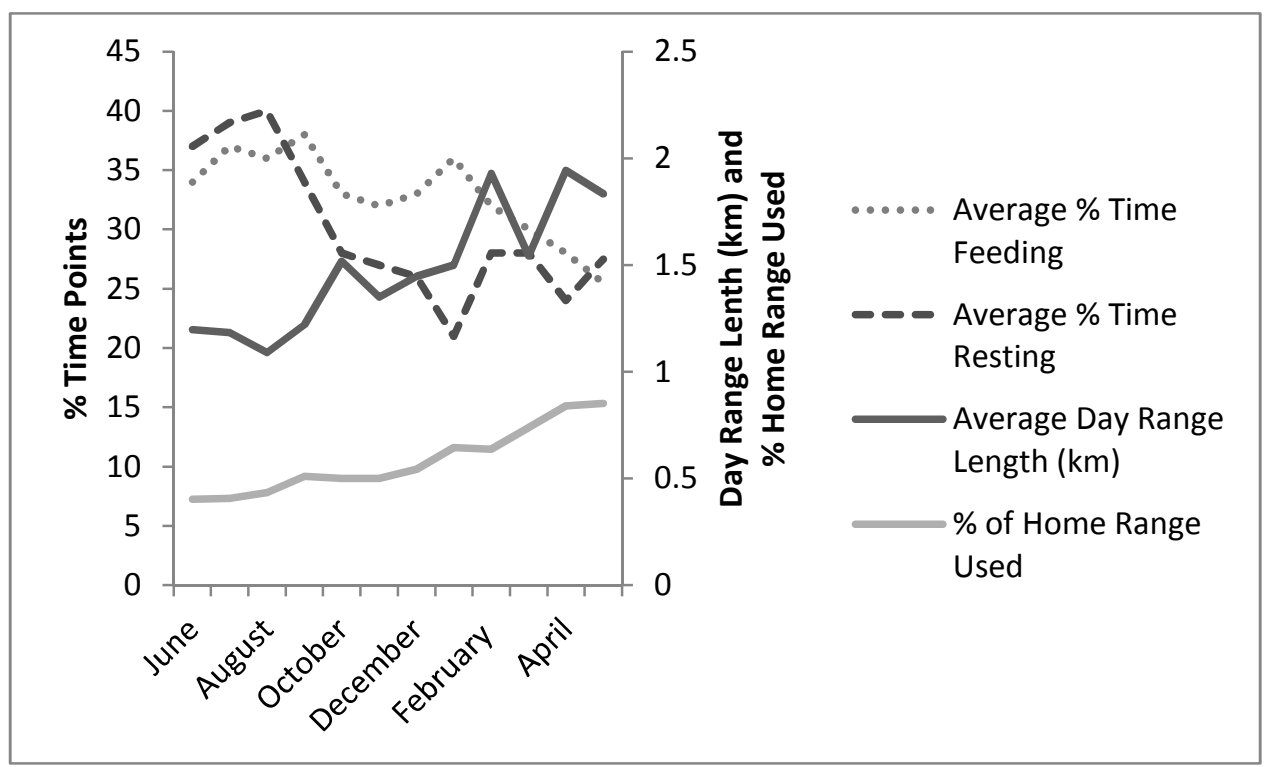

Figure 22. Average day range length and percentage of home range used by gibbons compared to the percentage of time spent resting and feeding in Nam Kading NPA, Laos, June 2011- May 2012. 


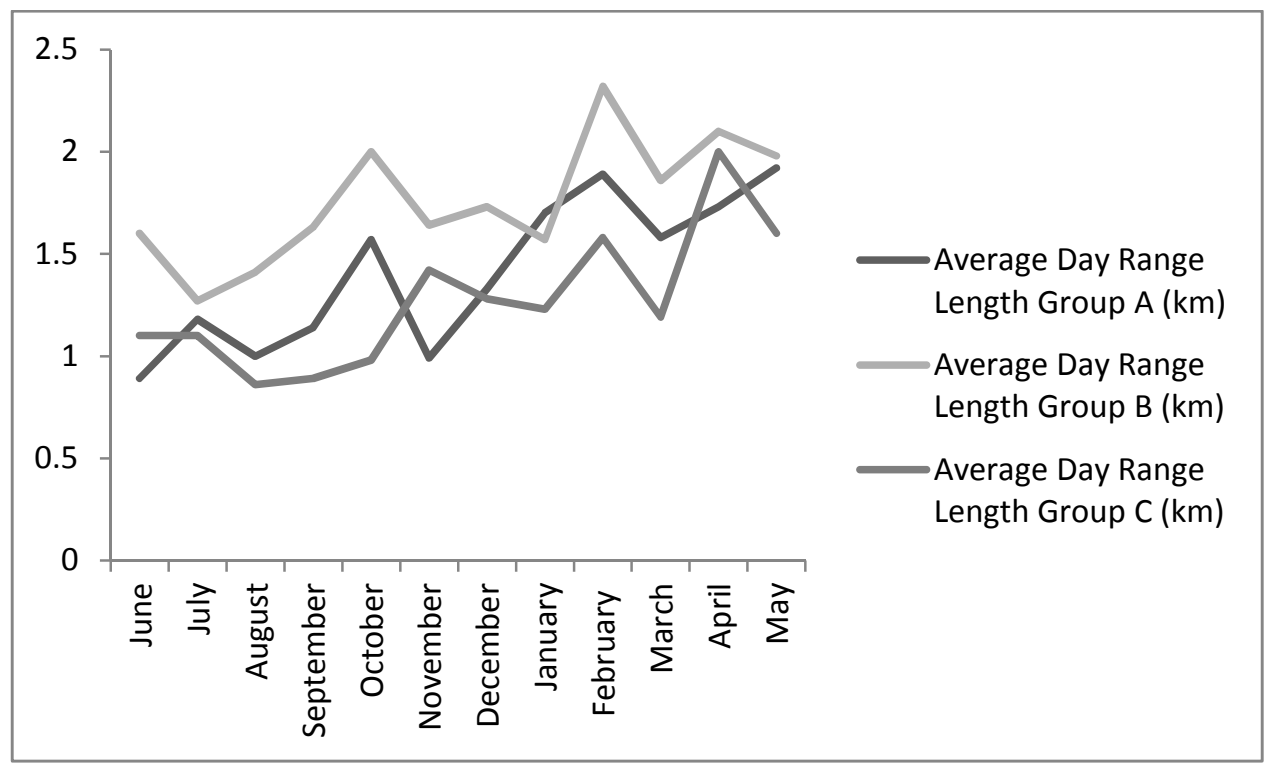

Figure 23. Average day range lengths $(\mathrm{km})$ across months for gibbon groups $\mathrm{A}, \mathrm{B}$, and $\mathrm{C}$ in Nam Kading NPA, Laos, June 2011- May 2012.

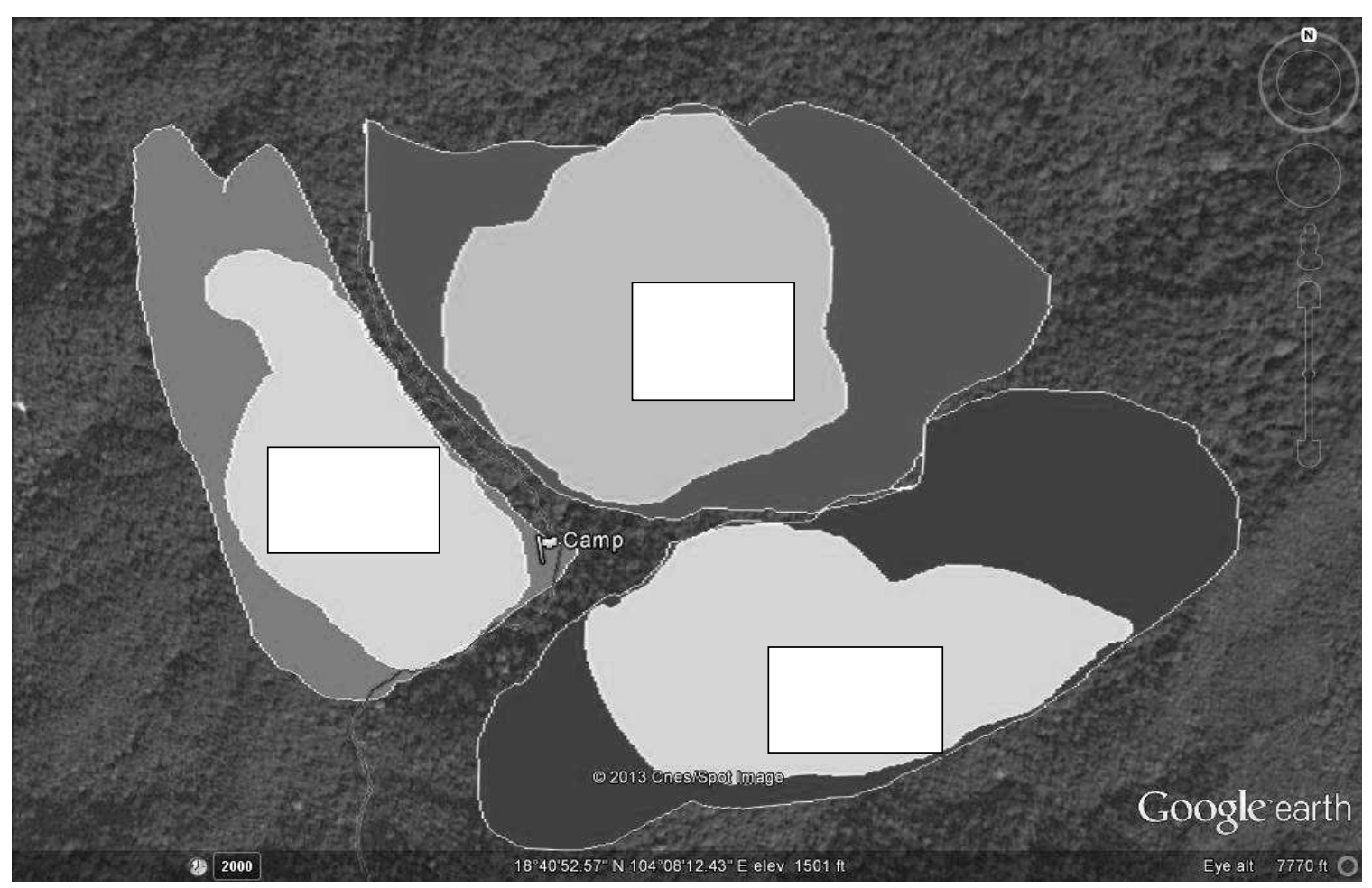

Figure 24. Home ranges for gibbon groups $\mathrm{A}, \mathrm{B}$, and $\mathrm{C}$ with an inset (light gray) of the total range area in the rainy season in Nam Kading NPA, Laos, June 2011- May 2012. 


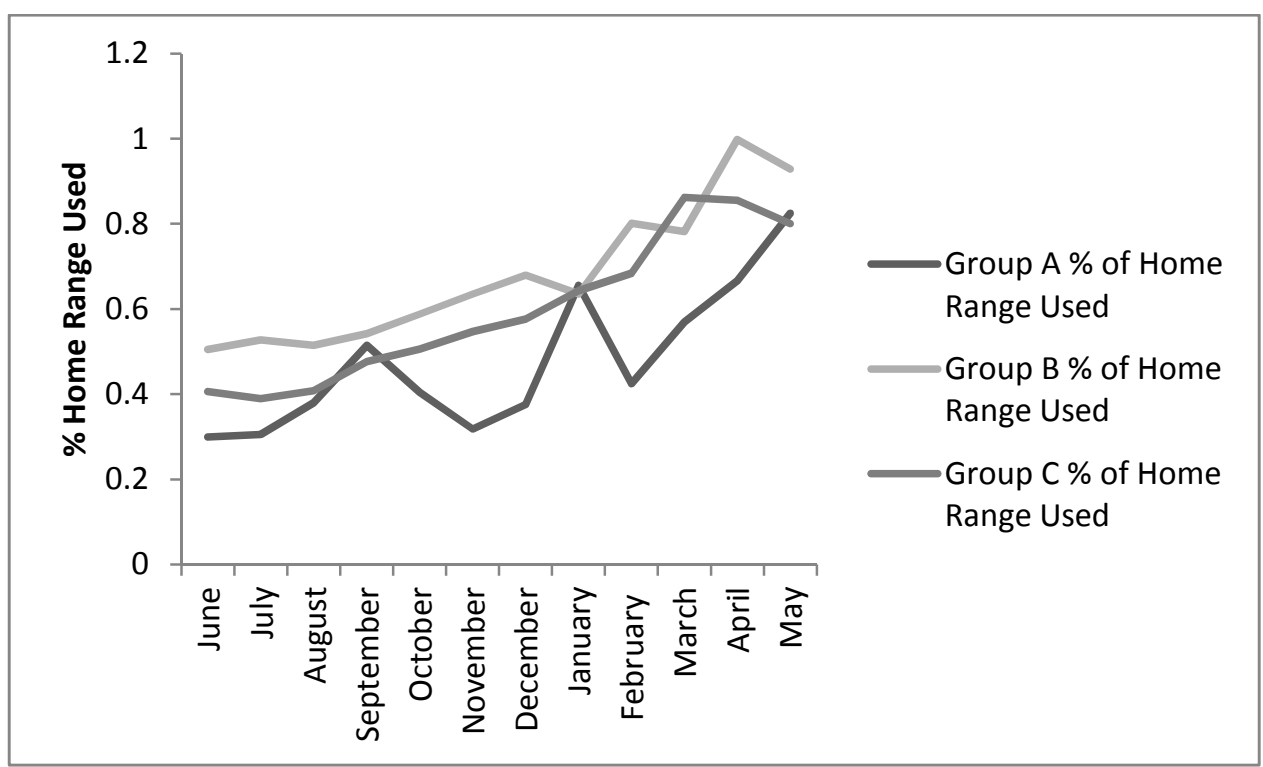

Figure 25. Proportion of total range used across months for gibbon groups $\mathrm{A}, \mathrm{B}$, and $\mathrm{C}$ in Nam Kading NPA, Laos, June 2011- May 2012.

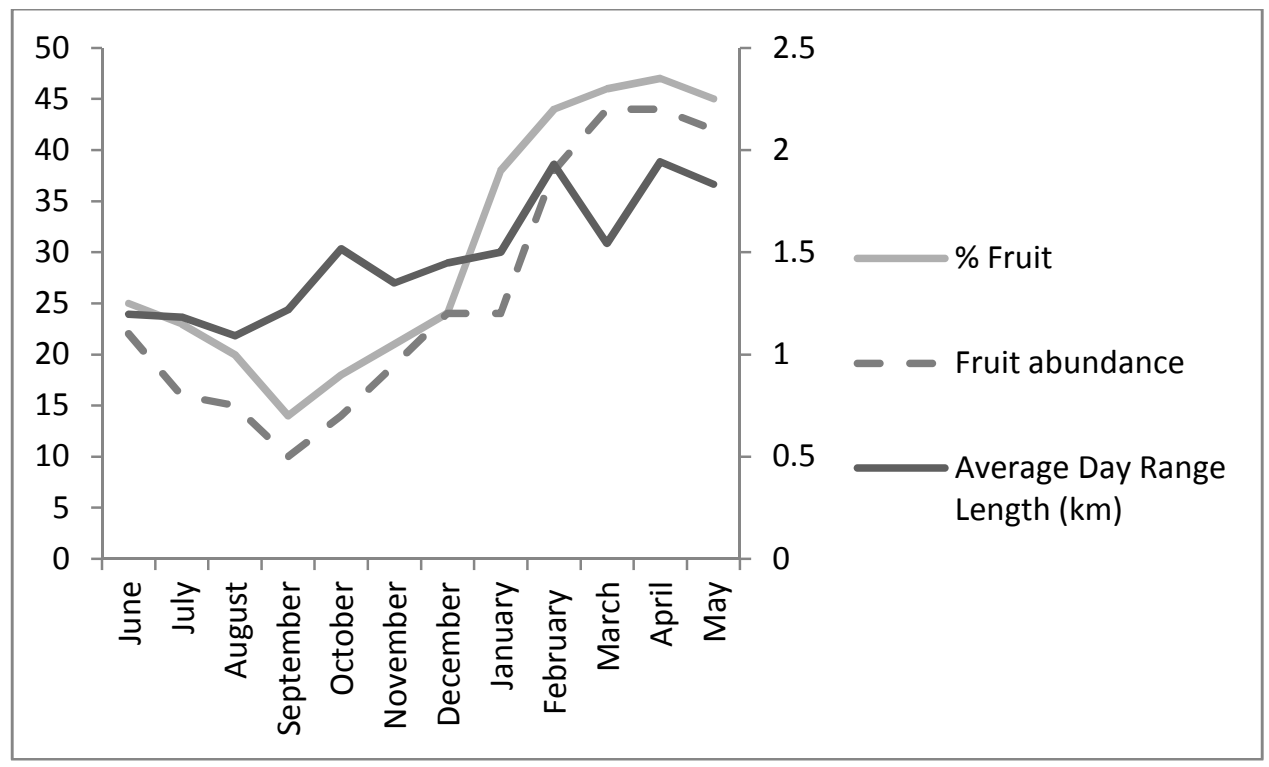

Figure 26. Gibbon day range lengths $(\mathrm{km})$ across months compared to fruit in diet and fruit abundance in Nam Kading NPA, Laos, June 2011- May 2012. 


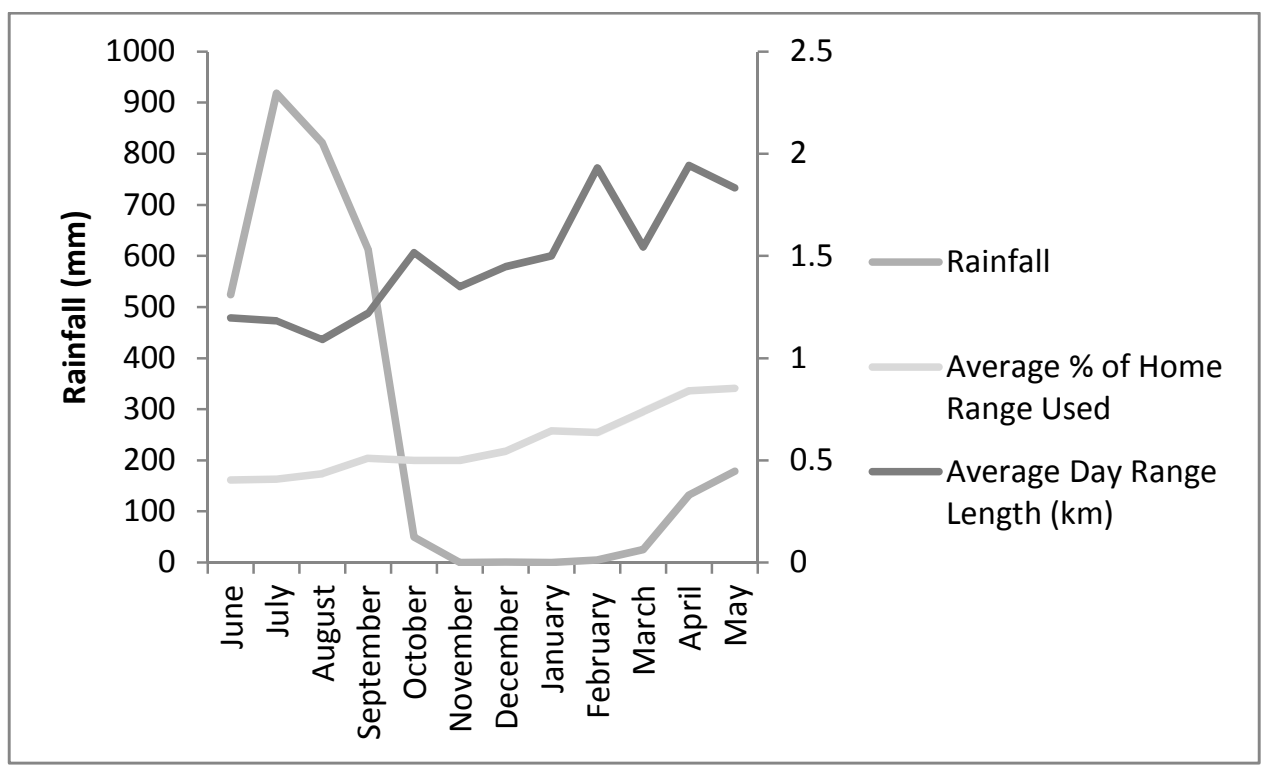

Figure 27. Gibbon day range lengths $(\mathrm{km})$ and home range use across months compared to rainfall in Nam Kading NPA, Laos, June 2011- May 2012.

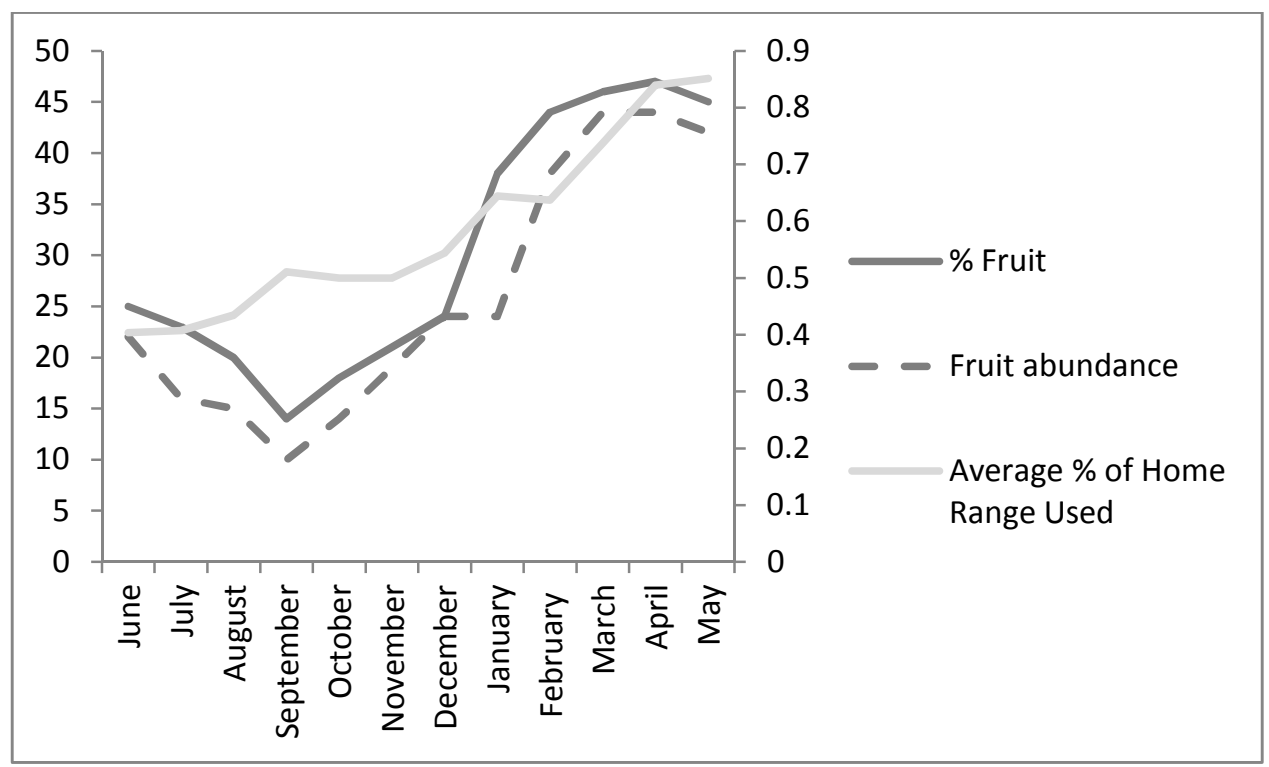

Figure 28. Gibbon home range use across months compared to fruit in diet and fruit abundance in Nam Kading NPA, Laos, June 2011- May 2012. 


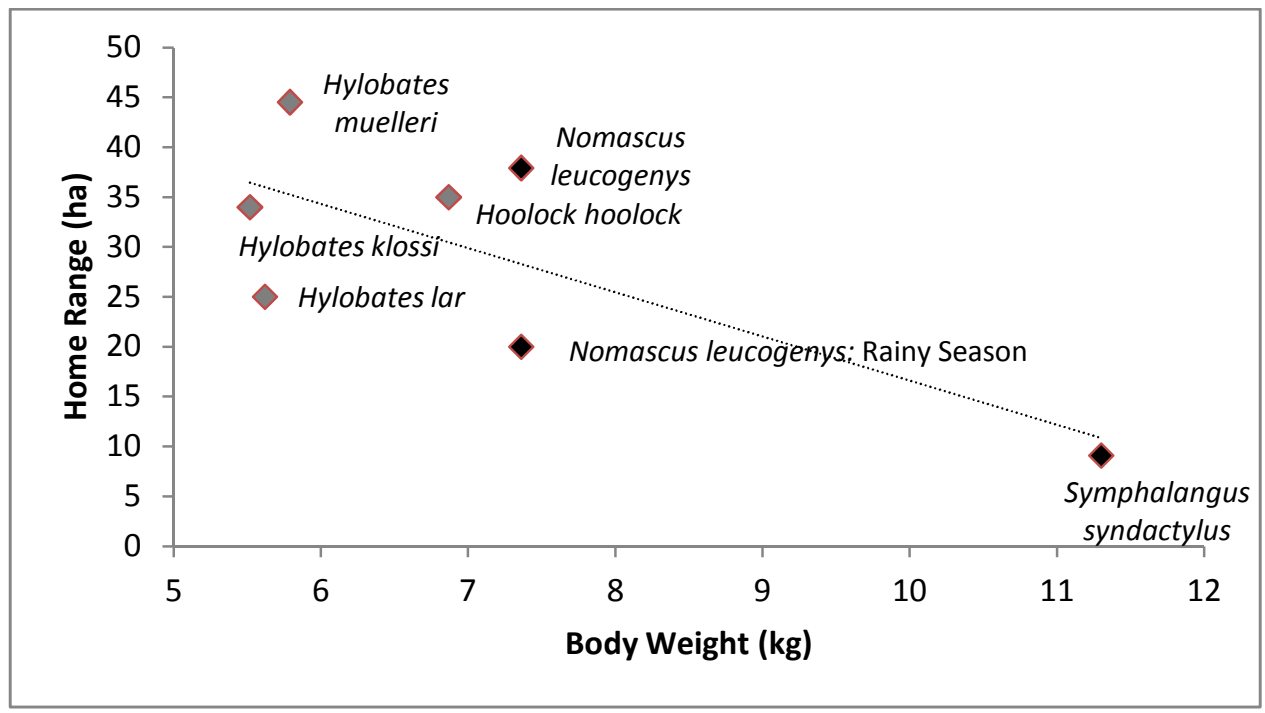

Figure 29. A bivariate plot of gibbon home range and body size. Folivores are represented in black and frugivores in gray. 


\section{References}

Ahsan, M.D.F (1994). Behavioral ecology of the Hoolock Gibbon (Hylobates hoolock) in Bangladesh, $\mathrm{PhD}$ thesis, University of Cambridge, Cambridge.

Ahsan, M. F. (2001). Socio-Ecology of the Hoolock Gibbon (Hylobates hoolock) in Two Forests of Bangladesh. In The Apes: Challenges for the 21st Century, Conference Proceedings, Chicago Zoological Society, 286-299.

Agetsuma, N., and Nakagawa, N. (1998). Effects of habitat differences on feeding behaviors of Japanese monkeys: Comparison between Yakushima and Kinkazan. Primates 39: 275-289.

Altmann, J. (1974). Observational study of behavior: sampling methods. Behaviour 32: 17-32.

Altmann, J., and Muruthi, P. (1988). Differences in daily life between semi-provisioned and wildfeeding baboons. American Journal of Primatology 15: 213-221.

Augspurger, C.K. (1982). A cue for synchronous flowering. In Leigh, E.G., Rand, S.J., Windsor, D.M. (eds.) The Ecology of a Tropical Forest. Smithsonian Institution Press, Washington D.C. pp. 135-150.

The Bangkok Post. (2011). Archives. Available from: www.bangkokpost.com/.

Bartlett, T.Q. (1999). Feeding and ranging behavior of the white-handed gibbons in Khao Yai National Park, Thailand. Ph.D. Dissertation, Department of Anthropology, Washington University.

Bartlett, T.Q. (2003). Intragroup and intergroup social interaction in white-handed gibbons. International Journal of Primatology 24: 239-59.

Bartlett, T.Q., (2007). The hylobatidae, small apes of Asia. In: Campbell, C.J., Fuentes, A., Mackinnon, K.C., Panger, M., Bearder, S.K. (Eds.), Primates in Perspective. Oxford University Press, New York, pp. 274-289.

Bartlett, T.Q. (2009). The gibbons of Khao Yai: Seasonal variation in behavior and ecology. Upper Saddle River, NJ: Pearson Prentice Hall.

Bauchop, T. (1978). Digestion of leaves in vertebrate arboreal folivores. In: The Ecology of Arboreal Folivores, ed. G.G. Montogomery. Smithsonian Institution Press. Washington D.C. 373-395.

Biegert, J. (1973). Dermatoglyphics in gibbons and siamangs. In: Rumbaugh, D. M. (ed.), Gibbon and siamang, vol. 2 (pp. 163-184). Basel: Karger.

Bleisch, W. V., and Chen, N. (1991). Ecology and behavior of wild black-crested gibbons (Hylobates concolor) in China with a reconsideration of evidence for polygyny. Primates 32: 539-548.

Bleisch, B., Geissmann,T., Manh Ha, N., Rawson, B. and Timmins, R.J. (2008). Nomascus leucogenys. In: IUCN 2011. IUCN Red List of Threatened Species

Bleisch, B., Geissmann, T., Timmins, R.J. and Xuelong, J. (2008). Nomascus concolor. In: IUCN 2011. IUCN Red List of Threatened Species. 
Bricknell, S. (1999). Hybridization and Behavioural Variation: A socio-ecological study of hybrid gibbons (Hylobates agilis albibarbis $x \mathrm{H}$. muelleri) in Central Kalimantan, Indonesia. $\mathrm{PhD}$ thesis, Australian National University, Canberra.

Brockelman, W.Y. (2011). Rainfall patterns and unpredictable fruit production in seasonally dry evergreen forest and their effects of gibbons. In: McShea, W.J., Davies, S.J., and Bhumpakphan, N. (eds). The ecology and conservation of seasonally dry forests in Asia. Washington D.C: Smithsonian Institution Scholarly Press.

Boinski, S. (1997). Habitat use by squirrel monkeys in a tropical lowaland forest. Folia Primatologica 49:151-67.

Burt, W.H. (1943). Territoriality and Home range concepts as applied to mammals. Journal of Mammalogy 24: 364-362.

Cannon, C.H., and Leighton, M. (2005). Comparative locomotor ecology of gibbons and macaques: Selection of canopy elements for crossing gaps. American Journal of Physical Anthropology 93, (4): 505-524.

Carpenter, C.R. (1940). A field study in Siam of the behavior and social relations of the gibbon (Hylobates lar). Comparative Psychology Monographs 16: 1-212.

Carpenter, C.R. (1958). Territoriality: A review of concepts and problems. In: Behavior and Evolution. Roe, A., Simpson, G.G. (eds.), pp. 224-250. New Haven: Yale University.

Chen, N. (1995). Ecology of the Black-Crested Gibbon (Hylobates concolor) in the Ailao Mt. Reserve, Yunnan, China. MA thesis, Mahidol University, Bangkok, Thailand.

Chivers, D.J. (1974). The siamang in Malaya. A field study of a primate in tropical rain forest. Contributions to primatology vol. 4. Karger, Basel and New York.

Chivers, D.J. (2001). The swinging singing apes: fighting for food and family in far-east forests. The Apes: Challenges for the $21^{\text {st }}$ century, Chicago Zoological Society, Brookfield Illinois, Brookfield Zoo.

Chivers, D.J. and Raemaekers, J. J. (1986). Natural and Synthetic Diets of Malayan Gibbons. In Primate Ecology and Conservation, J.G. Else and P.C. Lee (eds.), New York: Cambridge University Press.

Clutton-Brock, T.H. (1977). Primate Ecology. Academic Press, London, England

Clutton-Brock, T.H. (1977). Some aspects of intraspecific variation in feeding and ranging behavior in primates. In: Clutton-Brock, T.H. editor. Primate Ecology. New York: Academic Press. p. 539-556.

Coelho, A.M. (1986). Time and energy budgets. In: Mitchell G, Erwin J, editors. Comparative primate biology. Vol. 2A. Behavior, conservation, and ecology. New York: Alan R. Liss. p 141-166.

Coehlo, A.M., Bramblett, C.A., Quick, L.B., and Bramblett, S.S. (1976). Resource availability and population density in primates: A sociobioenergetic analysis of energy budgets of Guatemala howler and spider monkeys. Primates 17:63-80.

Conservation International. (2011). Largest Population of Critically Endangered Gibbon Discovered in Vietnam. Press Release. 
Cowlishaw, G. and Dunbar, R.I.M. (2000). Primate Conservation Biology. Chicago University Press: Chicago.

Darga, L.L., Baba, M. L., Weiss, M. L. and Goodman, M. (1984). Molecular perspectives on the evolution of the lesser apes. In: Preuschoft, H.; Chivers, D. J., Brockelman, W.Y. and Creel, N. (eds.), The lesser apes. Evolutionary and behavioural biology (pp. 448-466). Edinburgh: Edinburgh University Press.

Darga, L. L.; Goodman, M. and Weiss, M. L. (1973). Molecular evidence on the cladistic relationships of the Hylobatidae. In: Rumbaugh, D. M. (ed.), Gibbon and siamang, vol. 2 (pp. 149-162). Basel: Karger.

Davies, A.G., Oates, J.F. (1994). (eds.) Colobine Monkeys: Their Ecology, Behavior, and Evolution. Cambridge University Press, Cambridge.

Davies, A.G., Oates, J.F., Dasilva, G.L. (1999). Patterns of frugivory in three West African colobine monkeys. International Journal of Primatology 20 (3): 327-357.

Defler, T.R. (1995). The time budget of a group of wild woolly monkeys (Lagothrix lagotrica). International Journal of Primatology 16: 107-120.

Delacour, J. (1933). On the Indochinese gibbon. Journal of Mammology 14:71-72.

DiFiore A, Rodman P.S. (2001). Time allocation patterns of lowland woolly monkeys (Lagothrix lagotricha poeppigii) in a neotropical terra firma forest. International Journal of Primatology 22:449-480.

Doolittle, R. F.; Wooding, G. L.; Lin, Y. and Riley, M. (1971). Hominoid evolution as judged by fibrinopeptid structures. Journal of Molecular Evolution 1: 74-83.

Doran, D. (1997). Influence of seasonality on activity patterns, feeding behavior, ranging, and grouping patterns in chimpanzees. International Journal of Primatology 18: 183-206.

Duckworth, J. W., Salter, R. E. and Khounboline, K. (1999). Wildlife in Lao PDR: 1999 Status Report. IUCN/Wildlife Conservation Society/Center for Protected Area and Watershed Management, Vientiane.

Dunbar P. (1988). Maternal time budget of gelada baboons. Animal Behavior 36:970980.

Dunbar, R.I.M. (1992). Time: A hidden constraint on the behavioural ecology of baboons. Behavioral Ecology Sociobiology 31: 35-49.

Engkagul S. (1993). Flooding features in Bangkok and vicinity: Geographical approach. GeoJournal 31: 335-338.

Estrada, A., Juan-Solano, S., Martinez, A.T. and Coates-Estrada, R. (1999). Feeding and general activity patterns of a howler monkey troop living in a forest fragment at Los Tuxtlas, Mexico. American Journal of Primatology 48: 167-183.

Fan, P.F., Ni, Q.Y., Sun, G.Z., Huang, B., and Jiang, X.L. (2008). Seasonal Variations in the Activity Budget of Nomascus concolor jingdongensis at Mt. Wuliang, Central Yunnan, China: Effects of Diet and Temperature. International Journal of Primatology 29 (4): 1047-1057. 
Fan, P.F. and Jiang, X.L. (2008). Effects of food and topography on ranging behavior of black crested gibbon (Nomascus concolor jingdongensis) in Wuliang Mountain, Yunnan, China. American Journal of Primatology 70 (9): 871-878.

Fan, P.F. Jiang X. L., and Tian, C.C. (2009). The Critically Endangered black crested gibbon Nomascus concolor on Wuliang Mountain, Yunnan, China: the role of forest types in the species' conservation Oryx, 43(2): 203-208.

Fan, P.F., Ni, Q.Y., Sun, G.Z., Huang, B., Jiang, X.L., (2009). Gibbons under seasonal stress: the diet of the black crested gibbon (Nomascus concolor) on Mt. Wuliang, Central Yunnan, China. Primates 50: 37-44.

Fan, P.F. Hanlan, F., Zuofu, X., Wen, Z., Changyong, M., and Tao, H. (2010). Social Structure and Group Dynamics of the Cao Vit Gibbon (Nomascus nasutus) in Bangliang, Jingxi, China. Folia Primatologica 81:245-253.

Felsenstein, J. (1987). Estimation of hominoid phylogeny from a DNA hybridization data set. Journal of Molecular Evolution 26: 123-131.

Fleagle, J. G. (1984). Are there any fossil gibbons? In: Preuschoft, H.; Chivers, D. J.; Brockelman, W. Y. and Creel, N. (eds.), The lesser apes. Evolutionary and behavioural biology (pp. 431-447). Edinburgh: Edinburgh University Press.

Fleagle, J.G. (1999) Primate adaptation and evolution, second edition. Academic Press, San Diego and London.

Francis, C.M. (2008). A Guide to the Mammals of Southeast Asia. Princeton University Press.

Frankie, G. W., Baker, H.G. and Opler, P.A. (1974). Tropical Plant Phenoloy: applications for studies in community ecology. In Lieth, E.H. (ed.) Phenology and Seasonality Modeling. Springer-Verlag, Berlin, pp.287-296.

Freeland, W.J. and Janzen, D.H. (1974). Strategies in herbivory by mammals: the role of secondary plant compounds. American Naturalist 108: 269-289.

Ganzhorn, J.U. (1989). Primate species separation in relation to secondary compounds. Journal of Human Evolution 4(2):125-132.

Ganzhorn, J.U. (1992). Leaf chemistry and the biomass of folivorous primates in tropical forest. Oecologica 91: 540-547.

Ganzhorn, J.U. and Wright, P.C. (1994). Temporal patterns in primate leaf eating: the possible role of leaf chemistry. Folia Primatologica 63: 203-208.

Garber, P.A. (1987). Foraging strategies among living primates. Annual Review of Anthropology 16: 339-364.

Gaulin, S. and Konner, M.J. (1977). On the natural diet of primates, including humans. In: Wurtman, R. and Wurtman, J. Nutrition and the Brain, Vol 1. pp. 1-86. New York. Raven Press.

Gaulin, S. (1979). A Jarman/Bell Model of Primate Feeding Niches. Human Ecology 7: $1-20$.

Gaulin, S.J.C. and Gaulin, C.K. (1982). Behavioral ecology of Aloutta seniculus in Andean cloud forest. International Journal of Primatology 3:1-32. 
Geissmann, T. (1984). Inheritance of song parameters in the gibbon song, analyzed in 2 hybrid gibbons (Hylobates pileatus x H. lar). Folia Primatologica 42: 216-235.

Geissmann, T. (2002). Taxonomy and evolution of gibbons. In Soligo, C., Anzenberger, G., and Martin, R. D. (eds.), Anthropology and primatology into the third millennium: The Centenary Congress of the Zürich Anthropological Institute (Evolutionary Anthropology Vol. 11, Supplement 1), Wiley-Liss, New York, pp. 28-31.

Geissmann, T. (2003). Tape-recording primate vocalisations. In: Setchell, J.M., Curtis, D.J. Field and Laboratory Methods in Primatology. A Practical Guide. pp. 228238. Cambridge University Press.

Geissmann, T., Nguyen Xuan Dang, Lormée, N., and Momberg, F. (2000). Vietnam primate conservation status review 2000 - Part 1: Gibbons (English edition), Fauna and Flora International, Indochina Programme, Hanoi. 130 pp. ISBN 1-903703-034.

Geissmann, T. and Orgeldinger, M. (2000). The Relationship Between Duet Songs and Pair Bonds in Siamangs, Hylobates syndactylus. Animal Behaviour 60, 805-809.

Gittins, S. P. (1979). The Behaviour and Ecology of the Agile Gibbon (Hylobates agilis). Ph.D. dissertation, Cambridge University.

Gittins, S.P. (1982). Feeding and ranging in the agile gibbon. Folia Primatologica 38:3971.

Gittins, S.P. and Raemaekers, J.J. (1980). Siamang, lar and agile gibbons. In Chivers, D.J. (ed.), Malayan forest primates - Ten years' study in tropical rain forest, Plenum Press, New York, pp. 63-105.

Gittleman, J.L. and Harvey, P.H. (1982). Carnivore home-range size, metabolic needs and ecology. Behavioral Ecology and Sociobiology 10(1), pp 57-63.

Glander, K.E. (1978). Howling monkey feeding behaviour and plant secondary compounds: a study of strategies. In Montgomery, G.G. (ed.), The ecology of Arboreal Folivores, Smithsonian Institute Press, Washington D.C.

Glander, K.E. (1982). The impact of secondary compounds on primate feeding behaviour. Yearbook of Physical Anthropology 25: 1-18.

Glander, K. E., and Powzyk, J. A. (1995). Morphometrics of wild Indri indri and Propithecus diadema diadema, International Conference on the Biology and Conservation of Prosimians, London.

Goldman, D., Giri, P.R. and O'Brien, S.J. (1987). A molecular phylogeny of the hominoid primates as indicated by two-dimensional protein electrophoresis. Proceedings of the National Academy of Sciences, USA 84: 3307-3311.

Goldizen, A.Q., Terbough, J., Cornejo, F., Porras, D.T., Evans, R. (1988). Seasonal food shortage, weight loss, and the timing of births in saddle-backed tamarins (Sanguinus fuscicollis). Journal of Animal Ecology 57:893-901.

Goodall, J. (1986). The chimpanzees of Gombe: Patterns of Behavior. Belknap Press.

Greenburg, R and Gradwohl, J. (1986). Constant density and stable territoriality in some tropical insectivorous birds. Oecologia 69: 4, pp 618-625. 
Groves, C. P. (1989). A theory of human and primate evolution. Oxford: Clarendon Press.

Groves, C.P. (2005). Order Primates. In: Wilson, D.E., Reeder, D.M., (eds.) Mammal species of the world. $3^{\text {rd }}$ edition. Baltimore, MD: John Hopkins University press: 111-184.

Groves, C. P. (2005). Subfamily Colobinae. In Wilson, D. E.; Reeder, D. M. Mammal Species of the World (3rd ed.). Johns Hopkins University Press. pp. 167-178

Groves, C.P. and Wang, A. (1990). The gibbons of the subgenus Nomascus. Zoological Research 11:147-154.

Gursky S.L. (2007). The spectral tarsier. Upper Saddle River (NJ): Pearson Prentice Hall. 229p.

Haimoff, E. H., Yang, X.-J., He, S.-J., and Chen, N. (1987). Preliminary observations of wild black-crested gibbons (Hylobates concolor concolor) in Yunnan Province, People's Republic of China. Primates 28: 319-335.

Hamilton, R.A., and Galdikas, B.M.F. (1994). A preliminary study of food selection by the orangutan in relation to plant quality. Primates 35 (3):256-263.

Harvey, P.H. and Clutton-Brock, T.H. (1981). Primate Home Range Size and Metabolic Needs. Behavior Ecology Sociobiology 8:151-155.

Hanya, G. (2004). Seasonal variations in the activity budget of Japanese macaques in the coniferous forest of Yakushima: Effects of food and temperature. American Journal of Primatology 63: 165-177.

Hellekant, G.; Dubois, G.; Geissmann, T.; Glaser, D. and Van Der Weel, H. (1990). Taste responses of chorda tympani proper nerve in the white-handed gibbon (Hylobates lar). In: Døving, K. B. (ed.), ISOT X. Proceedings of the Tenth International Symposium on Olfaction and Taste held at the University of Oslo, Norway, July 1620, 1989 (pp. 115-131). Oslo: GCS A.S.

Hemingway, C.A. (1996). Morphology and phenology of seeds and whole fruit eaten by Milne-Edwards“ sifaka in Ranomafana National Park, Madagascar. International Journal of Primatology 17:637-659.

Hemingway, C.A. (1998). Selectivity and varibility in the diet of Mine-Edwards' Sifaka (Propithecus diadema edwardsi): Implications for folivory and seed-eating. International Journal of Primatology 19 (2): 355-376.

Hemingway, C.A. and Bynum, N. (2005). The influence of seasonality on primate diet and ranging. In: Brockman, D.K. and van Schaik, C.P. Seasonality in Primates: Studies of living and extinct humans and non-human primates. Cambridge: Cambridge University Press.

Hill, W.C.O. (1966). Primates, comparative anatomy and taxonomy. Vol. 6. University Press.

Hladik, C.M. (1978). Adaptive strategies of primates in relation to leaf-eating. In: The Ecology of Arboreal Folivores, ed. G.G. Montogomery. Smithsonian Institution Press. Washington D.C. 373-395.

Houston, A.I., McNamara, J.M. (Eds.), (1999). Models of Adaptive Behaviour: An Approach Based on States. Cambridge University Press, Cambridge, UK. 
Huang C, Wei F, Li M, Li Y, Sun R. (2003). Sleeping cave selection, activity pattern and time budget of white-headed langurs. International Journal of Primatology 24:813824.

Huchon, D. Chevret, P. Jordan, U. Kilpatrick, C. William; R., Vincent; Jenkins, P. D.; Brosius, Jürgen and Schmitz, Jürgen (2007). Multiple molecular evidences for a living mammalian fossil. PNAS 104(18): 7495-7499.

$\mathrm{Hu}, \mathrm{Y} ., \mathrm{Xu}, \mathrm{H}$. , and Yang, D. (1989). [The studies on ecology in Hylobates leucogenys]. Zoological Research 10(Supplement): 61-67 (Chinese text, English summary).

$\mathrm{Hu}, \mathrm{Y}$., Xu, H., and Yang, D. (1990). [Feeding ecology of the white-cheeked gibbon (Hylobates concolor leucogenys)]. Acta Ecologica Sinica 10: 155-159 (Chinese text, English summary).

Irwin, M.T. (2008). Feeding ecology of Propithecus diadema in Forest Fragments and Continuous Forest. International Journal of Primatology 29 (1): 95-115.

Irwin, M.T. (2008). Diademed sifaka (Propithecus diadema) ranging and habitat use in continuous and fragmented forest: higher density but lower viability in fragments? Biotropica 40 (2): 231-240.

Isabirye-Basuta G. (1989) Feeding ecology of chimpanzees in the Kibale Forest, Uganda. In: Heltne PG, Marquardt L.A., editors. Understanding chimpanzees. Cambridge, (MS): Harvard University Press. p 116-27.

Isbell, L.A., and Young, T.P. (1993). Social and ecological influences on activity budgets of vervet monkeys, and their implications for group living. Behavioral Ecology Sociobiology 32: 377-385.

Islam, M.A. and Feeroz, M.M (1992). Ecology of Hoolock gibbon of Bangladesh. Primates 33 (4): 451-464.

IUCN Red List. (2011). IUCN red list. Available online at: http://iucnredlist.org

Johnston, L. (2011). Laos NT2 trip report. Washington D.C. USAID.

Julliot, C. (1996). Fruit choice by red howler monkeys (Aloutta seniculus) in a tropical rain forest. American Journal of Primatology 40: 261-282.

Jungers, W.L. (1984). Scaling the Hominoid locomotor skeleton with special reference to lesser apes. In The Lesser Apes: Evolutionary and Behavioural Biology, ed. H. Preuschoft, D. J. Chivers, W.Y. Brockelman, and N. Creel, 228-241. Edinburgh: Edinburgh University Press.

Kappeler, M. (1981). The Javan Silvery Gibbon (Hylobates moloch). Ph.D. Dissertation, University Basel, Basel.

Kappeler, M. (1984). Diet and Feeding Behavior of the Moloch Gibbon. In: H. Preuschoft, D. J. Chivers, W.Y. Brockelman, and N. Creel (eds.) The Lesser Apes: Evolutionary and Behavioural Biology 228-241. Edinburgh: Edinburgh University Press.

Kay, R.N.B. and Davies, A.G. (1994). Digestive physiology. In: Colobine Monkeys Their Ecology, Behavior, and Evolution. Eds. Davies, A.G. and Oates, J.F. Cambridge University Press, New York. pp. 229-249. 
Keeling, M.E. and McClure, H.M. (1972). Clinical management, diseases, and pathology of the gibbon and siamang. In Gibbon and Siamang, ed. Rumbaugh, D.M. 207-249. Karger, Basel.

Kinzey, W.G. (1977). Diet and feeding behavior of Callicebus torquatus. In: CluttonBrock, T.H. (ed.) Primate Ecology: Studies of Feeding and Ranging behavior in lemurs, monkeys, and apes. London: Academic Press.

Kool, K.M. (1992). Food selection by the silver leaf monkey,Trachypithecus auratus sondaicus, in relation to plant chemistry. Oecologia 90 (Issue 4): 527-533.

Konrad, R., and Geissmann, T. (2006). Vocal diversity and taxonomy of the crested gibbons (genus Nomascus) in Cambodia. International Journal of Primatology 27: 713-745.

Kurup, G.U., and Kumar, A. (1993). Time budget and activity patterns of the lion-tailed macaque. International Journal of Primatology 14: 27-39.

Lan, D.Y. (1989). Preliminary study on the group composition, behavior, and ecology of black gibbons in southwest Yunnan. Zoological Research 10 (Supplement): 119126.

Leighton, D.R. (1987). Territoriality and Monogamy. In Primate Societies, ed. B.B. Smuts, D.L.Cheney, R.M. Seyfarth, R.W. Wrangham, and T.T. Strushaker, 135145. Chicago, Chicago University Press.

Leighton, M., and Leighton, D. R. (1983). Vertebrate responses to fruiting seasonality within a Bornean rain forest. In Sutton, S. L., Whitmore, T. C., and Chadwick, A. C. (eds.), Tropical Rainforest: Ecology and Management, Blackwell Scientific, Oxford, pp. 181-196.

Leighton, M. (1993). Modeling dietary selectivity by Bornean orangutans: Evidence for integration of multiple criteria in fruit selection. International Journal of Primatology 14 (2)257-313.

Li, Z.Y. and Rogers, E. (2004). Habitat quality and activity budgets of white-headed langurs in Fusui, China. International Journal of Primatology 25: 41-54.

Lippold, L.K., Vu Ngoc Thanh, Le Vu Khoi, Le Khac Quyet, Van Ngoc Thinh. (2011). A primate survey in Chu Mom Ray National Park, central Highlands, Vietnam with special reference to douc langur species (Pygathrix ssp). Journal of Natural Science Technology 27: 48-53.

MacArthur, R. H. and Pianka, E. R. (1966). On the optimal use of a patchy environment. American Naturalist, 100

MacKinnon, J. and MacKinnon, K (1977). The formation of a new gibbon group. Primates 18 (3): 701-708.

MacKinnon, J. and MacKinnon, K. (1980). Niche differentiation in a primate community. In: Chivers, D.J. (Ed.): Malayan forest primates: Ten years' study in tropical rain forest, pp. 167-190. Plenum Press, New York and London.

Maisels, F. (1993). Gut passage rate in guenons and mangabeys: another indicator of a flexible feeding niche? Folia Primatologica 61: 35-37.

Martin, P., and P. Bateson. (1986). Measuring Behavior: An Introductory Guide. Cambridge: Cambridge University Press. 
Matsumoto-Oda, A and Oda, R (1998). Changes in the activity budget of cycling female chimpanzees. American Journal of Primatology 46: 157-166.

McConkey, K.R., Aldy, F., Ario, A., and Chivers, D.J. (2002). Selection of fruit by gibbons (Hylobates muellerri x agilis) in the rain forests of central Borneo. International Journal of Primatology 23 (1): 123-145.

McConkey, K.R., Ario, A., Aldy, F., and Chivers, D.J., (2003). Influence of Forest Seasonality on Gibbon Food Choice in the Rain Forests of Barito Ulu, Central Kalimantan. International Journal of Primatology 24 (1): 19-32.

McConkey, K.R. and Chivers, D.J. (2007). Influence of gibbon ranging patterns on seed dispersal distance and deposition site in a Bornean forest. Journal of Tropical Ecology 23: 269-275.

McDowell, D., Scudder, T., Talbot, L.M. (2010). Lao People's Democratic Republic Nam Theun 2 mulipurpose project: sixteenth report of the international environmental and social panel of experts. Vientiane, Lao PDR: Report to Government of Lao PDR.

McNab, B.K. (1963). Bioenergetics and the determination of home range size. American Naturalist 97: 133-140.

McNab, B.K. (2002). The Physiological Ecology of Vertebrates: A View from Energetics. Ithaca: Cornell University Press.

McNamara, J.M., Houston, A.I., (1996). State-dependent life histories. Nature 380, 215221.

McNamara, J.M., Buchanan, K.L., (2005). Stress, resource allocation and mortality. Behavioral Ecology 16, 1008-1017.

McNeely, J.A. (1987). How dams and wildlife can coexist: natural habitats, agriculture, and major water resource development projects in tropical Asia. Conservation Biology 1:228-238.

McNeilage A. (2001). Diet and habitat use of two mountain gorilla groups in contrasting habitats in the Virungas. In: Robbins M.M., Sicotte P., Stewart K.J., editors. Mountain gorillas: three decades of research at Karisoke. Cambridge (England): Cambridge University Press. pp. 265-92.

Menon, S., and Poirier, F. (1996). Lion-tailed macaques in disturbed forest fragment: Activity patterns and time budget. International Journal of Primatology 17: 969985.

Meyers, D.M. (1993). The effects of resource seasonality on behaviour and reproduction in the golden-crowned sifaka in three Malagasy forests. Unpublished $\mathrm{PhD}$ dissertation. Duke University, Durham, North Carolina.

Milton, K. (1979). Factors influencing leaf choice by howler monkeys: a test of some hypotheses of food selection by generalist herbivores. American Naturalist 114: 362-378.

Milton, K. (1980). The foraging strategy of howler monkeys. New York: Columbia University Press.

Milton, K. (1981). Food choice and digestive strategies of two sympatric primate species. American Naturalist 117: 496-505. 
Milton, K. (1984). Habitat, diet, and activity patterns of free-ranging woolly spider monkeys. International Journal of Primatology 5:491-514.

Milton, K. and May, M.L. (1976). Body weight, diet, and home range area in primates. Nature 259: 459-462.

Mitani, J.C. and Rodman, P.S. (1979). Territoriality: The relation of ranging pattern and home range size to defendability, with an analysis of territoriality among primate species. Behavioral Ecology and Sociobiology 5(3):241-251.

Ministry of Agriculture and Forestry (MAF), (2011). Gibbon Conservation Action Plan for Lao PDR. Division of Forest Resource Conservation, Department of Forestry. Vientiane, Lao PDR.

Muruthi, P., Altmann, J., and Altmann, S. (1991). Resource base, parity, and reproductive condition affect females' feeding time and nutrient intake within and between groups of a baboon population. Oecologica 87: 467-472.

Nakagawa, N. (1989). Feeding strategies of Japanese monkeys against deterioration of habitat quality. Primates 30: 1-16.

Napier, J. (1963). The locomotor function of hominids. In: Washburn, S.(ed.) Classification and Human Evolution. Wenner Gren Foundation for Anthropological Research, Inc.

National Assembly Lao PDR (2007). Wildlife and aquatic law. Vientiane, Lao PDR: National Assembly.

National Research Council. (1978). Nutrient Requirements of Non-Human Primates, National Academy Press, Washington D.C.

National Research Council. (1981). Techniques for the study of primate population ecology. National Academy Press, Washington D.C.

Newstrom, L.E., Frankie, G.W., Baker, H.G., Colwell, R.K. (1994). Diversity of long term flowering patterns. In: McDade, L.A., Bawa, K.S., Hespenheide, H.A., and Hartshorn, G.S. (eds.) La Selva: Ecology and Natural History of a Neotropical Rain Forest, 142-60. Chicago: Chicago University Press.

Norscia, I., Carria, V., Borgognini-Tarli, S.M. (2006). Influence of dry season and food quality on behaviour and feeding strategy of Propithecus verrearxi in Kirindy, Madagascar. International Journal of Primatology 27:1001-22.

Nunes, A. (1996). Foraging and ranging patterns in white-belled spider monkeys. Folia Primatologica 65:85-99.

Oates, J.F. (1977). The guereza and its food. In Clutton-Brock, T.H. (ed.) Primate Ecology, Academic Press, London.

Oates, J.F. (1986). Food distribution and foraging behaviour. In Primate Societies, ed. Smuts, B.B. Cheney,D.L., Seyfarth, R.M., Wrangham, R.W. Strushaker, T.T. Chicago: University of Chicago Press: 197-209.

Oates, J.F. Swann, T., Zantovska, J. (1977). Secondary compounds and food selection by colobus monkeys. Biochemistry Systems Ecology 5: 317-21. 
O'Brien, T.G., and Kinniard, M.F. (1997). Behavior, diet, and movements of the Sulawesi crested black macaque (Macaca nigra). International Journal of Primatology 18: 321-351.

O'Brien, T.G., M.F. Kinnaird, A. Nurcahyo, M. Iqbal and M. Rusmanto (2004). Abundance and Distribution of Sympatric Gibbons in a Threatened Sumatran Rainforest. International Journal of Primatology 25 (2): 267-284.

Overdorff, D.J. (1993). Similarities, differences and seasonal patterns in the diet of Eulemur rubiventer and Eulemur fulvus rufus in the Ranomafana National Park, Madagascar. International Journal of Primatology 14:721-53.

Palombit, R.A. (1997). Inter- and intra-specific variation in the diets of sympatric siamang (Hylobates syndactylus) and white-handed gibbons (Hylobates lar). Folia Primatologica, 68:321-337.

Parra, R. (1978). Comparison of foregut and hindgut fermentation in herbivores. In Montogomery, G.G. (ed.) The Ecology of Arboreal Folivores. Smithsonian Institution, Washington D.C.

Passamani, M. (1998). Activity budget of geoffrey's marmoset (Callithrix geoffroyi) in an Atlantic forest in Southeastern Brazil. American Journal of Primatology 46: 333-340.

Peres, C.A. (1994). Primate responses to phenological changes in Amazonian Terra Firma Forest. Biotropica 26:98-112.

Peters, R. H. (1983). The ecological implications of body size. Cambridge: Cambridge University Press.

Phiapalath, P. (2009). Distribution, behaviour, and threat of red-shanked douc langur in Hin Namno National Protected Area, Khammouane Province, Lao PDR. PhD thesis, Nakhon Ratchasima, School of Biology, Suranaree University of Technology, Thailand.

Pollock, J.I. (1979). Spatial distribution and ranging behaviour in lemurs. In:The Study of Prosimian Behavior. Eds. Doyle, G.A. and Martin, R.D. Academic Press, New York. 359-409.

Powzyk, J.A. (1997). The socio-ecology of two sympatric Indrids. Propithecus diadema diadema and Indri indri: a comparison of feeding strategies and their possible repercussions on species-specific behaviors. Duke University. PhD Dissertation.

Powzyk, J.A., and Mowry, C.B. (2003). Dietary and feeding differences between sympatric Propithecus diadema diadema and Indri indri. International Journal of Primatology 24 (6): 1143-1162.

Raemaekers, J. (1978). Changes through the day in the food choice of wild gibbons. Folia Primatologica 30: 194-205.

Raemaekers, J. J. (1979). Ecology of Sympatric Gibbons. Folia Primatologica 31: 227245.

Raemaekers, J. J. (1980). Causes of Variation between Months in the Distance Traveled Daily by Gibbons. Folia Primatologica 34: 46-60. 
Rasmussen, D.R. (1980). Clumping and consistency in primate patterns of range use: definitions, sampling, assessment and application. Folia Primatologica 34: 111139.

Rawson, B. and Ruppell. J. (2012). Northern White-cheeked crested gibbons. Nomascus leucogenys. In: All the World's Primates. Eds. Noel Rowe and Marc Myers.

Richard, A.F. (1974). Patterns of mating in Propithecus verreauxi verreauxi. In: Prosimian Biology. ed. Martin. R.D. Doyle, G.A. and Walker, A.C. London: Duckworth. 49-74.

Richard A. (1978). Behavioral variation: case study of a malagasy lemur. London: Associated University Press. 213 p.

Ricklefs, R.E., Wikelski, M., (2002). The physiology/life-history nexus. Tree. Ecology Evolution. 17, 462-468.

Robinson, J.G. (1986). Seasonal variation in use of time and space by wedge-capped capuchin monkeys, Cebus olivaceus: Implications for foraging theory. Smithsonian Contributions to Zoology 431: 1-60.

Robinson, J.G. and Redford, K.H. (1986). Body size, diet, and population density of Neotropical forest mammals. The American Naturalist 128:5

Roff, D.A. (Ed.), (1992). The Evolution of Life Histories: Theory and Analysis. Chapman and Hall, New-York.

Roonwal, M.L. and Mohnot, S.M. (1977). Primates of South Asia: ecology, sociobiology and behavior, Harvard University Press, Cambridge.

Roos, C., and Geissmann, T. (2001). Molecular phylogeny of the major hylobatid divisions. Molecular Phylogenetics and Evolution 19: 486-494.

Ruby, J., Nathan, P,. Balasingh, J., Kunz, T.H. (2000). Chemical Composition of Fruits and Leaves Eaten by Short-Nosed Fruit Bat, Cynopterus sphinx. Journal of Chemical Ecology 26, 12: 2825-2841

Rudran, R (1978). Socioecology of the blue monkey (Cercopithecus mitis stuhlmanni) of the Kibale forest, Uganda. Smithsonian contributions to Zoology 249.

Ruppell, J. (2007a). The gibbons of Phong Nha Ke Bang National Park. Gibbon Journal 3: $50-55$

Ruppell, J. (2007b). The vocal diversity and taxonomy of Nomascus in central Vietnam and southern Laos. Master's thesis. Portland State University.

Ruppell, J. (2008). The gibbons of Pu Mat National Park. Gibbon Journal 4: 39-45.

Ruppell, J. (2009). The vocal diversity and taxonomy of Nomascus in central Vietnam and southern Laos. International Journal of Primatology 31:1, 73-94.

Sailer, L.D., Gaulin, S.J.C., Boster, J.S., Kurland, J.A. (1985). Measuring the relationship between dietary quality and body size in primates. Primates 26 (1): 12-27.

Sarich, V. M. and Cronin, J. E. (1976). Molecular systematics of the primates. In: Goodman, M., Tashian, R. E. and Tashian, J. H. (eds.), Molecular anthropology. Genes and proteins in the evolutionary ascent of the primates (pp. 141-170). New York: Plenum Press. 
Sauther, M.L. (1992). The effect of reproductive state, social status and "centrality" on the feeding behaviour of free-ranging female Lemur catta at Beza Mahafaly Special Reserve, Madagascar. American Journal of Physical Anthropology 18: 291.

Schmidt-Nielsen, K. (1984). Scaling: why is animal size so important? Cambridge University Press, Cambridge.

Schoener T.W. (1968). Sizes of feeding territories among birds. Ecology 49:123 141

Schultz, A. H. (1933). Observations on the growth, classification and evolutionary specialization of gibbons and siamangs. Human Biology 5: 212-255, and 385-428.

Schultz, A. H. (1973). The skeleton of the Hylobatidae and other observations on their morphology. In: Rumbaugh, D. M. (ed.), Gibbon and siamang, vol. 2 (pp. 1-54). Basel: Karger.

Setchell, J.M. and Curtis, D.J. Field and Laboratory Methods in Primatology. A Practical Guide. Cambridge University Press.

Sibley, C. G. and Ahlquist, J. E. (1984). The phylogeny of hominoid primates, as indicated by DNA-DNA hybridization. Journal of Molecular Evolution 20: 2-15.

Sibley, C. G. and Ahlquist, J. E. (1987). DNA hybridization evidence of hominoid phylogeny: Results from an expanded data set. Journal of Molecular Evolution 26: 99-121.

Simberloff, D. (1998). Flagships, umbrellas, and keystones: Is single-species management passe in the landscape era? Biological Conservation 83: 247-257.

Sinervo, B., Svensson, E., (1998). Mechanistic and selective causes of life history tradeoffs and plasticity. Oikos 83, 432-442.

Singh, S. (2008). Social challenges for integrating conservation and development: the case of wildlife use in Laos. Society of Natural Resources: 952-955.

Smith, R.J. and Jungers, W.L. (1997). Body mass in comparative primatology. Journal of Human Evolution 32: 523-559.

Soini, P. (1993). The ecology of the pygmy marmoset, Cebuella pygmaea: Some comparisons with two sympatric tamarins. In: Rylands, A.B (ed.) Marmosets and Tamarins: Systematics, Behavior, and Ecology. 257-61. Oxford: Oxford University Press.

Soule, M.E. (1986). Conservation Biology: The Science of Scarcity and Diversity. Sunderland: Sinauer.

Stanford, C. (1991). The capped langur in Bangladesh: behavioral ecology and reproductive tactics. Contributions to Primatology 26:1-179.

START. (2011). The study of climate change impact and vulnerability and adaptation of key systems and sectors to future climate variability and change. SysTem for Analysis Research and Training: Bangkok. http://cc.start.or.th.

Stauffer, R.L., Walker, A., Ryder, O.A., Lyons-Weiler, M., and Blair Hedges, S. (2001). Human and ape molecular clock and constraints on paleontological hypotheses. The Journal of Heredity 92 (6): 469-474.

Stearns, S.C. (Ed.), (1992). The Evolution of Life Histories. Oxford University press, Oxford. 
Sterling, E.J., Hurley, M.M., Minh, L.D. (2006). Vietnam: a Natural History. Yale University Press, New Haven and London.

Strier, K.B. (2004). Diet of a muriqui group (Brachyteles arachnoides) in continuous primary forest. Primates 45: 201-204.

Strier K.B. (1987). Activity budgets of woolly spider monkeys, or muriquis (Brachyteles arachnoides). American Journal of Primatology 13:385-395.

Srikosamatara, S. (1984). Ecology of Pileated Gibbons in South-East Thailand. In The Lesser Apes: Evolutionary and Behavioural Biology, ed. H. Preuschoft, D. J. Chivers, W. Y. Brockelman, and N. Creel, 242-257. Edinburgh University Press.

Struhsaker, T. T. (1975). The red colobus monkey. University of Chicago Press. Chicago.

Struhsaker, T. T. (1978) Food habits of five monkey species in the Kibale Forest, Uganda. In Chivers, D. and Herbert. J, (eds.) Recent advances in primatology. Academic Press, London.

Struhsaker, T. T. and Leland, L. (1979). Socioecology of five sympatric monkey species in the Kibale forest, Uganda. Advances in the study of Behavior 9: 159-227.

Su., H.H. and Lee, L.L. (2001). Food habits of Formosan rock macaques (Macaca cyclopis) in Jentse, Northeastern Taiwan, assessed by fecal analysis and behavioral observation. International Journal of Primatology 22 (3):359-377.

Terborgh, J. (1983). Five New World Primates: A Study in Comparative Ecology. Princeton, NJ: Princeton University Press.

Terborgh, J. (1986). Keystone plant resources in the tropical forests. In Michael E. Soulé (ed.). Conservation Biology: The Science of Scarcity and Diversity. Sunderland, Massachusetts: Sinauer Associates. pp. 330-344.

Thinh, V.N, Rawson, B., Hallam, C., Kenyon, M., Nadler, T., Walter, L., Roos, C. (2010): Phylogeny and distribution of crested gibbons (genus Nomascus) based on mitochondrial cytochrome $b$ gene sequence data. American Journal of Primatology 72:1047-1054.

Thinh, V.N., Hallam, C., Roos, C., and Hammerschmidt, K. (2011). Concordance between vocal and genetic diversity in crested gibbons. BMC Evolutionary Biology $11: 36$

Thorpe, W.H. (1963). Learning and Instinct in Animals. London: Metheun.

Tilson, R. L. (1979). Behavior of Hoolock Gibbons (Hylobates hoolock) during Different Seasons in Assam, India. Journal of Bombay Natural History Society 76: 1-16.

Timmins, R.J. and Duckworth, J.W. (1999). Status and conservation of douc langurs in Laos. International Journal of Primatology 20:469-489.

Tran Thu Hang (2010). Stopping the trade of Vietnam's primates: experiences and cases from ENV's Wildlife Crime Unit. In: Nadler, T., Rawson, B.M., Thinh, V.N (eds.) Conservation of primates in Indochina. Hanoi: Frankfurt Zoological Society and Conservation International. 233-236.

Turner, F.B. Jenrich, R.I, Weintraub, J.D. (1969). Home ranges and body size of lizards. Ecology 50: 1076-1081. 
Ujhelyi, M., Berker, B., Buk, P., and Geissmann, T. (2000). Observations of the behaviour of gibbons in the presence of mirrors. Journal of Comparative Psychology 114:253-262.

UNDP (2010). Working for the Lao PDR 2009. Vientiane, Lao PDR: UNDP.

Van der Pijl, L., (1969). Principles of Seed Dispersal in Higher Plants. Springer, Berlin.

van Schaik, C.P. Terbough, J.W., and Wright, S.J. (1993). The phenology of tropical forests: adaptive significance and consequences for primary consumers. Annual Review of Ecology and Systematics 24:353-77.

Vasey, N. (2004). Circadian rhythms in diet and habitat use in red ruffed lemurs (Varecia rubra) and white-fronted brown lemurs (Eulemur fulvus albifrons). American Journal of Physical Anthropology 124: 353-363.

Vasey, N. (2005). Activity budgets and activity rhythms in red ruffed lemurs (Varecia rubra) on the Maoala Peninsula, Madagascar: Seasonality and reproductive energetics. American Journal of Primatology 66: 23-44.

Vellayan, S. (1981). Chemical Composition and Digestibility of Natural and Domesitc Food of the Lar Gibbon (Hylobates lar) in Malaysia, MSc Thesis, Universiti Pertanian Malaysia, Serdang, Selangor.

Wienberg, J. and Stanyon, R. (1987). Fluoroscent heterochromatin staining in primate chromosomes. Human Evolution 2: 445-457

Whitten, A.J. (1982a). The Ecology of Singing in Kloss Gibbons (Hylobates klossii) on Siberut Island, Indonesia. International Journal of Primatology 3 (1): 33-51.

Whitten, A.J. (1982b). Home Range use by Kloss Gibbons (Hylobates klossii) on Siberut Island, Indonesia. Animal Behavior 30: 182-198.

Whitten, A.J. (1983). Diet and dominance among female vervet monkeys (Cercopithecus aethiops) American Journal of Primatology 5:139-159.

Whitten, A.J. (1984). Ecological comparisons between Kloss gibbons and other small gibbons. In The Lesser Apes: Evolutionary and Behavioural Biology, ed. $\mathrm{H}$. Preuschoft, D. J. Chivers, W. Y. Brockelman, and N. Creel, 219-227. Edinburgh University Press.

Whitington, C.L. (1992). Interactions between lar gibbons and pig-tailed macaques at fruit sources. American Journal of Primatology 26 (1): 61-64.

Williamson, E.A. and Feistner, A.T.C., (2003). Habituating primates: processes, techniques, variables and ethics. In: Setchell, J.M., Curtis, D.J. Field and Laboratory Methods in Primatology. A Practical Guide. pp. 25-39. Cambridge University Press.

Wright, S.J. (1995). Demography and life history of free-ranging Propithecus diadema edwardsi in Ranomafana National Park, Madagascar. American Journal of Physical Anthropology Supplement 20: 224.

Wright, S.J. and van Schaik, C.P. (1994). Light and phenology of tropical trees. American Naturalist 143:192-99. 
Yamagiwa, J. and Mwanza, M. (1994). Day journey length and daily diet of solitary male gorillas in lowland and highland habitats. International Journal of Primatology 15:207-24.

Ziegler, A.D., Lim, H.S., Jachowski, N.R., Wasson, R.J. (2012). Reduce urban flood vulnerability. Nature 481: 145.

Zhang, Y. (1992). Hainan gibbon (Hylobates concolor hainanus) threatened. Asian Primates -A Newsletter of the IUCN/SSC Primate Specialist Group 2(1): 6.

Zhang, Y. and Sheeran, L. (1994). Current status of the Hainan black gibbon (Hylobates concolor hainanus). Asian Primates - A Newsletter of the IUCN/SSC Primate Specialist Group 3(3-4): 3.

Zhang, S.Y. (1995). Activity and ranging patterns in relation to fruit utilization by brown capuchins (Cebus paella) in French Guiana. International Journal of Primatology 16:489-507.

Zhou, Q. Wei, F. Li, M., Huang, C., Luo, B. (2006). Diet and Food Choice of Trachypithecus francoisi in the Nonggang Nature Reserve, China. International Journal of Primatology 27(5), 1441-1460. 